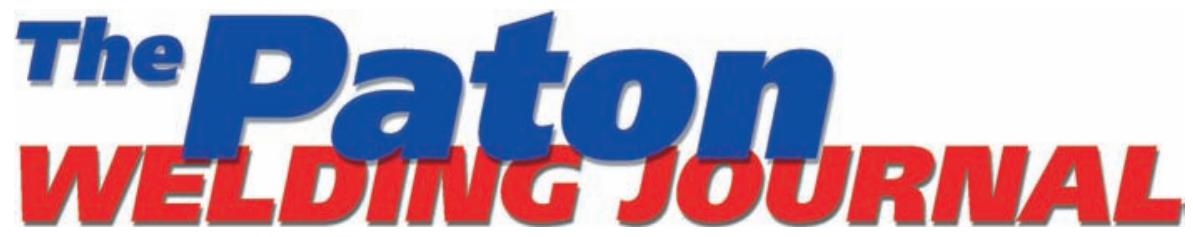

November 2016 No. 11

Published since 2000

\section{EDITORIAL BOARD \\ Editor-in-Chief B.E. Paton}

Scientists of PWI, Kiev S.I. Kuchuk-Yatsenko (vice-chief ed.), V.N. Lipodaev (vice-chief ed.)

Yu.S. Borisov, G.M. Grigorenko A.T. Zelnichenko, V.V. Knysh,

I.V. Krivtsun, Yu.N. Lankin, L.M. Lobanov, V.D. Poznyakov, I.A. Ryabtsev, K.A. Yushchenko

Scientists of Ukrainian Universities V.V. Dmitrik, NTU «KhPI», Kharkov V.V. Kvasnitsky, NTUU «KPl», Kiev V.D. Kuznetsov, NTUU «KPI», Kiev

\section{Foreign Scientists} N.P. Alyoshin

N.E. Bauman MSTU, Moscow, Russia Guan Qiao

Beijing Aeronautical Institute, China A.S. Zubchenko

DB «Gidropress», Podolsk, Russia M. Zinigrad

Ariel University, Israel V.I. Lysak

Volgograd STU, Russia

Ya. Pilarczyk

Welding Institute, Gliwice, Poland U. Reisgen

Welding and Joining Institute, Aachen, Germany G.A. Turichin

St. Petersburg SPU, Russia

Founders

E.O. Paton Electric Welding Institute, NASU International Association «Welding» Publisher

International Association «Welding» Translators

A.A. Fomin, O.S. Kurochko, I.N. Kutianova Editor

N.G. Khomenko

Electron galley

D.I. Sereda, T.Yu. Snegiryova Address

E.O. Paton Electric Welding Institute, International Association «Welding» 11 Kazimir Malevich Str. (former Bozhenko Str.), 03680, Kiev, Ukraine

Tel.: (38044) 20060 16, 2008277

Fax: (38044) 2008277,2008145

E-mail: journal@paton.kiev.ua

www.patonpublishinghouse.com

State Registration Certificate

KV 4790 of 09.01 .2001

ISSN 0957-798X

Subscriptions

$\$ 348,12$ issues per year,

air postage and packaging included.

Back issues available.

All rights reserved

This publication and each of the articles contained herein are protected by copyright.

Permission to reproduce material contained in this journal must be obtained in writing from the Publisher.

\section{CONTENTS}

\section{SCIENTIFIC AND TECHNICAL}

Krivtsun I.V., Krikent I.V. and Demchenko V.F. Numerical analysis of plasma characteristics of constricted and free-burning arc with a refractory cathode

Grigorenko G.M., Akhonin S.V., Zadorozhnyuk O.M. and Klochkov I.N. Structure and properties of fully-penetrated metal of two-phase titanium alloy with dispersion hardening at AAW

Babinets A.A., Ryabtsev I.A., Panfilov A.I., Zhdanov V.A. and Ryabtsev I.I. Influence of methods of arc surfacing with flux-cored wire on penetration of base metal and formation of deposited metal

Zhemanyuk P.D., Petrik I.A., Chigilejchik S.L., Yarovitsyn A.V. and Khrushchov G.D. Peculiarities of bead shape regulation in single-layer microplasma surfacing on edges of aircraft gas turbine engine blades

Khaskin V.Yu., Korzhik V.N., Chizhskaya T.G., Sidorets V.N. and Lo Zie. Effect of laser radiation absorption on efficiency of laser welding of copper and its alloys

\section{INDUSTRIAL}

Lankin Yu.N. and Soloviov V.G. Information-measuring system

for arc welding and surfacing

Burlaka V.V. and Gulakov S.V. Device for excitation and stabilization of welding arc 


\title{
NUMERICAL ANALYSIS OF PLASMA CHARACTERISTICS OF CONSTRICTED AND FREE-BURNING ARC WITH A REFRACTORY CATHODE*
}

\author{
I.V. KRIVTSUN ${ }^{1}$, I.V. KRIKENT ${ }^{2}$ and V.F. DEMCHENKO ${ }^{1}$ \\ ${ }^{1}$ E.O. Paton Electric Welding Institute, NASU \\ 11 Kazimir Malevich Str., 03680, Kiev, Ukraine. E-mail: office@paton.kiev.ua \\ ${ }^{2}$ Dnieprodzerzhinsk State Technical University \\ 2 Dnieprostrojevskaya Str., 51918, Dnieprodzerzhinsk, Ukraine
}

\begin{abstract}
Self-consistent mathematical model of the processes of energy-, mass- and electric transfer in the column and anode region of the electric arc with refractory cathode was used as a basis to perform numerical analysis of thermal, electromagnetic and gas-dynamic characteristics of arc plasma for constricted (plasma) and free-burning argon arc with copper water-cooled anode. Results of calculation of characteristics of arc column plasma show that distributions of electric current density, temperature and velocity of constricted arc plasma can greatly differ from the respective distributions for free-burning arc, depending on arc current, plasmatron nozzle channel diameter and plasma gas flow rate. Characteristics of near-anode layer of plasma arc also differ significantly from the respective characteristics of free-burning arc, depending on the above arcing mode parameters. Thus, by varying arc current, plasmatron nozzle channel diameter and plasma gas flow rate, it is possible to effectively control the characteristics of thermal, electromagnetic and, particularly, dynamic impact of the constricted arc on anode metal surface. 13 Ref., 1 Table, 10 Figures.
\end{abstract}

Ke y w or d s : constricted (plasma) arc, free-burning arc, refractory cathode, water-cooled anode, arc column, anode region, arc plasma characteristics, mathematical modeling

Application of a constricted (plasma) arc instead of free-burning one is one of the methods to improve the effectiveness of electric arc impact on metals, and, consequently, to increase the penetration depth and nonconsumable electrode welding speed. Limitation of transverse dimensions of the column of an arc with refractory cathode by the wall of plasmatron nozzle channel can lead to an essential increase of the density of electric current and heat flow, applied by the arc to the metal being welded, and variation of plasma gas flow rate enables varying in a broad range the dynamic impact of arc plasma flow on weld pool surface. Effective practical application of plasma arc as welding heat source requires having valid information on distributed characteristics of constricted arc plasma, as well as characteristics of its thermal, electromagnetic and gas-dynamic impact on the metal being welded. As experimental determination of such, important in practical terms, plasma arc characteristics as distribution of electric current density, heat flow and gas-dynamic pressure of plasma over the weld pool surface is difficult, because of high values of arc plasma temperature and temperature of the above-mentioned surface, smallness of geometrical dimensions of the arc anode region and a number of other factors, studying the plasma arc by mathematical modeling methods seems highly relevant (see, for instance, [1-6]). Therefore, the objective of this work is detailed numerical analysis of distributed characteristics of plasma column and anode region of the constricted arc, depending on its arcing mode, as well as their comparison with the respective characteristics for a free-burning arc.

Let us consider a stationary electric arc with a refractory cathode (W) and water-cooled (non-evaporating) anode $(\mathrm{Cu})$, burning in an argon flow at atmospheric pressure. We will study two variants - plasma arc, constricted by the wall of the cylindrical channel of plasmatron nozzle (Figure 1,a), and free-burning arc (Figure 1, b). At selection of mathematical model of arc plasma, we will assume that arc column plasma in both the cases is isothermal and single-component, containing only particles of shielding or plasma gas (Ar). Numerical analysis of such plasma characteristics can be performed using a self-consistent mathematical model of processes of energy-, mass-, and electric transfer in the column and anode region of the welding arc, proposed in [7], and reduced allowing for the above assumptions, as described in [8]. Assuming further that distributions of plasma character-

${ }^{*}$ Basing on the paper presented at the VIII International Conference on Mathematical Modelling and Information Technologies in Welding and Related Processes (Sept. 18-23, 2016, Odessa, Ukraine). 
istics of both the constricted and free-burning arc are axisymmetric, calculation of thermal, gas-dynamic and electromagnetic characteristics can be performed in both the cases using the same system of equations, the explicit form of which in cylindrical coordinates is given in [8]. Boundary conditions for the sought functions $\{v, u, T, \varphi)$, where $v, u$ are the radial and axial components of arc plasma velocity, $T$ is its temperature, $\varphi$ is the plasma electric potential, are assigned on the boundaries of calculated region $\Omega=\{0<r<R$, $0<z<L\}$, where $R$ is the calculated region radius, $L$ is the length of free-burning arc/open region of the constricted arc (see Figure 1), as follows.

Conditions for velocity and temperature of plasma and electric potential on the system axis of symmetry $(r=0)$ are assigned as follows:

$$
\left.v\right|_{r=0}=0 ;\left.\frac{\partial u}{\partial r}\right|_{r=0}=\left.\frac{\partial T}{\partial r}\right|_{r=0}=\left.\frac{\partial \varphi}{\partial r}\right|_{r=0}=0 .
$$

On the outer boundary of the calculated region $(r=R)$, we can write for plasma velocity and electric potential [8]:

$$
\left.\frac{\partial(\rho v r)}{\partial r}\right|_{r=R}=0 ;\left.\quad u\right|_{r=R}=0 ;\left.\quad \frac{\partial \varphi}{\partial r}\right|_{r=R}=0,
$$

where $\rho$ is the mass density of the plasma.

We will assign boundary condition for plasma temperature at $r=R$, depending on the direction of plasma flow motion on this boundary [8]:

$$
\begin{aligned}
& \left.T\right|_{r=R}=T, \text { at }\left.v\right|_{r=R} \leq 0 ; \\
& \left.\frac{\partial T}{\partial r}\right|_{r=R}=0, \text { at }\left.v\right|_{r=R}>0,
\end{aligned}
$$

where $T_{0}$ is the ambient gas temperature.

On the boundary of arc column plasma with the anode layer which is assumed to be infinitely thin $(z=L)$, we will use the condition of energy balance $[7,8]$, corrected allowing for the work function of anode material $\varphi_{m}$ :

$$
-\left.\chi \frac{\partial T}{\partial z}\right|_{z=L}+\left.j_{a} \frac{k}{e}\left(\frac{5}{2}-\delta\right) T\right|_{z=L}=\left(\Delta \varphi-\varphi_{m}\right) j_{a}+q_{a},
$$

where $\chi$ is the coefficient of plasma heat conductivity; $j_{\mathrm{a}}=-\left.j_{\mathrm{z}}\right|_{\mathrm{z}=L}$ is the density of electric current on the anode; $k$ is the Boltzmann constant; $e$ is the electron charge; $\delta$ is the constant of thermodiffusion of electrons in arc plasma; $\Delta \varphi$ is the difference of potentials between the outer boundary of the anode layer and anode surface; $q_{\mathrm{a}}$ is the heat flow into the anode, determined according to anode region model [7], at $T_{\text {ea }}=T_{\mathrm{a}}$, where $T_{\text {ea }}$ is the electron temperature in the anode layer, $T_{\mathrm{a}}=\left.T\right|_{\mathrm{z}=1}$ is the arc plasma temperature on its boundary with the arc column.

With good approximation, the electric potential of the anode surface can be regarded constant, and assumed, for instance, to be equal to zero. Then the boundary condition for plasma potential on the

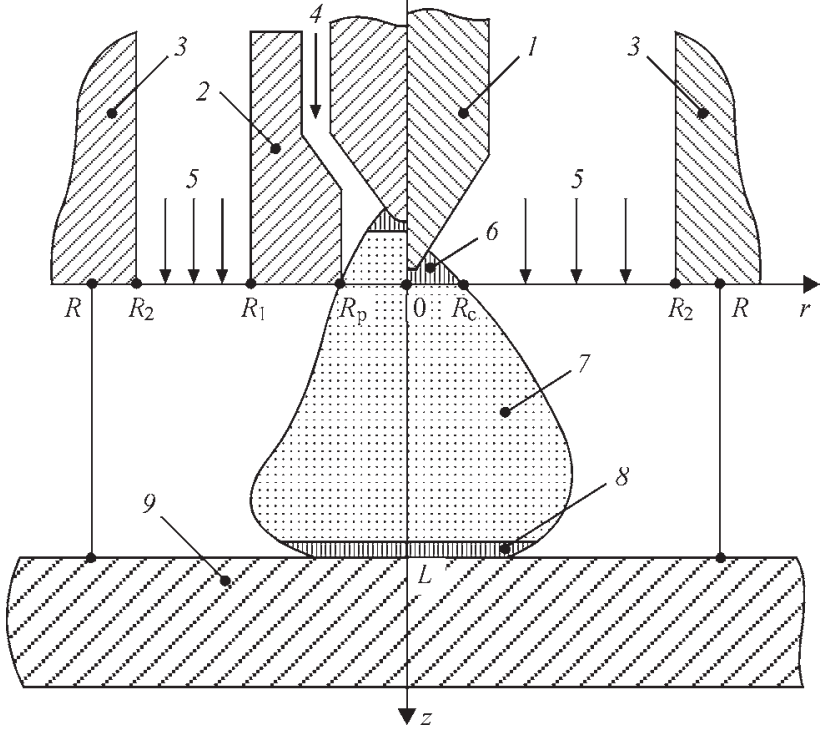

Figure 1. Schematic for calculation of characteristics of constricted (plasma) ( $a$ ) and free-burning $(b)$ arc with refractory cathode: 1 - thermocathode; 2 - plasma-forming nozzle; 3 - nozzle for shielding gas feeding; 4 - plasma gas; 5 - shielding gas; 6 - cathode region; 7 - arc column; 8 - anode layer; 9 - water-cooled anode

boundary of arc column with the anode layer $(\mathrm{z}=L)$ can be written as follows:

$$
\left.\varphi\right|_{z=L}=\Delta \varphi .
$$

Boundary conditions in plane $z=0$ for free-burning arc are assigned similarly to how it was done in work [8]. In particular, in the zone of the arc cathodic binding $\left(r \leq R_{\mathrm{c}}\right.$ ) (see Figure 1, $b$ ) the following conditions are assumed for temperature and electric potential of arc plasma:

$$
\left.T\right|_{z=0}=T_{c}(r) ;\left.\quad \sigma \frac{\partial \varphi}{\partial z}\right|_{z=0}=j_{c}(r),
$$

where $\sigma$ is the specific electric conductivity of plasma, and distributions of plasma temperature $T_{c}(r)$ and current density $j_{c}(r)$ on the boundary of cathode region with the arc column are selected by recommendations of [9].

$$
\begin{aligned}
& \text { At } R_{c}<R \leq r \text { we can write: } \\
& \qquad\left.T\right|_{z=0}=T_{0} ;\left.\frac{\partial \varphi}{\partial z}\right|_{z=0}=0 .
\end{aligned}
$$

Radial component of plasma velocity vector at $z=0$ is taken to be zero, and conditions for axial component of velocity vector are assigned as follows:

$$
\begin{gathered}
\left.u\right|_{z=0}=u_{0}, \text { at } r<R_{2} ; \\
\left.u\right|_{z=0}=0, \text { at } R_{2} \leq r \leq R,
\end{gathered}
$$

where $u_{0}$ is the shielding gas velocity; determined by its flow rate and inner radius of protective nozzle $R_{2}$ (see Figure 1, $b$ ).

As regards boundary conditions in the inlet section of the calculated region $(z=0)$ for the constricted (plasma) arc, they are assigned as follows. Assuming that the distance from the cathode working end 
to plasmaforming channel edge (see Figure $1, a$ ) is essentially larger than its radius $R_{p}$, it can be taken that a one-dimensional flow of arc plasma (in the direction of $\mathrm{OZ}$ axis) is in place at the channel outlet, its temperature and velocity depending only on the radial coordinate; radial components of plasma velocity and electric field intensity are equal to zero, and pressure gradient $d p / d z$ and axial component of electric field $E_{z}$ are constant across the channel section [1]. In this case, distributions of temperature $T(r)$ and axial component of plasma velocity $u(r)$ on the channel edge $\left(r \leq R_{p}\right)$ are found by solving one-dimensional equations:

$$
\begin{gathered}
\frac{1}{r} \frac{d}{d r}\left(r \chi \frac{d T}{d r}\right)+\sigma E_{z}^{2}-\psi=0 ; \\
\frac{1}{r} \frac{d}{d r}\left(r \eta \frac{d u}{d r}\right)-\frac{d p}{d z}=0 .
\end{gathered}
$$

Here, $\psi$ are the losses of plasma energy for radiation; $\eta$ is the coefficient of plasma dynamic viscosity, and the value of axial component of electric field (electric potential gradient) $E_{z}=-(d \varphi / d z)$ and pressure gradient $d p / d z$ are found from integral relationships:

$$
I=2 E_{z} \int_{0}^{R_{p}} \sigma r d r ; G=2 \pi \int_{0}^{R_{p}} \rho u r d r,
$$

where $I$ is the arc current; $G$ is the mass flow of plasma gas.

Boundary conditions for equations (9), (10) are selected in keeping with the conditions of flow symmetry (1) and conditions of «sticking» on the cooled wall of plasma-forming channel that yields:

$$
\begin{gathered}
\left.\frac{\partial T}{\partial r}\right|_{r=0}=\left.\frac{\partial u}{\partial r}\right|_{r=0}, \quad \text { at } \quad r=0 ; \\
T=T_{0} ; \quad u=0, \quad \text { at } \quad r=R_{p} .
\end{gathered}
$$

At $R_{r}<r \leq R$ boundary conditions for temperature and electric potential coincide with (7), radial component of plasma velocity vector is assumed to be zero, and conditions for axial component of velocity are assigned as follows:

$$
\begin{gathered}
\left.u\right|_{z=0}=0, \text { at } R_{p} \leq r \leq R_{1} ; \\
\left.u\right|_{z=0}=u_{0}, \text { at } R_{1}<r<R_{2} ; \\
\left.u\right|_{z=0}=0, \text { at } R_{2} \leq r \leq R,
\end{gathered}
$$

where $u_{0}$ is the shielding gas velocity in the case of a constricted arc, determined by its flow rate, as well as inner $R_{1}$ and outer $R_{2}$ radii of the nozzle for its feeding (see Figure 1, $a$ ).

Initial system of equations [8], together with boundary conditions (1)-(8) for free-burning arc and (1)-(5), (9)-(13) for plasma arc, was solved numerically, by finite difference method. Temperature dependencies of thermodynamic properties, transport coefficients and emissivity of arc plasma were determined using calculated data for isothermal argon plasma of atmospheric pressure, given in [10]. At numerical solution of gas-dynamic and heat problems, joint Lagrangian-
Euler method was used [11, 12], which was adapted to the conditions of the compressible medium.

Comparative numerical analysis of arc plasma characteristics, as well as characteristics of its thermal, electromagnetic and gas-dynamic impact on the anode surface for constricted (plasma) arc and free-burning arc, was performed at the following parameters: arc current $I=100,150,200$ A; length of free-burning arc/length of plasma arc open region $L=$ $=3 \mathrm{~mm}$; diameter of plasmatron nozzle channel $d=$ $=2 R_{p}=2,3,4 \mathrm{~mm}$; mass flow of plasma gas (Ar) was varied in the range of $G=0.10-0.75 \cdot 10^{-4} \mathrm{~kg} / \mathrm{s}$, that corresponds to volume flow of $0.34-2.55 \mathrm{l} / \mathrm{min}$. In the case of plasma arc, the inner and outer radii of annular nozzle for feeding the shielding gas (Ar) $R_{\mathrm{i}}$ $=4.4 \mathrm{~mm}, R_{2}=7.7 \mathrm{~mm}$ (see Figure 1, a); shielding gas rate $u_{0}==0.65 \mathrm{~m} / \mathrm{s}$. In the case of free-burning arc $R_{2}=7.7 \mathrm{~mm}$ (see Figure $1, b$ ); $u_{0}=0.5 \mathrm{~m} / \mathrm{s}$. In both the cases, the radius of calculated region $R$ was selected equal to $8 \mathrm{~mm}$; temperature of water-cooled anode surface, temperature of plasma-forming and protective nozzle walls, as well as temperature of the fed shielding gas $T_{0}$ was taken to be equal to $500 \mathrm{~K}$.

Figure 2 gives the isolines of plasma temperature in the column of constricted (see Figure 2, a) and free-burning arc (see Figure 2, b). As follows from calculated data presented in this Figure, constriction of plasma arc initial region by the wall of the channel blown by plasma gas flow, leads to a certain elongation of the isotherms along the arc axis and to increase of the length of the column high-temperature region ( $T \geq$ $\geq 16000 \mathrm{~K}$ ), compared to free-burning arc. As regards radial distributions of arc plasma temperature, in the case of 100 ampere arc, formed by a plasmatron with nozzle channel diameter of $2 \mathrm{~mm}$, the temperature in the column center turns out to be somewhat higher than the respective temperature for a free-burning arc, rising insignificantly with increase of plasma gas flow (Figure 3, a). For the case of $I=200 \mathrm{~A}, d=4 \mathrm{~mm}$, the temperature in plasma arc center turns out to be a little lower than that for a free-burning arc (at preservation of the tendency to slight increase of axial value with $G$ increase, shown in Figure 3, $b$ ), that is indicative of weakening of the effect of arc column constriction at the respective increase of current and diameter of plasmaforming channel.

A more clearly marked feature appears in calculated distributions of electric current density in the arc column, given in Figure 4. In both the considered cases current density in the center of plasma arc column turns out to be lower than the respective values for a free-burning arc (see Figure 4). An important circumstance here is the change of the nature of radial distribution of value $\left|j_{z}\right|$ for a constricted arc, compared with the free-burning one, namely, appearance of a «plateau» in the respective distributions near the column axis (see solid curves in Figure 4). 
Figure 5 gives the results of distributions of the axial component of arc plasma velocity in the midsection of the column of the constricted and free-burning arc $(z=1.5 \mathrm{~mm})$. As follows from calculated data, given in this Figure, plasma velocity in the constricted arc column is much higher than the velocity of arc plasma for a free-burning arc, rising slightly with increase of plasma arc current and plasma-forming channel diameter (see respective solid curves in Figure 5), and significantly (almost proportionally) rising at increase of plasma-forming gas flow rate (see curves 1, 2 in Figure 5).

Before going over to analysis of near-anode plasma characteristics, it should be noted that one of the causes for the above behavioural features of radial distributions of plasma temperature and electric current density in the constricted arc column at increase of current and diameter of plasma-forming channel relative to the respective distributions for a free-burning arc, can be selection of boundary conditions for plasma temperature and velocity at the edge of plasmatron nozzle channel in the form of (9), (10). So, at small values of channel diameters use of the assump-

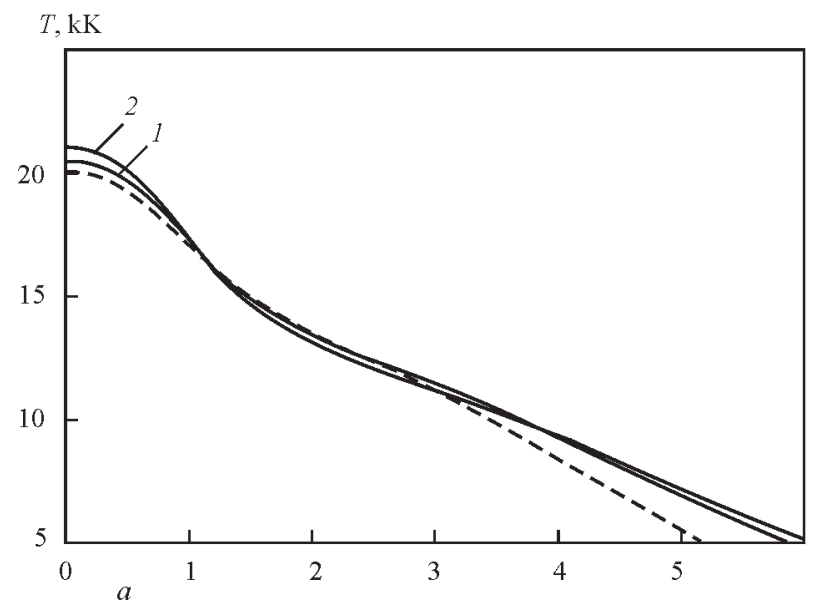

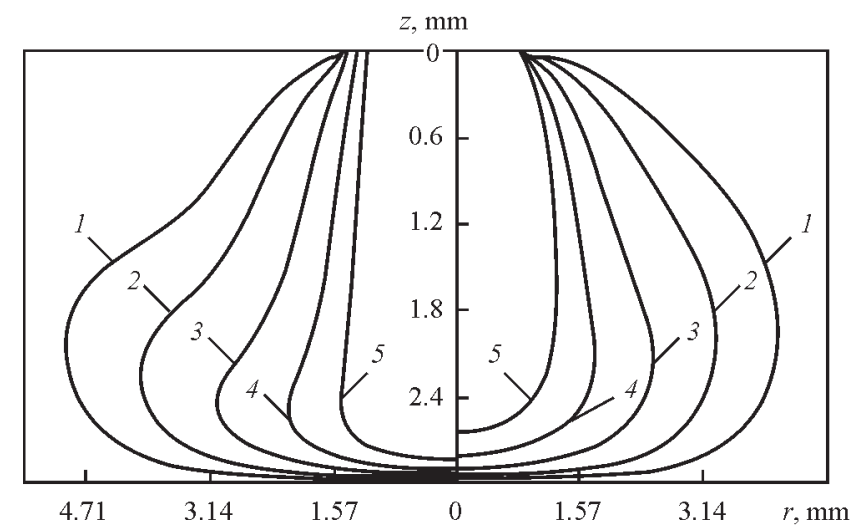

Figure 2. Isolines of temperature of column plasma in constricted (a) and free-burning (b) argon arc with a refractory cathode (W) and water-cooled anode (Cu) at current $I=150 \mathrm{~A}$, arc open region length $L=3 \mathrm{~mm}$, plasma-forming channel diameter $d=3 \mathrm{~mm}$ and plasma gas flow rate (Ar) $G=0.4 \cdot 10^{-4} \mathrm{~kg} / \mathrm{s}(1.36 \mathrm{l} / \mathrm{min}): 1-T=$ $=10 ; 2-12 ; 3-14 ; 4-16 ; 5-18 \mathrm{kK}$

tion of one-dimensionality of arc plasma flow at the channel outlet and use of conditions (9, (10), respectively, appears sufficiently substantiated, while at $R_{p}$ increase more correct results can be obtained by solving the initial equations in the entire region, including that of arc plas-

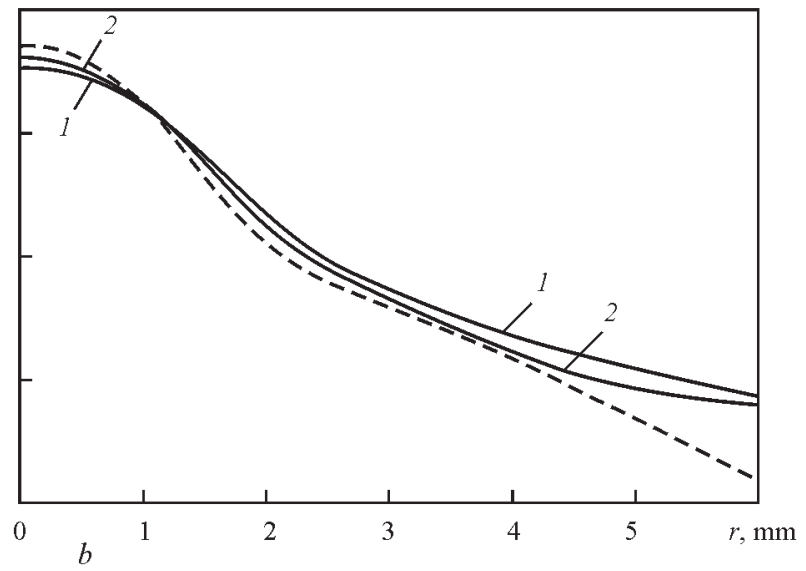

Figure 3. Radial distributions of plasma temperature in section $z=1.5 \mathrm{~mm}$ of plasma arc column: $a-1=100 \mathrm{~A} ; d=2 \mathrm{~mm} ; 1-$ $G=0.1 \cdot 10^{-4} \mathrm{~kg} / \mathrm{s}(0.34 \mathrm{l} / \mathrm{min}), 2-G=0.2 \cdot 10^{-4} \mathrm{~kg} / \mathrm{s}(0.68 \mathrm{l} / \mathrm{min}) ; b-1=200 \mathrm{~A} ; d=4 \mathrm{~mm} ; 1-G=0.4 \cdot 10^{-4} \mathrm{~kg} / \mathrm{s}(1.36 \mathrm{l} / \mathrm{min}) ; 2-$ $G=0.75 \cdot 10^{-4} \mathrm{~kg} / \mathrm{s}(2.55 \mathrm{l} / \mathrm{min})$ (dashed curves are the respective distributions for free-burning arc)
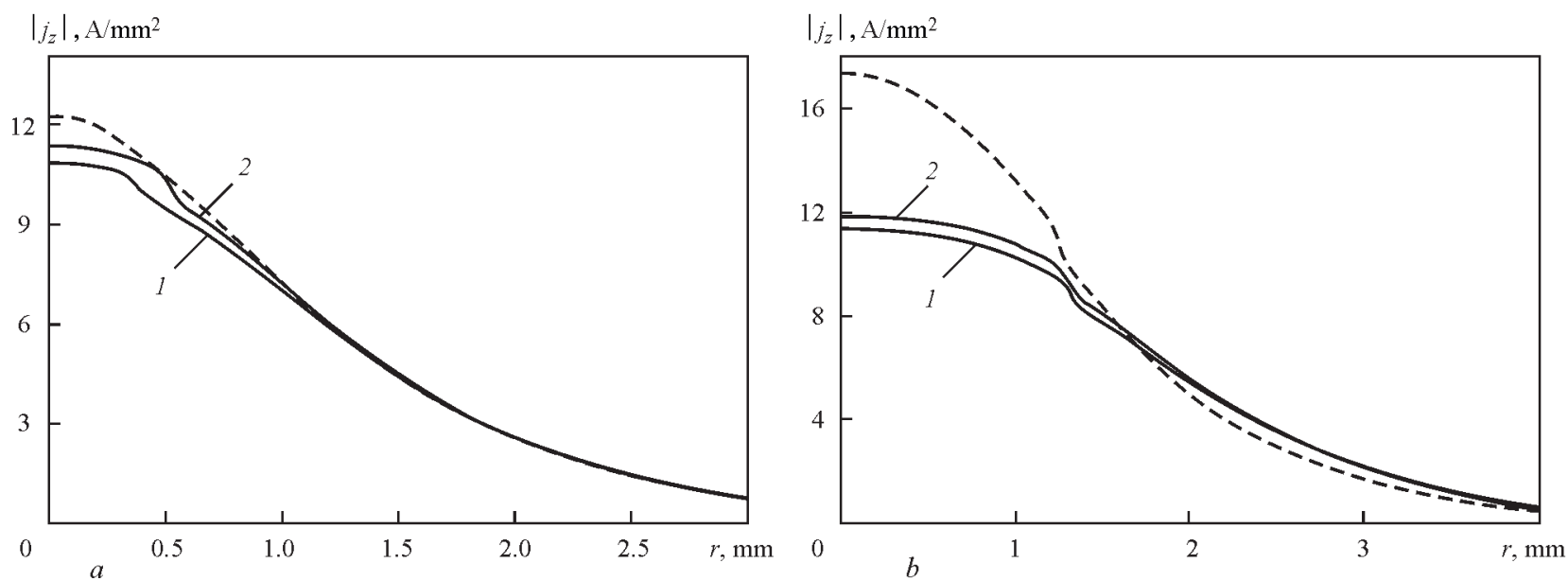

Figure 4. Radial distributions of axial component of electric current density in section $z=1.5 \mathrm{~mm}$ of the column of plasma and free-burning arc (parameters and designations are the same, as in Figure 3) 

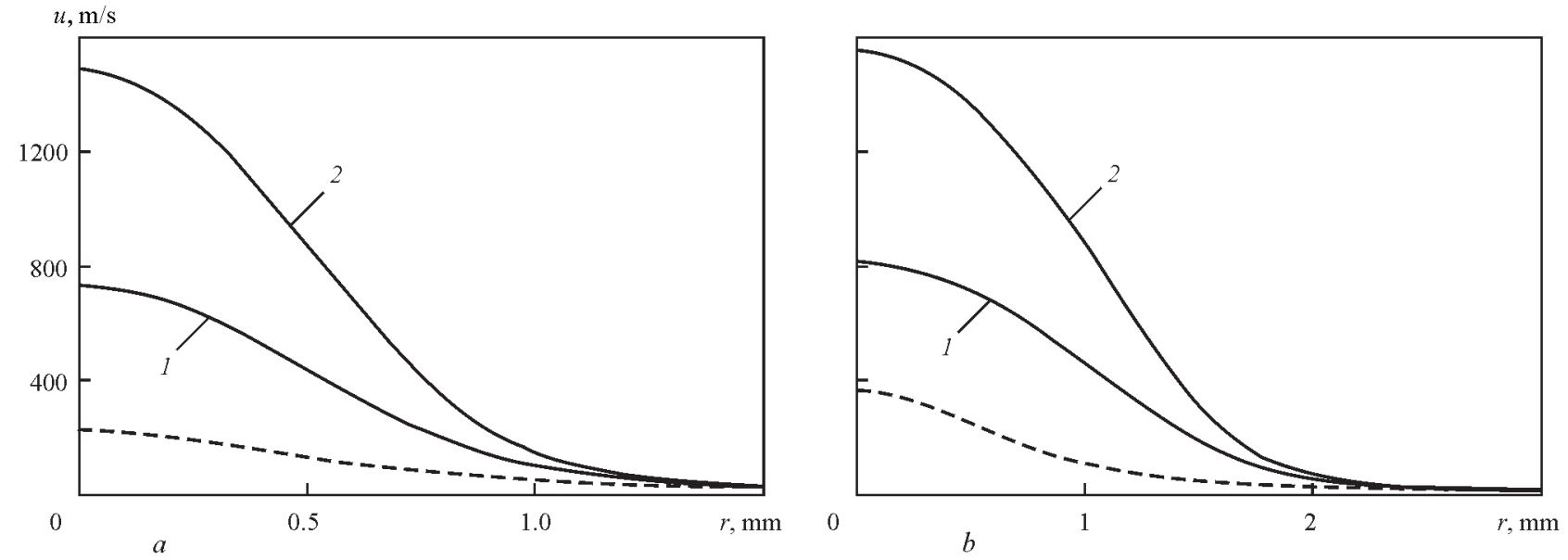

Figure 5. Radial distributions of axial component of plasma velocity in section $z=1.5 \mathrm{~mm}$ of the column of plasma and free-burning arc (parameters and designations are the same, as in Figure 3)

ma inside the plasmatron nozzle channel (see Figure 1, $a$ ), that we intend to do at the next research stage.

Figures 6, 8 give the calculated distributions of arc plasma characteristics on the boundary of the anode layer with the arc column, and Figures 7, 9, 10 show the distributed characteristics of its electric, thermal and dynamic impact on the anode surface. Unlike radial distributions of plasma temperature in the arc column (see Figure 3), arc plasma temperature near the constricted arc anode turns out to be markedly higher than the near-anode plasma temperature for a free-burning arc, increasing with the increase of plasma gas flow rate, here profile $T_{2}(r)$ becomes «fuller» with $G$ rise (see Figure 6 ). This is related to more effective transfer of thermal energy towards the anode by high-velocity flow of constricted arc plasma, compared to a relatively weak convective transfer of thermal energy in the case of a free-burning arc (see Figure 5).

Distributions $j_{a}(r)$ given in Figure 7, are indicative of a higher degree of contraction of 100 A plasma arc anode region, compared to a free-burning one, while at $I=200$ A the opposite is observed (see Figure 7).

In addition, similar to radial distributions of near-anode plasma temperature, the profiles of electric current density distribution on plasma arc anode become «fuller» with increase of plasma gas flow, due to a certain lowering of current density on the axis (compare curves 1, 2 in Figure 7). The cause for that are not only the above features of behaviour of $T_{a}(r)$ distributions for a constricted arc (see Figure 6), but also restructuring of radial distributions of plasma potential on the boundary of the column with plasma arc anode layer, compared to free-burning arc (Figure 8). As shown in [13], this leads to a change of radial component of electric field intensity $E_{r}=-(d \varphi / d r)$, in the considered case - to its reduction in the near-axis zone of the anode region (see Figure 8), and, consequently, to a change of the vector of electric current density in near-anode arc plasma, which determines the pattern of current flowing between the plasma and anode surface.

Figure 9 gives radial distributions of the heat flow applied by the arc to the anode. In case of 100 A plasma $\operatorname{arc}(d=2 \mathrm{~mm})$ value $q_{\mathrm{a}}$ significantly exceeds the
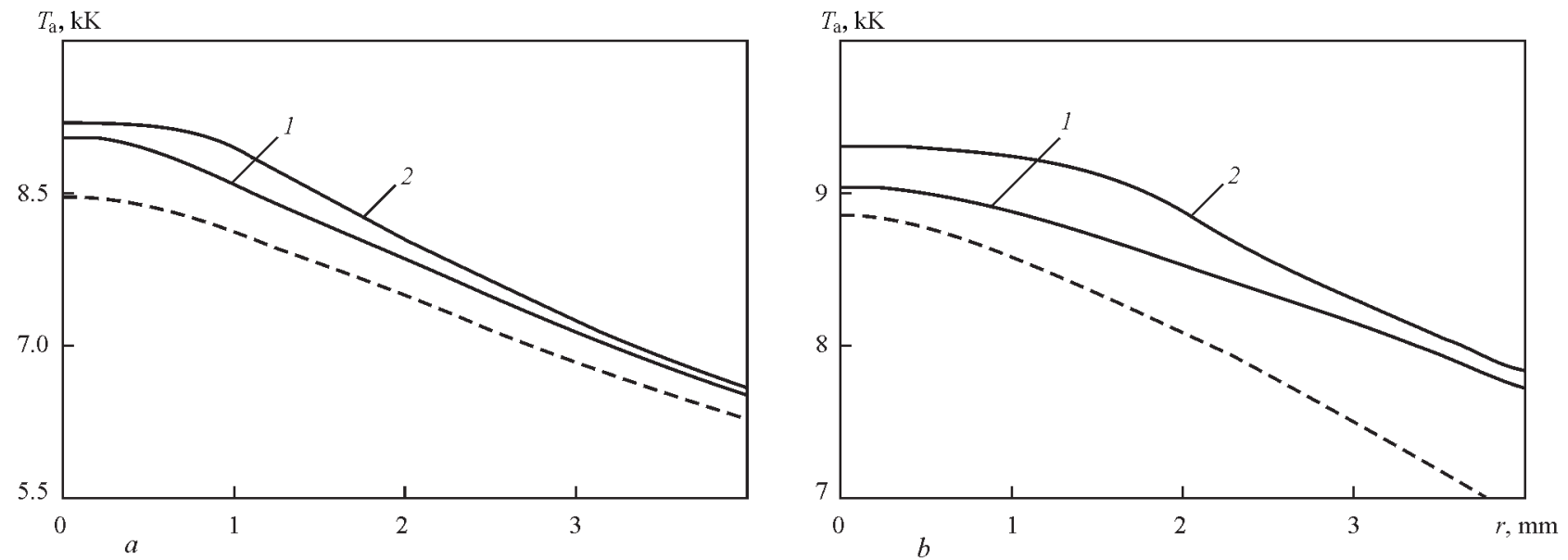

Figure 6. Radial distributions of plasma temperature on the boundary of plasma arc anode layer: $a-I=100 \mathrm{~A} ; d=2 \mathrm{~mm} ; 1-G=$ $=0.1 \cdot 10^{-4} \mathrm{~kg} / \mathrm{s}(0.34 \mathrm{l} / \mathrm{min}), 2-G=0.2 \cdot 10^{-4} \mathrm{~kg} / \mathrm{s}(0.68 \mathrm{l} / \mathrm{min}) ; b-I=200 \mathrm{~A} ; d=4 \mathrm{~mm} ; 1-G=0.4 \cdot 10^{-4} \mathrm{~kg} / \mathrm{s}(1.36 \mathrm{l} / \mathrm{min}), 2-G=$ $=0.75 \cdot 10^{-4} \mathrm{~kg} / \mathrm{s}(2.55 \mathrm{l} / \mathrm{min})$ (dashed curves are the respective distributions for free-burning arc) 

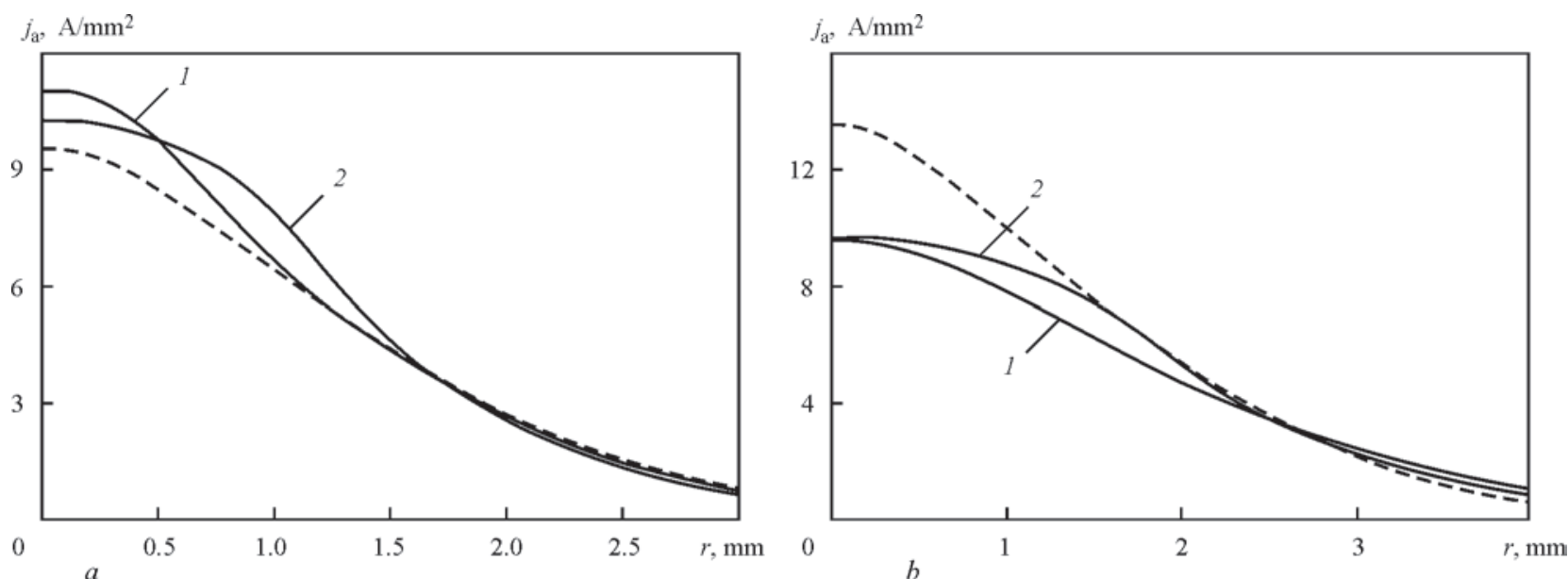

Figure 7. Radial distributions of electric current density on the anode of plasma and free-burning arc (parameters and designations are the same as in Figure 6)
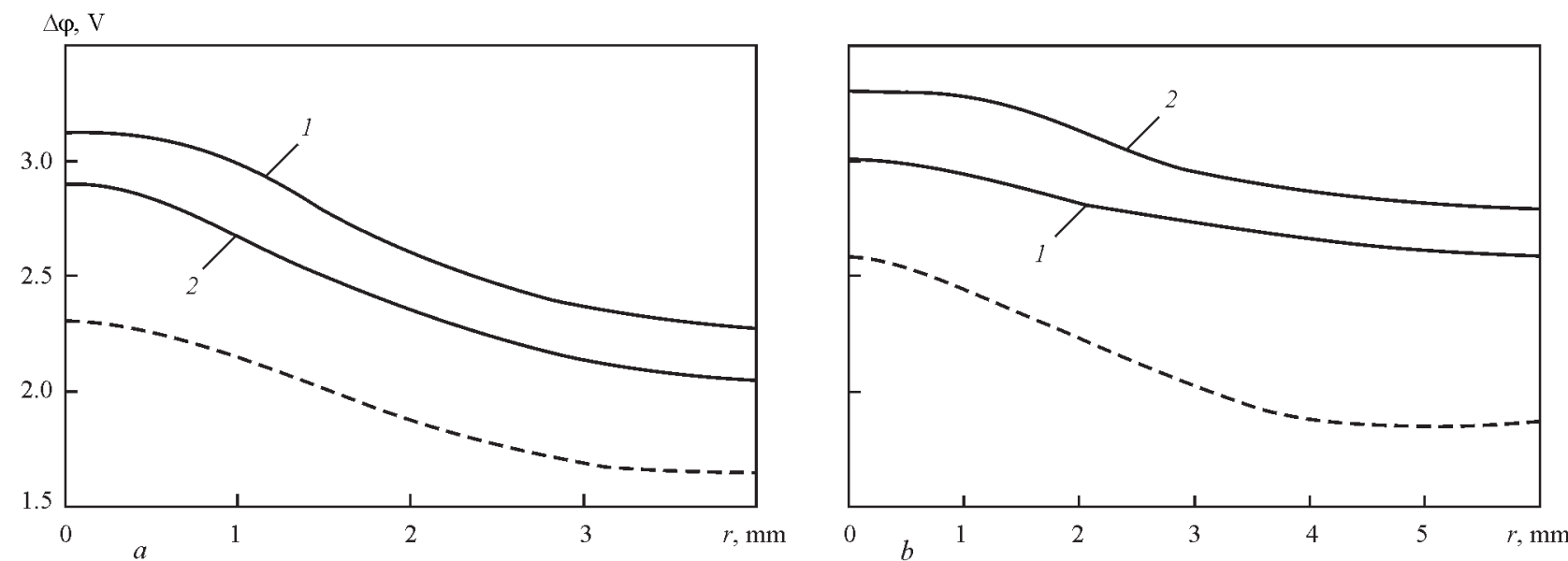

Figure 8. Radial distributions of plasma potential on the boundary of anode layer of plasma and free-burning arc (anode surface potential was taken to be constant and equal to zero, parameters and designations are the same as in Figure 6)
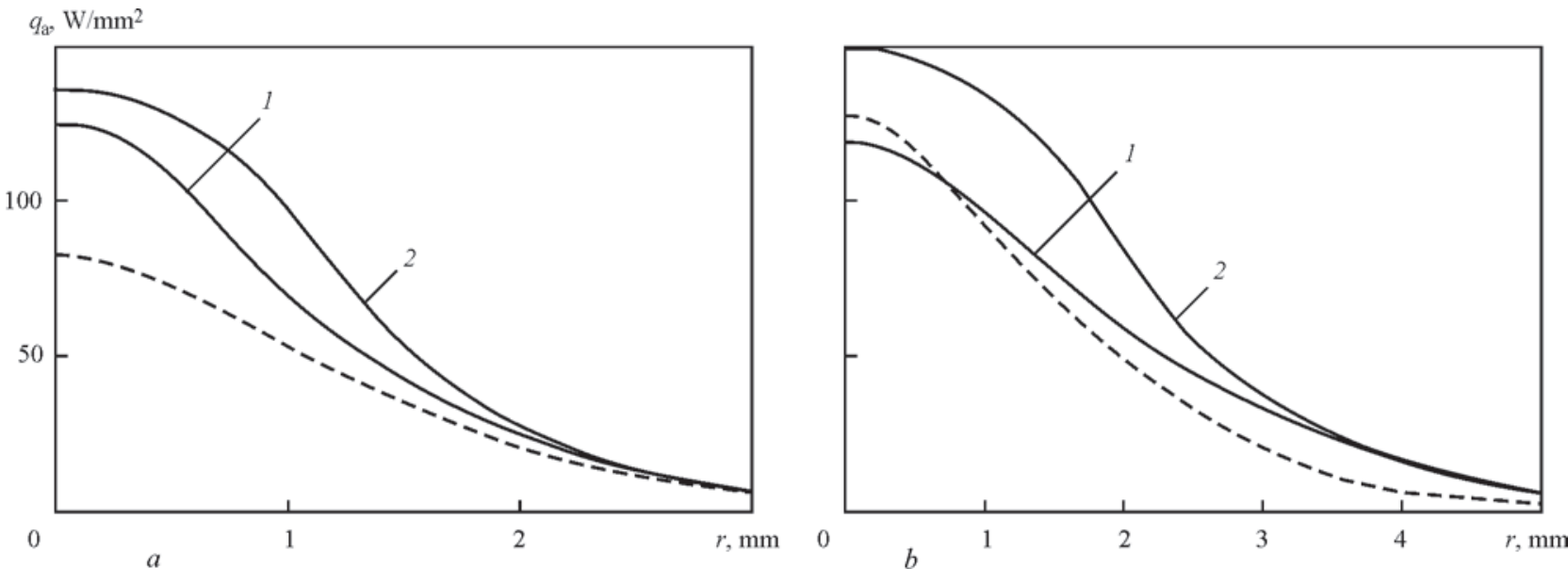

Figure 9. Radial distributions of heat flow to the anode for plasma and free-burning arc (parameters and designations are the same as in Figure 6)

respective values for a free-burning arc; and with increase of plasma gas flow rate an increase of heat flow density, disproportional by the radial coordinate is observed, leading to its profile becoming fuller (see Figure $9, a)$. At $I=200 \mathrm{~A}(d=4 \mathrm{~mm})$, axial value of heat flow applied to the anode by the constricted arc, can be both smaller than value $q_{a}(0)$ for a free-burning arc (at low flow rate of plasma gas), and greater than it (at $G$ increase), as shown in Figure 9, $b$. As regards integral values of power applied by the arc to the anode $Q_{a}=2 \pi \int^{\infty} q_{a} r d r$, in all the considered cases, this value for the plasma arc turns out to be significantly 

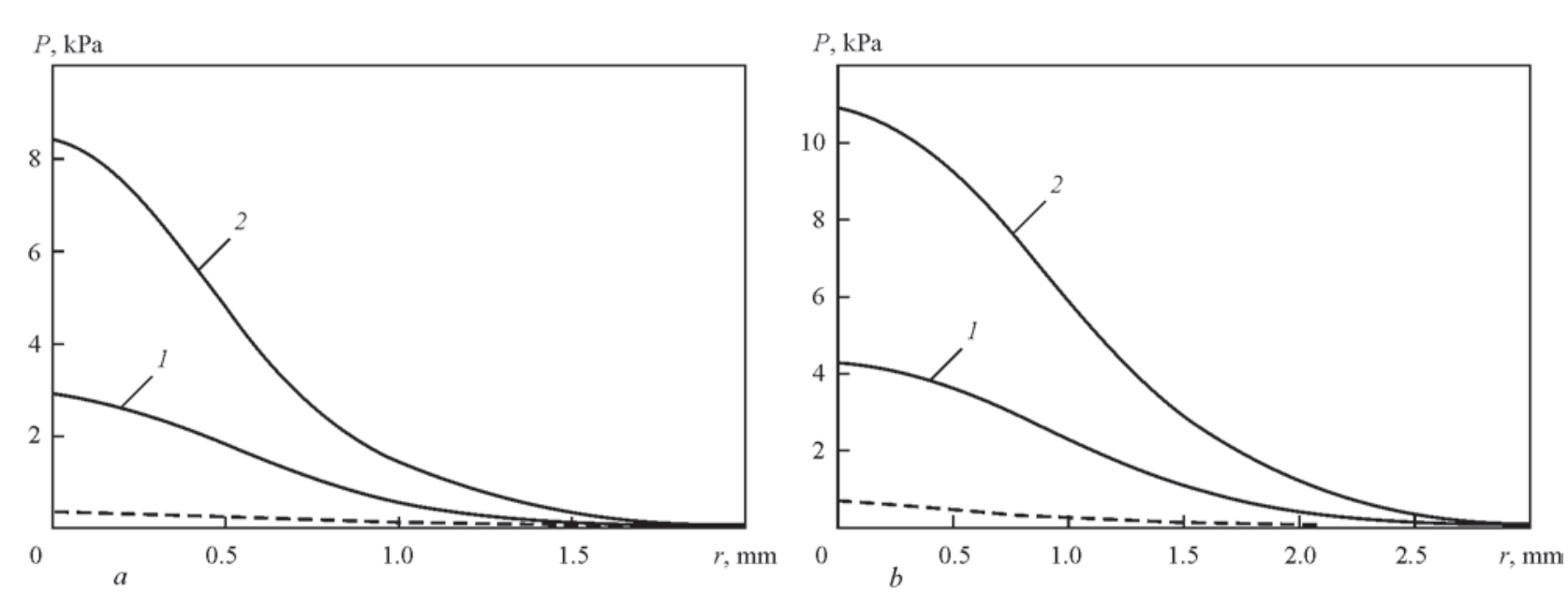

Figure 10. Radial distributions of gas-dynamic pressure of plasma flow to the anode surface for plasma and free-burning arc (parameters and designations are the same as in Figure 6)

Power $Q_{\mathrm{a}}$ applied to the anode by a constricted (plasma) arc and free-burning argon arc

\begin{tabular}{|c|c|c|}
\hline Arc type & $\begin{array}{c}I=100 \mathrm{~A} \\
(d=2 \mathrm{~mm})\end{array}$ & $\begin{array}{c}I=200 \mathrm{~A} \\
(d=4 \mathrm{~mm})\end{array}$ \\
\hline Free-burning & $789 \mathrm{~W}$ & $1724 \mathrm{~W}$ \\
\hline \multirow{2}{*}{ Constricted (plasma) } & $\begin{array}{c}999 \mathrm{~W} \\
(G=0.34 \mathrm{l} / \mathrm{min})\end{array}$ & $\begin{array}{c}2518 \mathrm{~W} \\
(G=1.36 \mathrm{l} / \mathrm{min})\end{array}$ \\
\cline { 2 - 3 } & $\begin{array}{c}1187 \mathrm{~W} \\
(G=0.68 \mathrm{l} / \mathrm{min})\end{array}$ & $\begin{array}{c}3139 \mathrm{~W} \\
(G=2.55 \mathrm{l} / \mathrm{min})\end{array}$ \\
\hline
\end{tabular}

higher than that for a free-burning one, and it rises with increase of plasma gas flow rate, as follows from calculated data given in the Table. The main cause for that is intensive transfer of thermal energy from the high-temperature region of the constricted arc column towards the anode, performed by a higher-velocity flow of arc plasma, than in the case of a free-burning arc (see Figure 5).

Another important characteristic of the arc impact on the anode surface is gas-dynamic pressure $P$ of arc plasma flow on the above surface. Calculated distributions of value $P$ along the anode surface are given in Figure 10. As follows from the calculated data given in this Figure, gas-dynamic pressure on the surface of constricted arc plasma anode is significantly higher than the respective values for a free-burning arc, increasing with increase of plasma arc current and plasmatron nozzle channel diameter (compare the respective solid curves in Figure 10, $a, b$ ), and rising considerably at increase of plasma gas flow rate (compare curves 1 and 2 in Figure 10, $a, 10, b$ ).

On the whole, modeling results, presented in the Table and in Figures 7, 9, 10 lead to the conclusion that change of plasma gas flow rate in plasma welding is an effective means of influencing not only the value and distribution of gas-dynamic pressure of constricted arc plasma on weld pool surface, but also the respective characteristics of its thermal and electromagnetic impact on the metal being welded.
1. Engelsht, V.S., Gurovich, V.Ts., Desyatkov, G.A. et al. (1990) Low-temperature plasma. Novosibirsk: Nauka. Vol. 1: Theory of electric arc column.

2. Beulens, J.J., Milojevic, D., Schram, D.C. et al. (1991) A two-dimensional nonequilibrium model of cascaded arc plasma flows. Phys. Fluids B, 3(9), 2548-2557.

3. Dowden, J., Kapadia, P. (1994) Plasma arc welding: a mathematical model of the arc. J. of Physics D: Applied Physics, 27(5), 902-910.

4. Wendelstorf, J., Decker, I., Wohlfahrt, H. et al. (1996) TIG and plasma arc modeling: a survey. Mathematical modelling of weld phenomena 3. London: The Institute of Materials, 848-897.

5. Jenista, J., Heberlein, V.R., Pfender, E. (1997) Numerical model of the anode region of high current electric arcs. IEEE Transact. on Plasma Sci., 25(5), 883-890.

6. Schnick, M., Fuessel, U., Spille-Kohoff, A. (2010) Numerical investigations of the influence of design parameters, gas composition and electric current in plasma arc welding (PAW). Welding in the World, 54(Issue 3), 87-96.

7. Krivtsun, I.V., Demchenko, V.F., Krikent, I.V. (2010) Model of the processes of heat-, mass- and charge transfer in the anode region and column of the welding arc with refractory cathode. The Paton Welding J., 6, 2-9.

8. Krikent, I.V., Krivtsun, I.V., Demchenko, V.F. (2012) Modelling of processes of heat-, mass- and electric transfer in column and anode region of arc with refractory cathode. Ibid., 3, 2-6.

9. Wendelstorf, J., Simon, G., Decker, I. et al. (1997) Investigation of cathode spot behavior of atmospheric argon arcs by mathematical modeling. In: Proc. of the $12^{\text {th }}$ Int. Conf. on Gas Discharges and their Applications (Germany, Greifswald, 1997). Vol. 1, 62-65.

10. Boulos, M.I., Fauchais, P., Pfender, E. (1997) Thermal plasmas: Fundamentals and applications. New York and London: Plenum Press, Vol. 1.

11. Lyashko, I.I., Demchenko, V.F., Vakulenko, S.A. (1981) Version of method of splitting of equations of viscous incompressible fluid dynamics on Lagrange-Euler lattices. Doklady AN Ukr.SSR. Seriya A, 7, 43-47.

12. Demchenko, V.F., Lesnoj, A.B. (2000) Lagrange-Euler method of numerical solution of multidimensional problem of convective diffusion. Dopovidi NANU, 11, 71-75.

13. Krivtsun, I.V., Krikent, I.V. Demchenko, V.F. et al. (2015) Interaction of $\mathrm{CO}_{2}$-laser radiation beam with electric arc plasma in hybrid (laser + TIG) welding. The Paton Welding J., 3/4, 6-15. 


\title{
STRUCTURE AND PROPERTIES OF FULLY-PENETRATED METAL OF TWO-PHASE TITANIUM ALLOY WITH DISPERSION HARDENING AT AAW
}

\author{
G.M. GRIGORENKO, S.V. AKHONIN, O.M. ZADOROZHNYUK and I.N. KLOCHKOV \\ E.O. Paton Electric Welding Institute, NASU \\ 11 Kazimir Malevich Str., 03680, Kiev, Ukraine. E-mail: office@paton.kiev.ua
}

\begin{abstract}
Tungsten inert gas welding remains the most widespread, relatively easy and versatile method for manufacture of the structures of titanium alloys. Welding can be performed in different spatial positions and equipment can be sufficiently fast readjusted at change of joint type and thickness of metal being welded. Aim of present work lies in study and comparison of a structure and mechanical properties of fully-penetrated metal of high-strength titanium alloys with dispersion hardening and without it, produced using argon-arc method. It is shown that in comparison with titanium alloy VT23 an experimental dispersion-hardened alloy has higher strength indices of fully-penetrated metal, however ductility and impact toughness are extremely low, therefore this type of welding and heat treatment is not recommended for it. 11 Ref., 6 Tables, 16 Figures.
\end{abstract}

Keywords: argon-arc welding, TIG, structure, dispersion hardening, titanium silicides, mechanical properties, heat treatment

Structural high-strength titanium-based alloys due to their unique characteristics, such as high specific strength at keeping satisfactory ductility and high corrosion resistance, have found wide application in aircraft and rocket construction as well as gas-turbine engine production. Thus, for example, a frame design of modern passenger aircrafts has by mass around $15 \%$ of complexly-alloyed titanium alloys and that for military aircrafts makes up to $40 \%$. Further development of aircraft and rocket engineering requires significant increase of service properties of titanium alloys. One of the ways to rise the ultimate strength of such alloys is dispersion hardening of metal due to precipitation of disperse particles from solid solution [1-5].

Tungsten inert gas welding is still one of the most widespread, relatively easy and versatile methods for manufacture of the structures of titanium alloys [6].

In addition to experimental $(\alpha+\beta)$-alloy (close on composition to known Ti-1008 [7] (Table 1), the investigations were also carried out on structure, phase composition and mechanical properties of argon-arc welded joints of commercial high-strength alloy VT23. It is medium $(\alpha+\beta)$-alloy of martensite class, which transfers from $\beta$-phase to martensite form after quenching. This alloy differs from other by increased process ductility that allows using rolling, milling, drawing, stamping, flanging and other operations, related with shaping in process of part manufacture [8].

Rise of alloy doping level promotes for increase of their sensitivity to welding thermal cycle and danger of welded joint brittle fracture due to reduced ductility. Two-phase titanium $(\alpha+\beta)$-alloys considerably increase strength characteristics after aging and quenching. However, high strength of these alloys, with few exceptions, is impossible to realize in the welded structures, that is caused by difficulties, appearing in process of quenching and aging of the structures, and specifically by reduced ductility of welded joints in thermally-hardened state [9].

Aim of this investigation lies in study of effect of TIG welding method on weldability of titanium alloys with dispersion hardening. The results of examination of structure, phase composition and mechanical properties of pilot alloy base metal are described in details in work [7].

Welding heating was carried out by tungsten non-consumable electrode (no filler wire) without full penetration of metal. Welding current made $350 \mathrm{~A}$, welding rate was $10 \mathrm{~m} / \mathrm{h}$ and $12 \mathrm{~V}$ arc voltage.

Table 1 shows composition of examined alloys.

Microstructure of a fully-penetrated metal of experimental alloy No.6 represents coarse elongated grains normal to fusion line (Figure 1). The structure and phase composition are determined by argon-arc welding thermal cycle (Figure 2).

Microhardness of the fully-penetrated metal made $3680 \mathrm{MPa}$, whereas, it reduced to $3430 \mathrm{MPa}$ in HAZ metal, and then in the direction to base metal its value increased to $4010 \mathrm{MPa}$. SEM examination on 
Table 1. Composition of examined alloys, wt.\%

\begin{tabular}{|c|c|c|c|c|c|c|c|c|c|c|}
\hline Alloy & Alloy type & Al & Sn & Zr & Nb & Mo & V & Cr & Fe & Si \\
\hline No.6 & $(\alpha+\beta)$ & 4.29 & 4.39 & 5.95 & 4.26 & 1.57 & 0.68 & 0 & 0 & 0.35 \\
\hline VT23 & $(\alpha+\beta)$ & 4.55 & 0 & $<0.35$ & $<0.15$ & 2.05 & 4.50 & 1.2 & 0.60 & $<0.15$ \\
\hline
\end{tabular}

JAMP9500F unit discovered that the weld disperse particles of complex silicides, which were detected in experimental alloy base metal [7], were virtually almost diluted in process of metal penetration, due to what their identification was impossible. Some amount of nanoparticles of titanium alumosilicides was found along grain boundaries (Figure 3,a). It explains reduction of microhardness in the fully-penetrated metal in comparison with the base metal.

Alternation of $150 \mu \mathrm{m}$ width bands without particles and around $83 \mu \mathrm{m}$ width bands with significant amount of disperse particles (Figure 3, $b$ ) is observed in fusion area of the fully-penetrated metal with the base metal of given specimen. This is the area where the main phase transformations take place (temperature range $890-1668{ }^{\circ} \mathrm{C}$ in Figure 2). Microhardness of this area near fusion line makes $3730 \mathrm{MPa}$, that is, apparently, related with presence of hardening particles of titanium alumosilicides in place of microhardness measurement.

Considerable increase of particle amount is observed in HAZ metal in contrast to fully-penetrated metal structure. Size of complex silicide particles var- ies from $50 \mathrm{~nm}$ to $1 \mu \mathrm{m}$. They are mainly uniformly located in the grain body as well as along the boundaries. Shape of grains approaches to equilibrium, forming triple boundary in the top of their contact (Figure 4).

The most uniform distribution of particles and the maximum microhardness (up to $4010 \mathrm{MPa}$ ) are observed in the base metal. These particles are also located in the grain body as well as along the boundaries. Size of the particles varies in $70-150 \mathrm{~nm}$ range (Figure 5).

Volume fraction of the particles was calculated using STIMAN software. As was shown above, the particles are virtually absent in the weld. Their volume fraction made $0.9 \%$ along the fusion line. Their size and amount in HAZ metal increased to $1.4 \%$ and that in the base metal made $1.9 \%$.

An area, containing all structural constituents, was taken for qualitative determination of phase composition. Table 2 shows composition of disperse hardening particles, $\alpha$-phase and $\beta$-phase of the experimental alloy welded joint. The characteristic spectra were collected from areas for analysis, indicated in Figure 6.
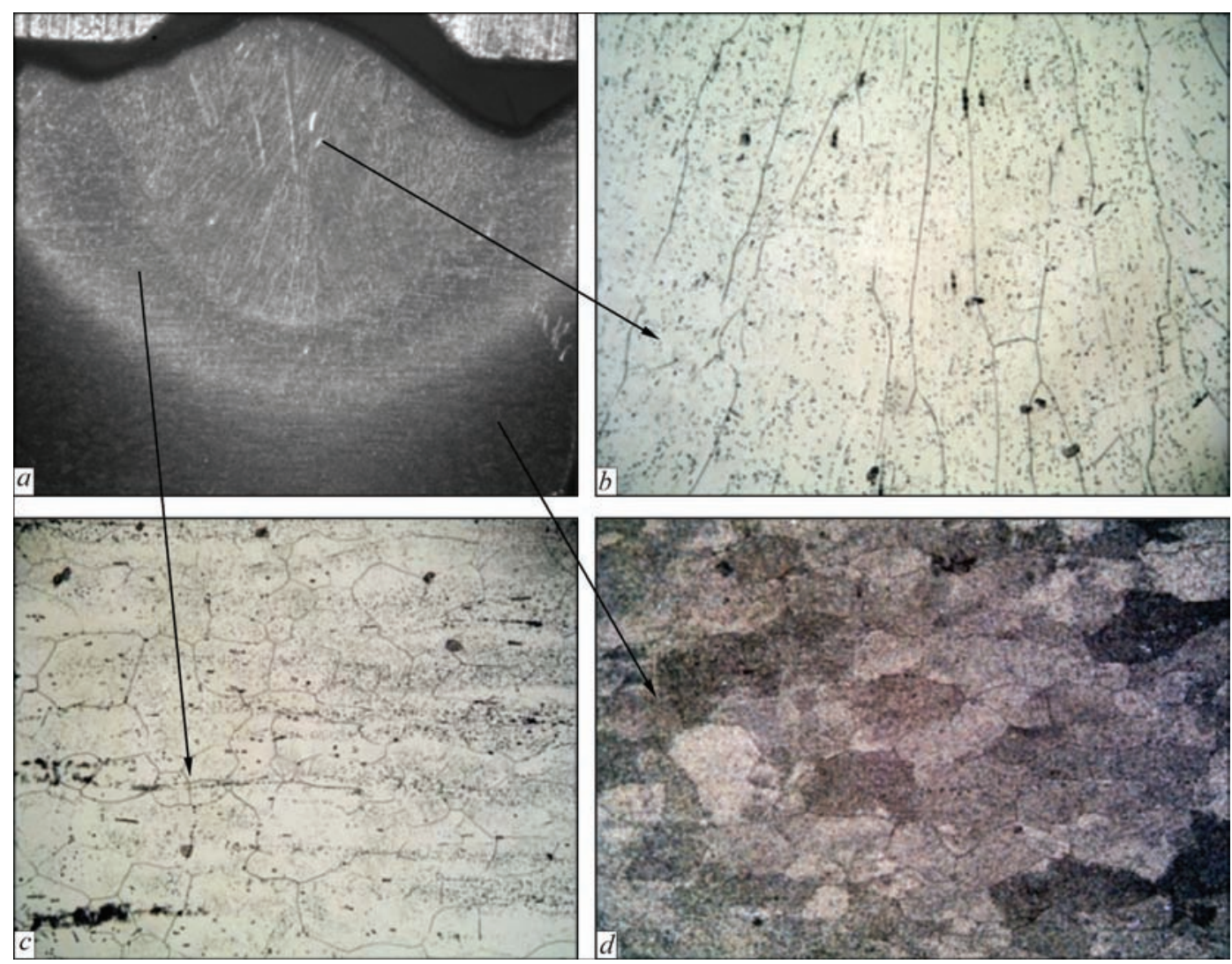

Figure 1. Different areas of alloy No. 6 with fully-penetrated metal, $\times 10(a)$; microstructure of fully-penetrated metal, $\times 100(b)$; microstructure of HAZ metal, $\times 100(c)$; microstructure of base metal, $\times 100(d)$ 


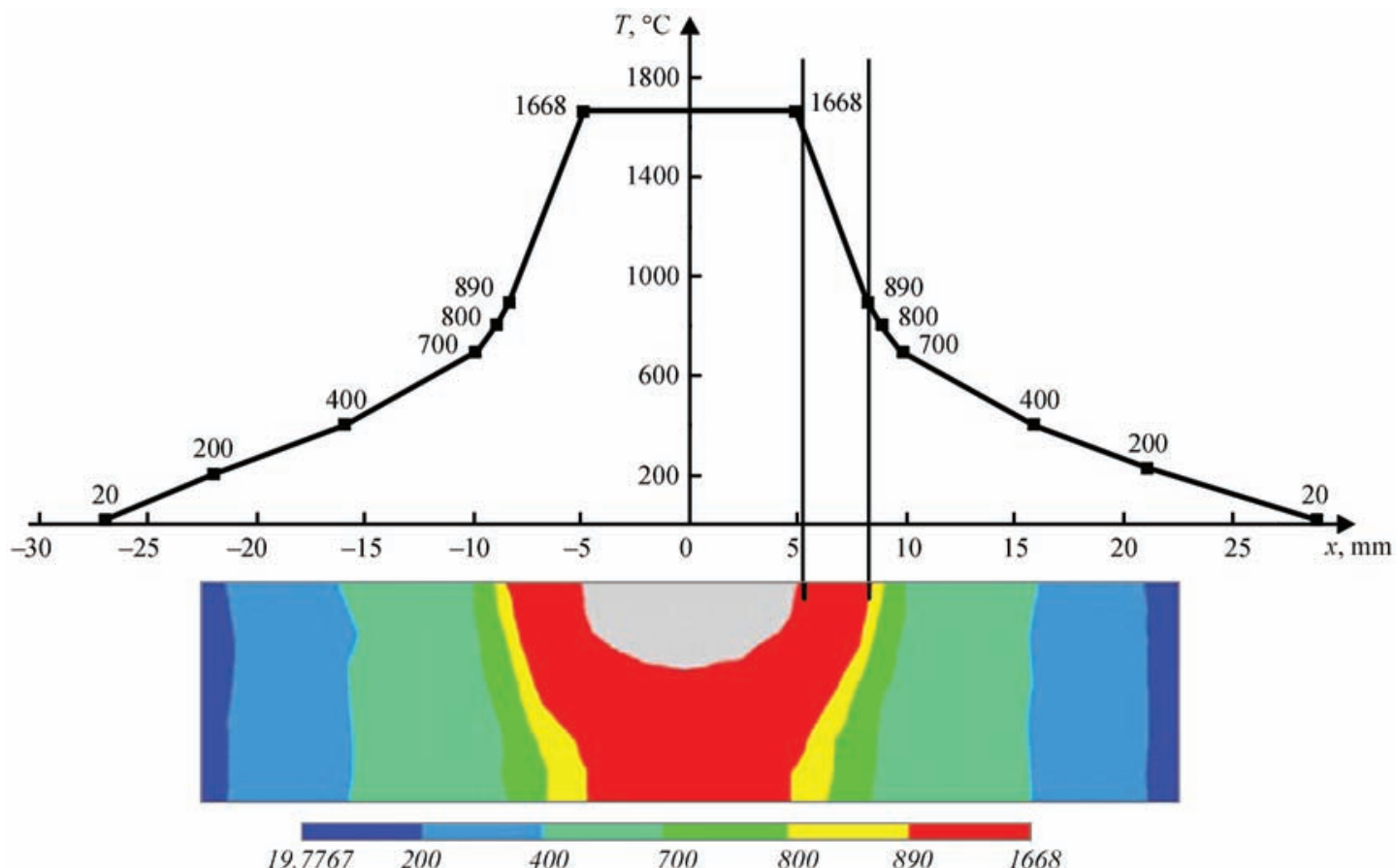

Figure 2. Thermal cycle of argon-arc welding of $(\alpha+\beta)$-titanium alloys

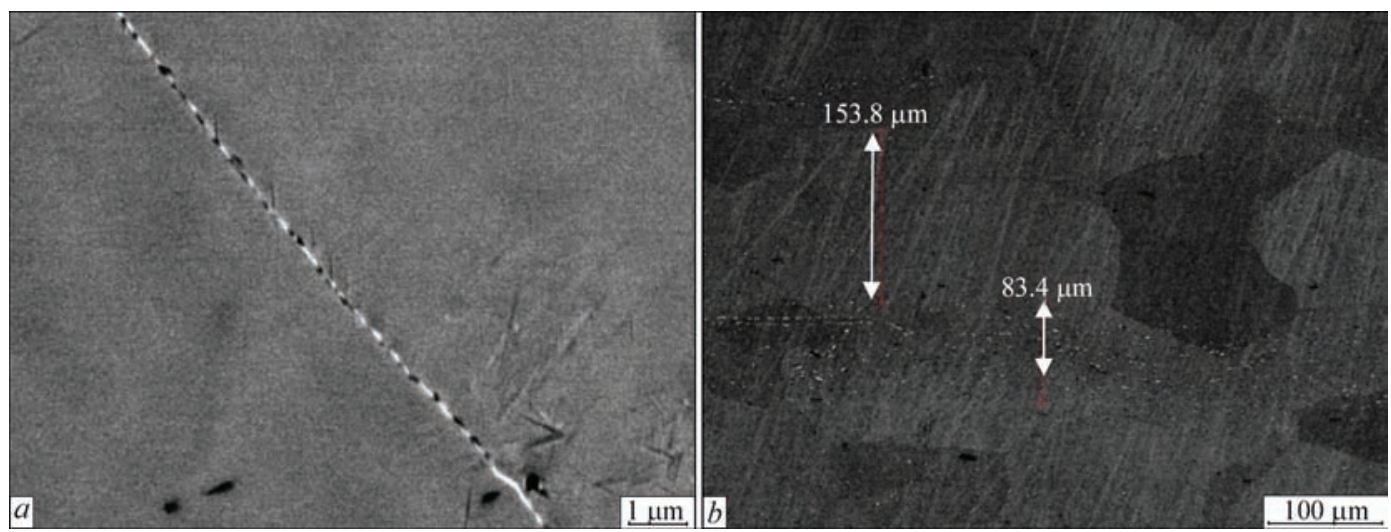

Figure 3. Microstructure of fully-penetrated metal of experimental alloy: $a$ — grain boundary in fully-penetrated metal area, $\times 1000$; $b$ - area of fusion line, $\times 200$

The results of micro X-ray analysis show that analysis of spectra 1 and 2 was carried out in areas of complex silicides (increased content of silicon and zirconium), that in spectrum 3 in area of $\beta$-phase (high

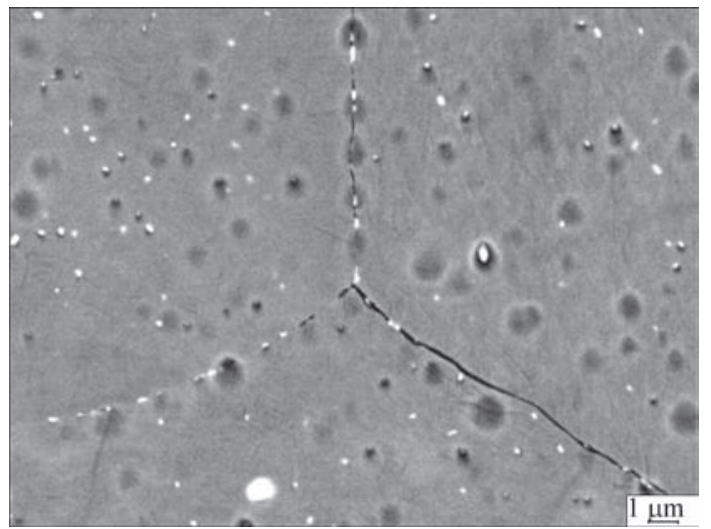

Figure 4. Triple boundary of grains in HAZ metal of experimental alloy, $\times 5000$ content of heavy elements of niobium, molybdenum and vanadium, which differ by light coloring on SEM image), and spectrum 4 in area of $\alpha$-phase with higher aluminum content, respectively.

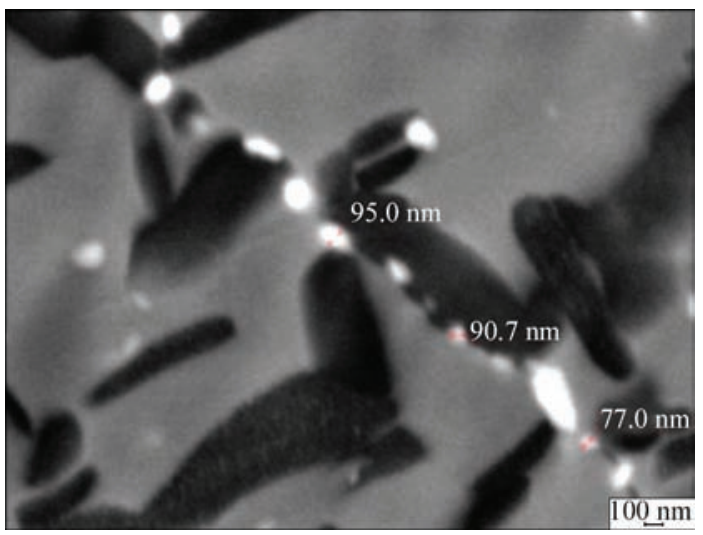

Figure 5. Nature of distribution of particles along base metal grain boundary of experimental alloy, $\times 30000$ 
Table 2. Composition of phase constituents of experimental alloy (wt.\%)

\begin{tabular}{|c|c|c|c|c|c|c|c|c|c|}
\hline $\begin{array}{c}\text { Analysis area } \\
\text { (number of spectrum) }\end{array}$ & $\mathrm{Al}$ & $\mathrm{Si}$ & $\mathrm{Ti}$ & $\mathrm{V}$ & $\mathrm{Zr}$ & $\mathrm{Nb}$ & $\mathrm{Mo}$ & $\mathrm{Sn}$ & Total \\
\hline 1 & 4.24 & 5.36 & 38.70 & 0.00 & 27.24 & 4.61 & 2.50 & 4.28 & 100 \\
\hline 2 & 3.71 & 1.98 & 51.78 & 0.86 & 15.11 & 6.31 & 8.32 & 4.00 & 100 \\
\hline 3 & 2.97 & 0.31 & 58.05 & 5.19 & 7.34 & 9.53 & 13.17 & 2.17 & 100 \\
\hline 4 & 9.40 & 0.18 & 67.15 & 0.67 & 6.73 & 4.07 & 1.33 & 7.42 & 100 \\
\hline
\end{tabular}

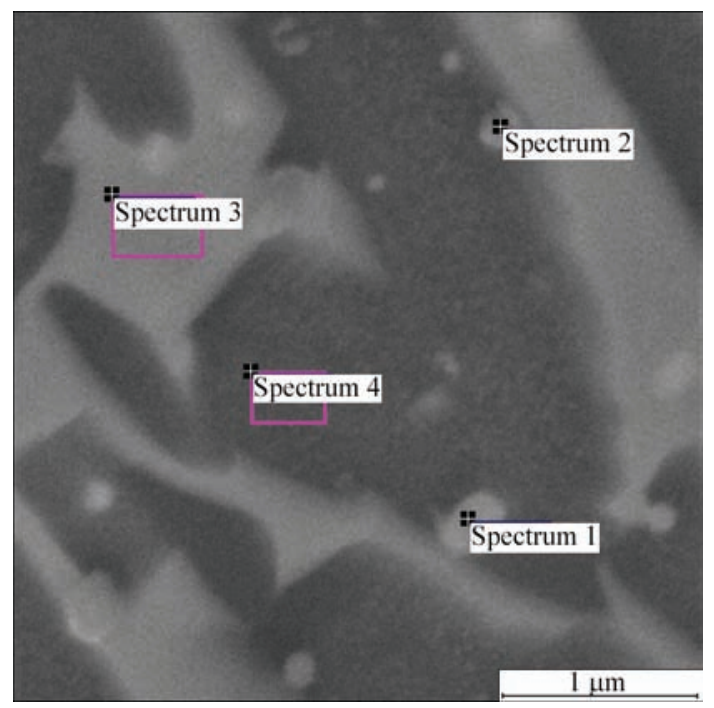

Figure 6. Electron image of analysis areas of energy dispersive spectrometry (EDS), $\times 20000$

Simulation of post-weld furnace heat treatment (HT) was carried out after examinations of structure and phase composition of fully-penetrated metal of ex- perimental alloy. The following heating mode was used, namely to $1000{ }^{\circ} \mathrm{C}$ (1 hour), cooling to $600-650{ }^{\circ} \mathrm{C}$ (1 hour) with further cooling to room temperature.

Microstructure of the fully-penetrated metal of experimental alloy after HT represents itself the same coarse elongated grains as before HT, but there was a crack in the fully-penetrated metal (Figure 7).

Microhardness of the fully-penetrated metal makes $3860 \mathrm{MPa}$, whereas it decreases in HAZ metal to 3600-3200 values, and rises insignificantly to $3580 \mathrm{MPa}$ value in the base metal. Thus, the fully-penetrated metal after HT is characterized by maximum hardness and strength, but at the same time low ductility that results in crack formation.

After heat treatment the area of fully-penetrated metal contains significant amount of uniformly located hardening disperse particles of different size (Figure 8) that provides for increased value of microhardness in comparison with HAZ and base metal.

The particles of smaller size and in lower amount were found in HAZ. The particles of coarser size are

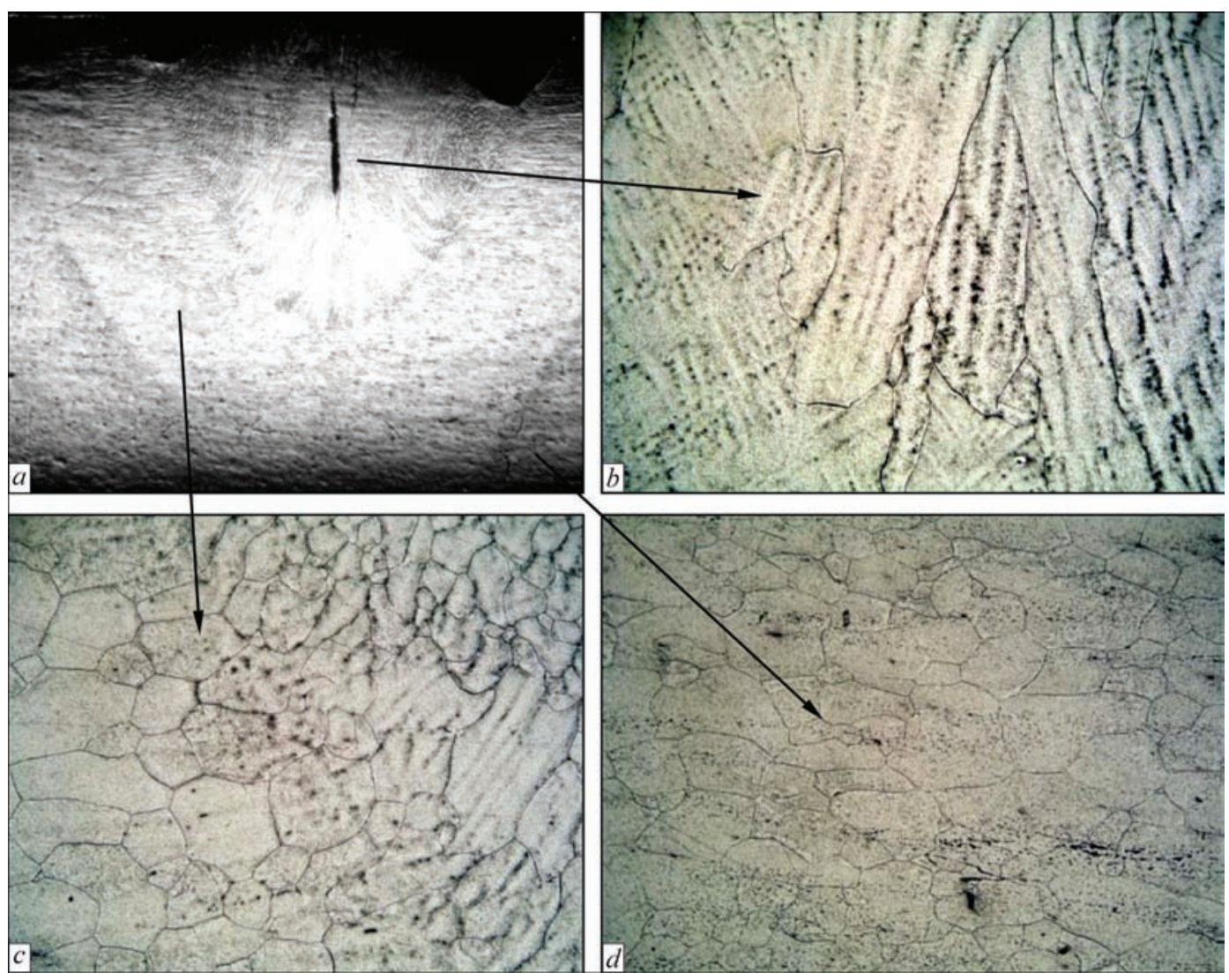

Figure 7. Macrostructure of fully-penetrated metal of experimental alloy after HT, $\times 10(a)$; microstructure of area of fully-penetrated metal, $\times 100(b)$; microstructure of HAZ metal, $\times 100(c)$; microstructure of base metal, $\times 100(d)$ 
observed in the base metal. Volume fraction of particles in the area of fully-penetrated metal makes $1.9 \%$, that in HAZ is $1.7 \%$, and $2.1 \%$ in the base metal. This, probably, indicates that the large amount of particles in the fully-penetrated metal grows in size due to high temperature during HT process. Their volume fraction in the base metal is somewhat higher due to their size coarsening.

Examinations of grain boundaries and composition of the particles of experimental alloy after HT were carried out on scanning electron high resolution microscope TESCAN MIRA 3 LMU with OXFORD INSTRUMENTS INCA ENERGY + microanalysis system.

Significant accumulation of the hardening spherical particles is observed along the boundaries of weld grains. Their sizes are varied in wide limits, i.e. from $50 \mathrm{~nm}$ to $1 \mu \mathrm{m}$ (Figure 9, a). Coagulated silicides were also found (Figure 9, $b$ ) along the boundaries. Such conglomerates along the grain boundaries pro-

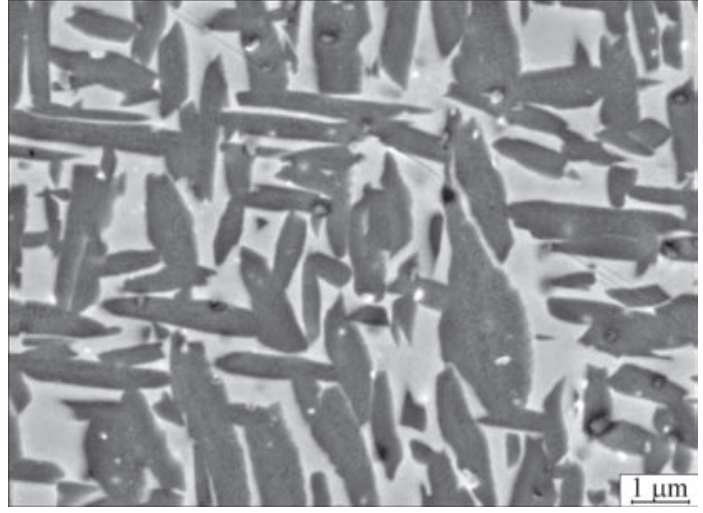

Figure 8. Distribution of disperse particles of complex silicides on surface of microsection of pilot experimental after HT, $\times 10000$ mote large internal stresses that can be a possible reason of crack formation.

The results of examinations of the fully-penetrated experimental two-phase alloy were compared with the results of examination of commercial alloy VT23.

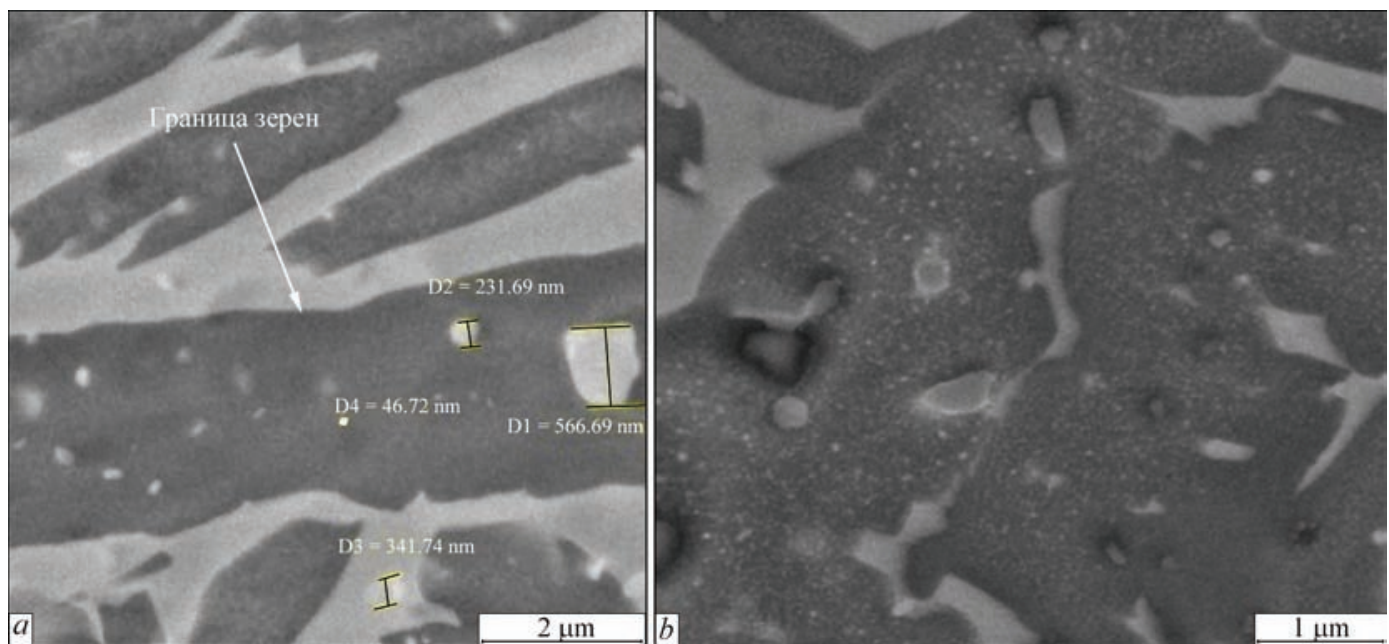

Figure 9. Image in backscattered electrons of grain boundary in area of fully-penetrated metal of alloy No.6 after HT: $a$ - area of grain boundaries with particles, 7000; $b$ - coagulated silicides along grain boundary, $\times 20000$

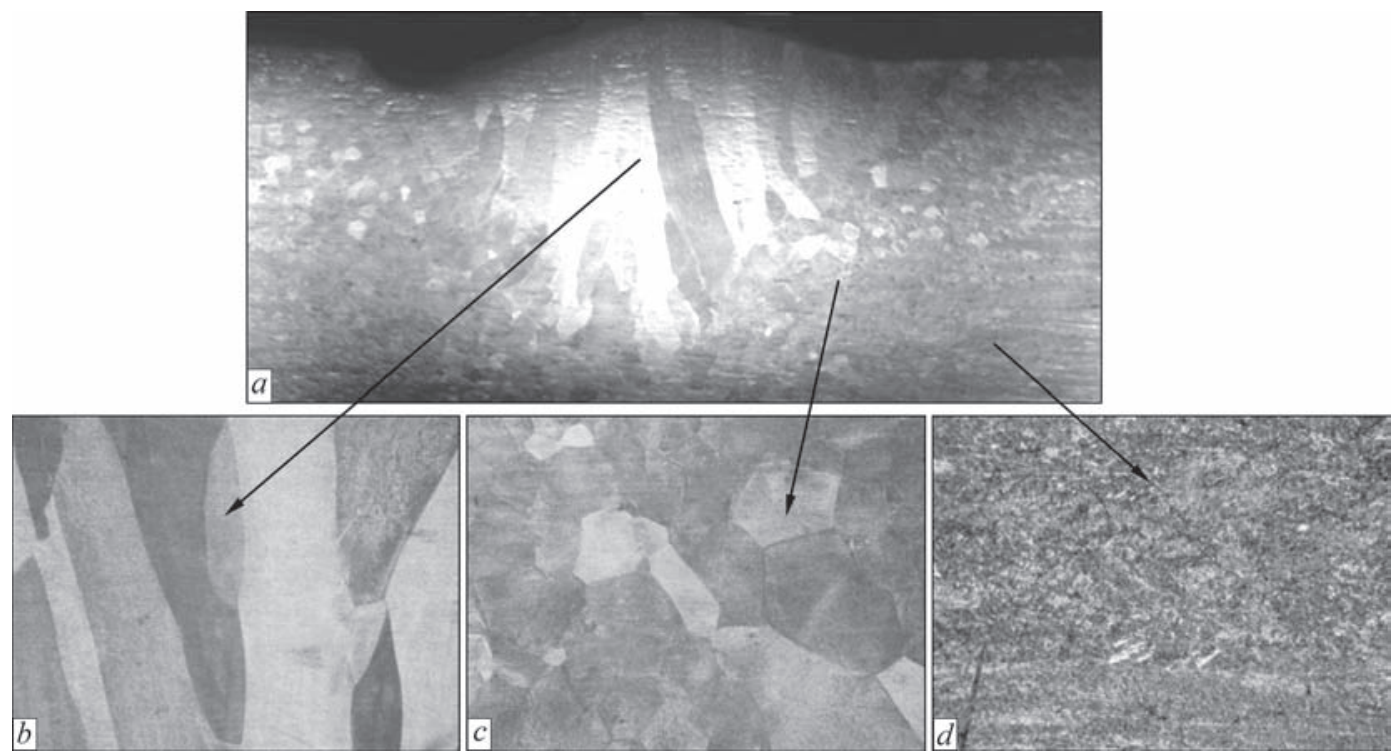

Figure 10. Macrostructure of fully-penetrated metal of alloy VT23, $\times 10(a)$; microstructure in the center of fully-penetrated metal, $\times 50$ (b); microstructure of HAZ metal area, $\times 50(c)$; microstructure of base metal, $\times 100(d)$ 
Table 3. Composition of $\alpha$ and $\beta$-phases of fully-penetrated alloy VT23 (wt.\%)

\begin{tabular}{|c|c|c|c|c|c|c|c|c|}
\hline $\begin{array}{c}\text { Area of analysis } \\
\text { (number of spectrum) }\end{array}$ & $\mathrm{Al}$ & $\mathrm{Si}$ & $\mathrm{Ti}$ & $\mathrm{V}$ & $\mathrm{Cr}$ & $\mathrm{Fe}$ & Mo & Total \\
\hline 1 & 4.21 & 0.20 & 82.03 & 5.63 & 1.23 & 0.65 & 3.92 & 100 \\
\hline 2 & 3.51 & 0.34 & 76.22 & 8.06 & 2.20 & 2.20 & 5.04 & 100 \\
\hline
\end{tabular}

Macrostructure of the fully-penetrated metal of alloy VT23 has virtually no difference from macrostructure of the experimental alloy (Figure 10, $a$ ). The same elongated coarse grains normal to fusion line (Figure $10, b)$ are observed. Microhardness of the area of fully-penetrated metal makes 3550-3560 MPa. The areas of coarse grain, but of more equilibrium type (Figure 10, c) are also observed at transfer in HAZ. Microhardness in HAZ metal rises to 3750-3950 MPa values. The base metal of VT23 welded joint contains a two-phase structure (Figure 10, $d$ ) with microhardness value of around $3200 \mathrm{MPa}$. Such a distribution of microhardness is related with the fact of formation in the fully-penetrated metal and HAZ metal of metastable $\alpha^{\prime \prime}$-phase of martensite type, which differ by high hardness. Besides this, precipitation of $\alpha_{1}$-phase (low-temperature modification of $\alpha$-phase), which is more ductile [10], takes place in the fully-penetrated metal.

Examinations of structure of the fully-penetrated metal of commercially developed alloy VT23, made using SEM TESCAN MIRA 3 LMU, showed that the area of fully-penetrated metal, HAZ and base metal has pure grain boundaries without embrittling precipitations, pores and microcracks (Figure 11).

Analysis of composition of VT23 alloy fully-penetrated metal (Table 3 in Figure 11) was carried out in the same way as in the case of experimental alloy.

The fully-penetrated metal of titanium alloys No.6 and VT23 after argon-arc welding simulation was subjected to tensile and impact tests. The results of mechanical tests are given in Table 4.

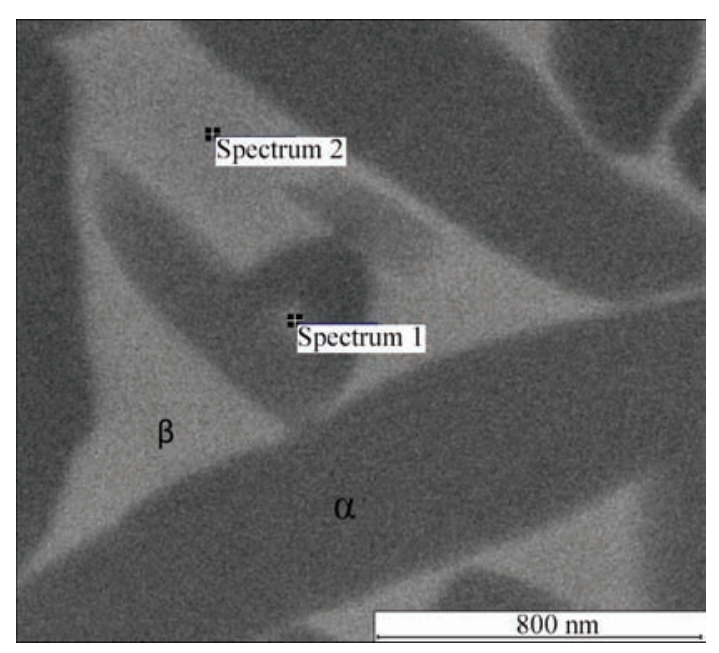

Figure 11. Image in backscattered electrons of microstructure of grain boundary in the VT23 weld, $\times 30000$
Specimen of alloy No.6 was broken in a grip place in tensile testing of the cylinder specimens. This, probably, is related with the fact that all loading falls at the area with microcracks. Due to this non-typical for given alloy low strength was received. Therefore, additional compression tests were carried out (testing machine UTM-100 with maximum loading $100 \mathrm{kN}$ ). The results of mechanical compression tests are given in Table 5.

Thus, the ultimate strength of the fully-penetrated metal was received in compression testing and it makes $80 \%$ of base metal ultimate strength $\left(K_{t}=0.8\right)$, and yield strength of the fully-penetrated metal was even larger than the base metal indices.

Fracture surface after impact tests of Charpy specimens in the area of fully-penetrated metal represents itself a local area, formed on microchip mechanism (Figure 12). Its presence indicates a quasi-brittle nature of this metal area fracture. The microcracks can be seen at larger magnifications (Figure 13).

The same as in the case of microsection examination, no disperse particles of titanium alumosilicides were found on the fracture surface. This verifies an earlier expressed idea that these particles are partially melted and can not be identified due to high temperature and duration of argon-arc process. It is agreed with the possibility of invertible flow of dispersion mechanism [11]. Composition of the fully-penetrated metal area corresponds to matrix content, and the particles are not found.

After HT of alloy No.6 fully-penetrated metal, it was also subjected to mechanical impact and tensile

Table 4. Mechanical properties of base metal and fully-penetrated alloys No.6 and VT23

\begin{tabular}{|c|c|c|c|c|c|}
\hline \multicolumn{2}{|c|}{ Alloy } & $\sigma_{y}, \mathrm{MPa}$ & $\sigma_{\mathrm{t}}, \mathrm{MPa}$ & $K C V, \mathrm{~J} / \mathrm{cm}^{2}$ & $\Delta, \%$ \\
\hline \multirow{2}{*}{ VT23 } & BM & 1050 & 1200 & 42 & 5 \\
\cline { 2 - 6 } & $\begin{array}{c}\text { Fully-pene- } \\
\text { trated metal }\end{array}$ & 1084 & 1128 & 29.6 & 1.3 \\
\hline \multirow{2}{*}{ No.6 } & BM & 1330 & 1420 & 4 & 1 \\
\cline { 2 - 6 } & $\begin{array}{c}\text { Fully-pene- } \\
\text { trated metal }\end{array}$ & - & 560 & $<1$ & $<1$ \\
\hline
\end{tabular}

Table 5. Mechanical properties of base metal and fully-penetrated alloy No.6 in compression testing

\begin{tabular}{|c|c|c|c|c|}
\hline \multicolumn{2}{|c|}{ Alloy } & $\sigma_{y}$, MPa & $\sigma_{t}$, MPa & $\psi, \%$ \\
\hline \multirow{2}{*}{ No.6 } & BM & 1220 & 1850 & 6 \\
\cline { 2 - 5 } & Fully-penetrated metal & 1315 & 1440 & 2.5 \\
\hline
\end{tabular}




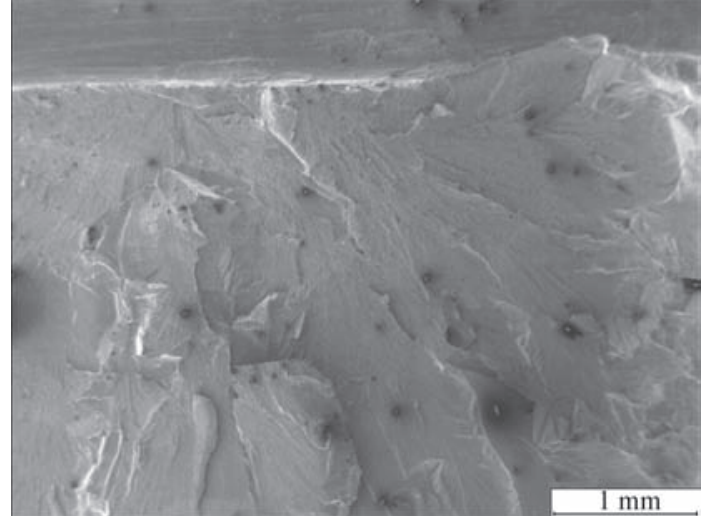

Figure 12. Fracture surface of fully-penetrated metal of experimental alloy, $\times 25$

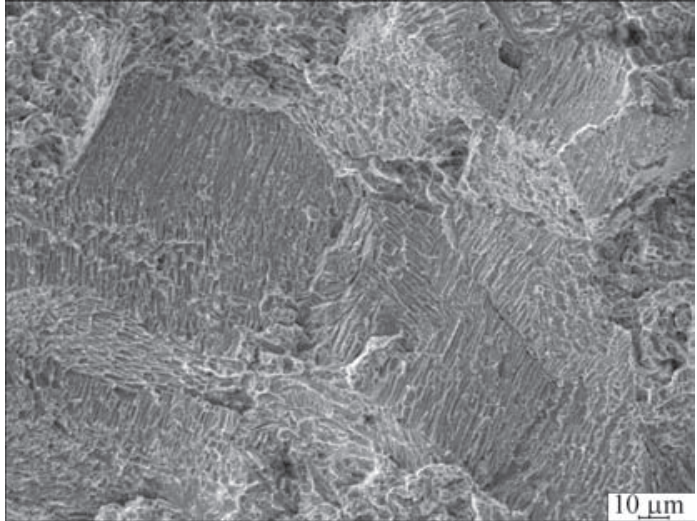

Figure 14. Fracture surface of experimental alloy specimen after $\mathrm{HT}, \times 500$

Table 6. Composition of structure constituents of fracture of alloy No.6 fully-penetrated metal after HT, wt.\% (on Figure 15, a)

\begin{tabular}{|c|c|c|c|c|c|c|c|c|c|}
\hline $\begin{array}{c}\text { Area of analysis } \\
\text { (number of spectrum) }\end{array}$ & $\mathrm{Al}$ & $\mathrm{Si}$ & $\mathrm{Ti}$ & $\mathrm{V}$ & $\mathrm{Zr}$ & $\mathrm{Nb}$ & Mo & Sn & Total \\
\hline 1 & 3.83 & 8.45 & 38.89 & 1.21 & 35.63 & 3.48 & 1.38 & 4.77 & 100 \\
\hline 2 & 3.72 & 9.44 & 38.94 & 0.38 & 38.75 & 1.84 & 0.43 & 4.57 & 100 \\
\hline 3 & 8.50 & 0.24 & 70.43 & 1.52 & 6.10 & 3.55 & 0.73 & 7.79 & 100 \\
\hline
\end{tabular}

tests. Small magnifications show the chip areas with equiaxial coarse grain structure (Figure 14).

If large magnifications revealed only microcracks directly after argon-arc welding simulation, than in this case secondary intergranular cracks can be obviously observed even at 500 fold magnification. This indicates high sensitivity of this alloy to HT heating.

At large magnifications considerable amount of disperse hardening particles as well as microcracks were found. They are located along the boundaries and grain body. In HT the particles increased in size to values which can be identified using SEM. They are located in the fracture pits that indicate more ductile fracture type of metal. Low level of ductility of this material can be related with increase of amount and extension of microcracks due to temperature gradient in HT heating. Detected particles have different size from $1 \mu \mathrm{m}$ to $50 \mathrm{~nm}$. Nature of particle distribution and chemical analysis of phase constituents are presented in Figure 15 and in Table 6 (on Figure 15, a).
The results of chemical analysis show that all the particles, which are detected on the fracture surface after HT are titanium alumosilicides. HT promotes for rise of their size to $50 \mathrm{~nm}$ and more.

Fractographic analysis of the fracture surface was also carried out after mechanical tests of commercial high-strength alloy VT23.

The fracture surface is less brittle in comparison with experimental alloy (Figure 16) that verifies higher indices of impact toughness and ductility.

Thus, the following can be concluded after examination of the fully-penetrated metal of experimental dispersion-hardened $(\alpha+\beta)$-titanium alloy and commercial high-strength $(\alpha+\beta)$-titanium alloy VT23, received by TIG:

- directly after welding simulation, hardening titanium alumosilicides in area of the fully-penetrated metal are partially dissolved due to long-term effect of high temperature, i.e after TIG the fully-penetrated metal of experimental alloy is not dispersion-hard-

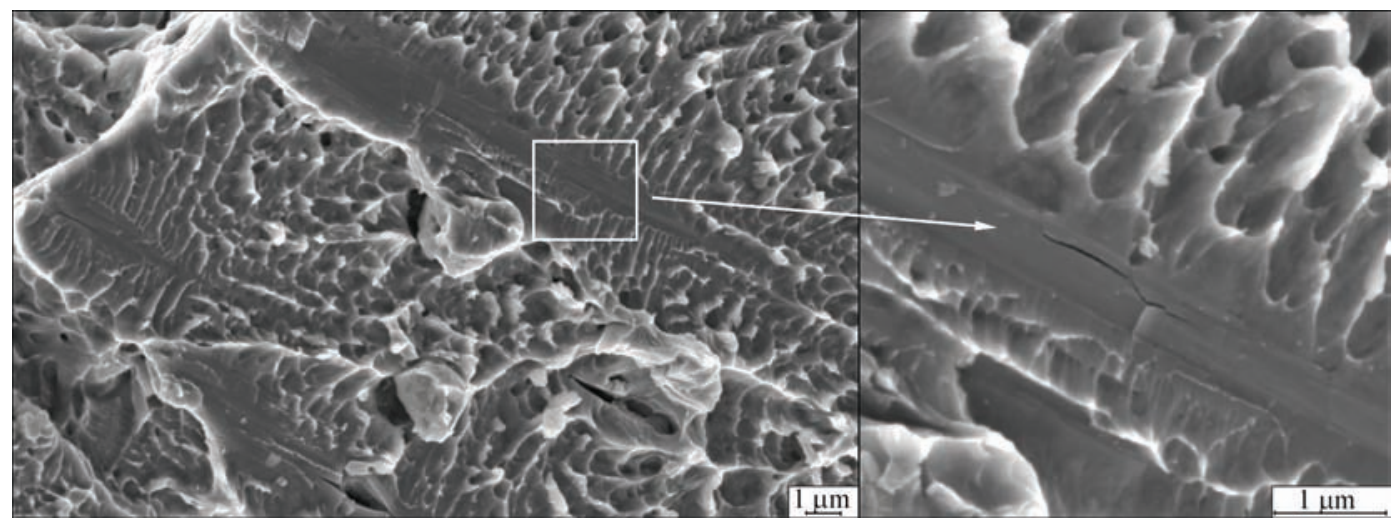

Figure 13. Fracture area of experimental alloy with microcracks, $\times 5000(\times 20000)$ 


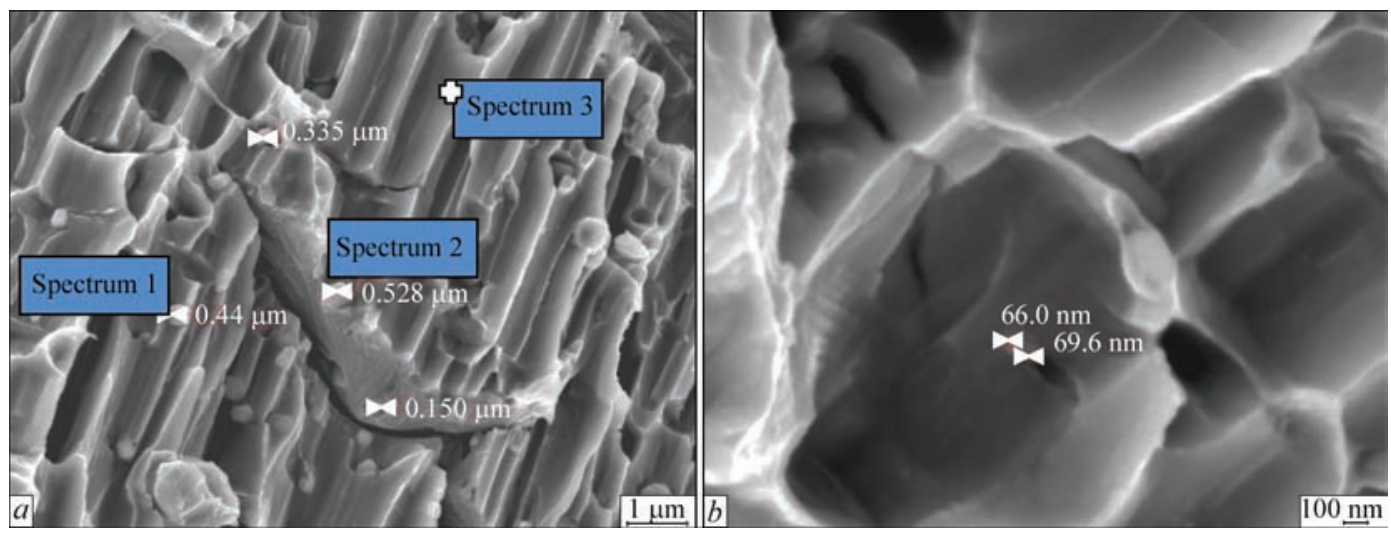

Figure 15. Fracture of fully-penetrated metal of experimental alloy after HT: $a$ - hardening particles and microcracks, $\times 10000 ; b-$ nanoparticles in fracture pit and nanosize cracks, $\times 40000$
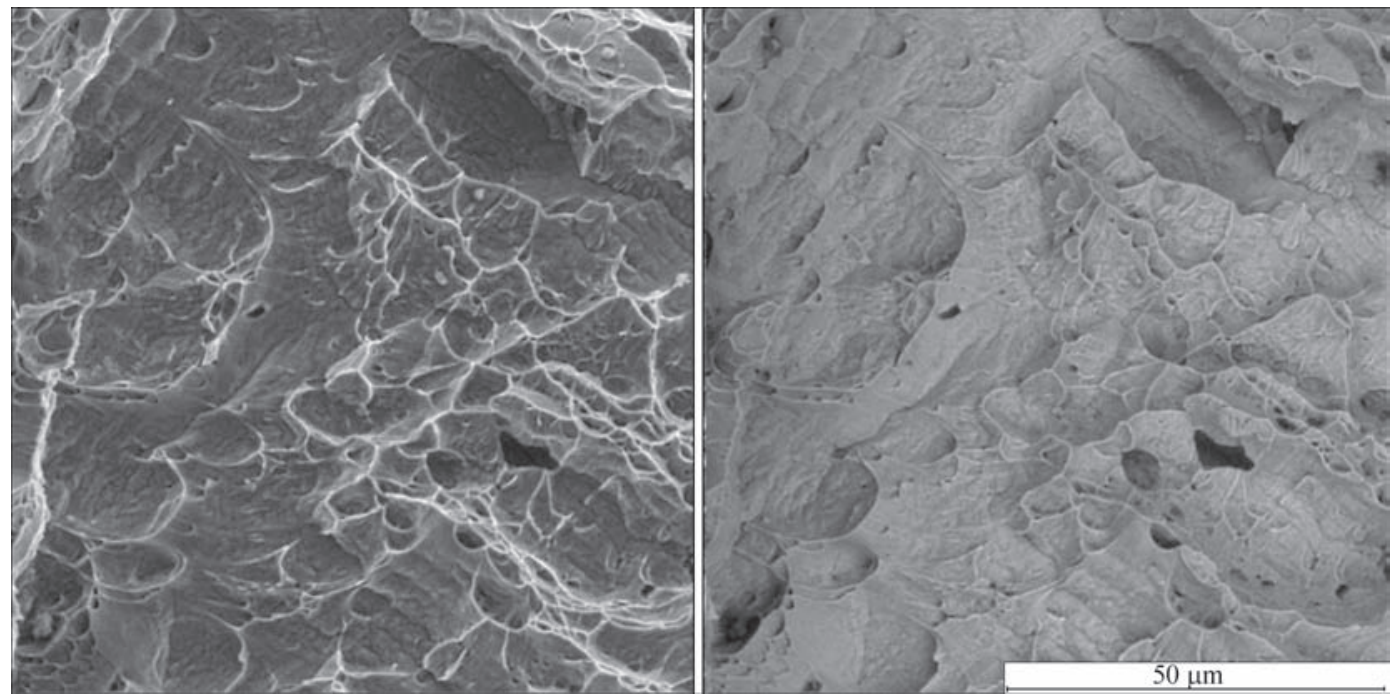

Figure 16. Fracture of fully-penetrated metal of VT23 alloy: $a$ - in the secondary electrons; $b$ - in backscattered, $\times 4000$

ened, but contains solid-solution hardening. Besides, the microcracks, caused by post-weld stresses, are observed at larger magnifications;

- coarsening of the hardening particles due to coagulation processes takes place after HT. These particles promote for more ductile fracture on pit tear mechanism. The microcracks increase in size and amount and result in crack in the middle of the fully-penetrated metal. This takes place due to temperature gradient in HT heating;

- in comparison with commercial high-strength $(\alpha+\beta)$-titanium alloy VT23, experimental dispersion-hardened alloy has higher indices of strength, but extremely low ductility and impact toughness, therefore this type of welding and HT can not be recommended for it.

1. Goldshtejn, M.I., Grachev, S.V., Veksler, Yu.G. (1985) Special steels: Manual for inst. of higher education. Moscow: Metallurgiya.

2. Rzhevskaya S.V. (2004) Materials science: Manual. Moscow: Logos.

3. (2003) Metals and alloys: Refer. Book. Ed. by Yu.P. Solntsev. St.-Petersburg: NPO Professional.

4. Trefilov, V.I. (1987) Strain hardening and fracture of polycrystalline metals.

5. Bochvar, A.A. (2012) Increase in strength or hardening of materials. http://do.gendocs.ru/docs/index-233261.html

6. Zamkov, V.N. (1986) Metallurgy and technology of welding of titanium and its alloys. Kiev: Naukova Dumka.

7. Grigorenko, G.M., Akhonin, S.V., Taranova, T.G. et al. (2012) Dispersion-hardened titanium alloys of Ti-Si-X system. Sovremennaya Elektrometallurgiya, 1, 45-53.

8. NPO Titan. Information. http://www.npctitan.ru/spravka/alloys/23/

9. Glazunov, S.G., Moiseev, V.N. (1974) Structural titanium alloys. Moscow: Metallurgiya.

10. Akhonin, S.V., Belous, V.Yu., Muzhichenko, A.F. et al. (2013) Mathematical modeling of structural transformations in HAZ of titanium alloy VT23 during TIG welding. The Paton Welding J., 3, 24-27.

11. Grigorenko, G.M., Zadorozhnyuk, O.M. (2012) Dispersion hardening as a way to increase the properties of new generation titanium alloys. Sovremennaya Elektrometallurgiya, 4, $42-50$.

Received 12.04.2016 


\title{
INFLUENCE OF METHODS OF ARC SURFACING WITH FLUX-CORED WIRE ON PENETRATION OF BASE METAL AND FORMATION OF DEPOSITED METAL
}

\author{
A.A. BABINETS ${ }^{1}$, I.A. RYABTSEV ${ }^{1}$, A.I. PANFILOV ${ }^{2}$, V.A. ZHDANOV $^{1}$ and I.I. RYABTSEV ${ }^{1}$ \\ ${ }^{1}$ E.O. Paton Electric Welding Institute, NASU \\ 11 Kazimir Malevich Str., 03680, Kiev, Ukraine. E-mail: office@paton.kiev.ua \\ ${ }^{2}$ OJSC «Steel Work» \\ 13 Tbilisskaya Str. 50005, Krivoy Rog, Ukraine
}

\begin{abstract}
The influence of methods of automatic arc surfacing on penetration of base metal, quality of formation and geometric sizes of deposited beads was investigated. In the experiments nine batches of flux-cored wires (25Kh5FMS type of deposited metal) of the diameter of 1.8; 2.4 and $2.8 \mathrm{~mm}$ for submerged arc, shielding gas and open arc surfacing were used. The surfacing was carried out in a wide range of modes: $I_{\mathrm{s}}=150-450 \mathrm{~A} ; U_{\mathrm{s}}=20-34 \mathrm{~V}$ at the same surfacing speed of $20 \mathrm{~m} / \mathrm{h}$. It was found that the greatest influence on formation of deposited beads is exerted by arc voltage. Moreover, the range of $\Delta U_{\mathrm{T}}$ voltages, at which a good formation of deposited beads and absence of pores is provided, does not coincide during surfacing by different methods with wire of the same diameter. The results obtained in this work can be used for selecting the method of arc surfacing, surfacing modes, which ultimately meet the operating conditions and the requirements to the deposited metal for definite parts. These results will be also used in databases in the development of computer programs for robotized additive technologies of arc surfacing. 13 Ref., 1 Table, 6 Figures.
\end{abstract}

Keywords: arc surfacing, surfacing modes, additive technologies of surfacing, flux-cored wire, deposited metal, penetration, formation of deposited metal

Flux-cored wire is one of the most universal electrode materials for mechanized and automated arc surfacing (welding) [1-3]. Among the main advantages of fluxcored wire, as compared to the other electrode materials, a rather simple adaptation of its chemical composition to the composition and properties of the parts being deposited, high arc burning stability, relatively low spattering of electrode metal and good formation of deposited beads can be mentioned [4-8].

Depending on the method of surfacing the fluxcored wires can be divided into three classes: for submerged arc surfacing, surfacing in the shielding gases and using open arc (self-shielding) [1, 9].

It is widely known, that the surfacing modes have a significant effect on penetration of base metal and quality of formation of deposited metal [1-10]. However, in most cases, the data presented in the mentioned works are uncoordinated, because they describe the properties of deposited metal produced using different methods applying different surfacing materials and modes. Moreover, when developing the technology for surfacing of different parts it is often necessary to provide not only the quality and preset properties of deposited metal, but also the specified geometric sizes of deposited beads and volume of base metal in the deposited metal (VBMD), etc. [9].
The aim of this work is the systematic investigation of influence of different methods of automatic arc surfacing and surfacing parameters on penetration of base metal, quality of formation and geometric sizes of deposited beads using surfacing materials of the same chemical composition and diameters.

The accumulation of databases on the modes of different methods of arc surfacing, geometric sizes of deposited beads, VBMD values and the value of penetration considering the previously developed expert systems on surfacing technologies $[11,12]$ and the proposed computer system advisor for selection of technology for surfacing typical parts [13] can further serve as a basis for development of computer programs for robotized additive technologies of arc surfacing.

Materials and methods of investigations. For investigations nine batches of experimental flux-cored wires were manufactured for submerged arc surfacing (AN-26P), shielding gas (82\% $\mathrm{Ar}+18 \% \mathrm{CO}_{2}$ ) and with open arc applying self-shielding flux-cored wire (shielding system $\mathrm{CaO}+\mathrm{TiO}_{2}+\mathrm{MgO}+\mathrm{CaF}_{2}+\mathrm{Al}_{2} \mathrm{O}_{3}$ ) of the diameters of 1.8; 2.4 and $2.8 \mathrm{~mm}$. The metallic part of the charge of flux-cored wires was calculated in the way to produce deposited metal of one type: 25Kh5FMS. For surfacing the universal surfacing installation U-653 was used, completed with the pow- 
Influence of surfacing mode using flux-cored wires of $1.8 \mathrm{~mm}$ diameter on formation of deposited metal and VBMD depending on the method of surfacing

\begin{tabular}{|c|c|c|c|c|c|}
\hline \multirow[b]{2}{*}{ Number } & \multicolumn{2}{|c|}{ Surfacing mode } & \multirow[b]{2}{*}{ Formation (presence of pores) } & \multirow[b]{2}{*}{ VBMD, \% } & \multirow[b]{2}{*}{ Appearance of deposited beads } \\
\hline & $I_{\mathrm{s}}, \mathrm{A}$ & $U_{s}, \mathrm{~V}$ & & & \\
\hline \multicolumn{6}{|c|}{ Submerged arc surfacing } \\
\hline 1 & 241 & 26.9 & Satisfactory. Narrow bead & 30.5 & \multirow{7}{*}{ 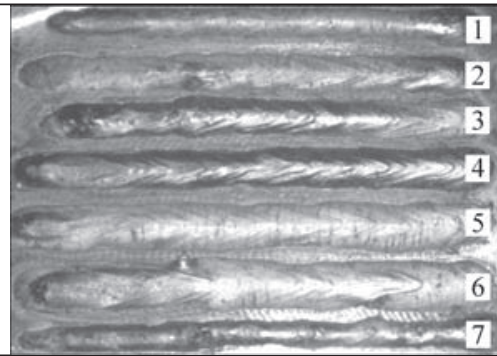 } \\
\hline 2 & 245 & 27.9 & Good & 44 & \\
\hline 3 & 290 & 27.8 & Poor & 44.5 & \\
\hline 4 & 298 & 27.7 & Poor & 51.3 & \\
\hline 5 & 301 & 28.9 & Good & 44 & \\
\hline 6 & 311 & 28.6 & Satisfactory & 48.5 & \\
\hline 7 & 224 & 26.5 & Poor. Narrow bead & 25.5 & \\
\hline \multicolumn{6}{|c|}{ Shielding gas surfacing } \\
\hline 1 & 237 & 26.5 & Good & 42.5 & \multirow{7}{*}{ 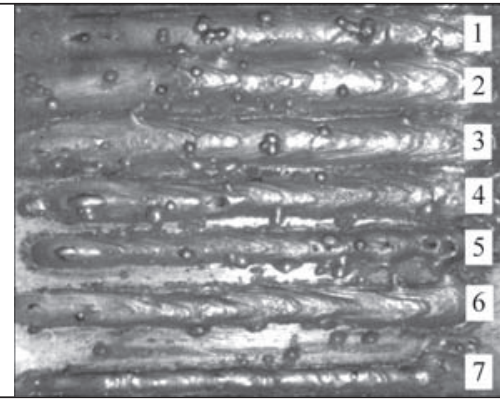 } \\
\hline 2 & 331 & 26.5 & Good & 50 & \\
\hline 3 & 316 & 27.3 & Good & 46 & \\
\hline 4 & 272 & 27.6 & Satisfactory (pores) & 50 & \\
\hline 5 & 171 & 28.3 & Satisfactory (pores) & 49.3 & \\
\hline 6 & 161 & 26.7 & Satisfactory & 50 & \\
\hline 7 & 172 & 23.0 & Satisfactory. Narrow bead & 25.8 & \\
\hline \multicolumn{6}{|c|}{ Open arc surfacing } \\
\hline 1 & 256 & 23.4 & Good & 47.5 & \multirow{6}{*}{ 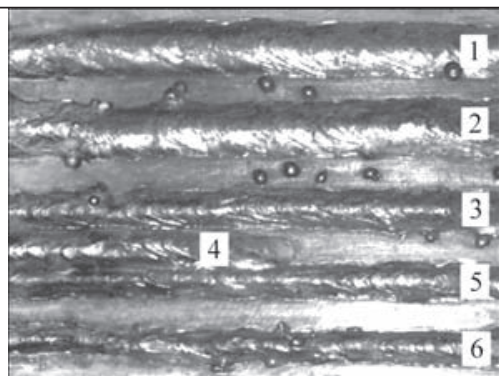 } \\
\hline 2 & 239 & 23.7 & Good & 45.5 & \\
\hline 3 & 227 & 22.3 & Good. Narrow bead & 48 & \\
\hline 4 & 236 & 22.2 & Good. Narrow bead & 38.5 & \\
\hline 5 & 218 & 22.3 & Good. Narrow bead & 51.5 & \\
\hline 6 & 232 & 23.3 & Satisfactory. Narrow bead & 26.5 & \\
\hline
\end{tabular}

er source VDU-506. The surfacing using flux-cored wires of different types and diameters was carried out on the plates of St.3 steel of $15 \mathrm{~mm}$ thickness in a wide range of modes: surfacing current $I_{\mathrm{s}}$ was from 150 to $450 \mathrm{~A}$; voltage $U_{s}$ was from 20 to $34 \mathrm{~V}$. The record and control of electrical parameters of surfacing mode was performed using the developed computer information-measuring system [13]. The surfacing speed of $20 \mathrm{~m} / \mathrm{h}$ in all the experiments remained constant, because in the range of $20-40 \mathrm{~m} / \mathrm{h}$ at other unchanged parameters the surfacing speed almost does not affect the geometric sizes of deposited beads [9].

In the process of the experiments the expert evaluation of quality of deposited bead formation, presence of pores, etc. was carried out. For measurements of basic geometric parameters of deposited beads on macrosections, cut out from deposited workpieces, the instrumental microscope BMI-1 was used. The mean value of $\gamma_{0}$ (VBMD) was determined according to six-eight cross-sections for each deposited bead according to the formula

$$
\gamma_{\mathrm{b}}=\frac{F_{\mathrm{b}}}{F_{\mathrm{b}}+F_{\mathrm{d}}} \cdot 100 \%,
$$

where $F_{\mathrm{b}}, F_{\mathrm{d}}$ are cross-sectional areas of molten base metal and deposited metals, respectively.

The obtained data were entered to the table general for each method. As an example, below the table is presented with characteristics of separate beads, deposited by submerged arc surfacing, surfacing in shielding gases and using open arc with flux-cored wires of $1.8 \mathrm{~mm}$ diameter.

Influence of methods and modes of surfacing on geometric sizes of deposited beads and VBMD. The basic parameters of surfacing mode are: current value, polarity and type; arc voltage; surfacing speed; electrode diameter and surfacing pitch [9]. In surfacing of rotation bodies the basic parameters include also the displacement from zenith (deposition of outer surfaces) or nadir (deposition of inner surfaces).

One of the most important characteristics of surfacing process are penetration value and volume of base metal. It is widely known that with decrease in 
penetration and VBMD not only the consumption of expensive surfacing materials is reduced, but also the quality and operating properties of deposited parts are improved. According to (1), VBMD value depends on the cross-section area of molten base and deposited metal. Thus, VBMD will decrease if the growth of surfacing area occurs faster than the growth of the area of molten base metal.

Figures 1-3 show experimental data on penetration depth of base metal, width of deposited beads and VBMD for the wires of $1.8 \mathrm{~mm}$ (solid lines) and $2.8 \mathrm{~mm}$ diameter (dashed lines) during surfacing using three different methods: submerged arc (a), shielding gas (b) and open arc (c).

As is seen from Figures 1 and 2, the improvement in electric parameters of surfacing mode leads to increase in penetration depth of base metal and width of deposited beads. It is the most significantly manifested in submerged arc surfacing. The increase in current and voltage results in almost proportional increase in
VBMD (Figure 3). This is explained by the fact, that increase in current leads to increase in effective thermal capacity of the arc, due to which the penetration depth and rate of electrode melting are increased.

It was found that at the same mode of surfacing using wire of one diameter, the lower VBMD can be obtained in submerged arc surfacing. Obviously, this is connected with higher thermal efficiency coefficient of this process due to better heat transfer between the arc and the base metal and the absence of heat losses for radiation and spattering the electrode metal. As a result, the growth of surfacing area occurs faster than the growth of the area of molten base metal.

Moreover, to provide the minimum possible penetration considering the quality formation of deposited beads (see below) is possible in the case of open arc surfacing with the wire of $1.8 \mathrm{~mm}$ diameter. Also, it should be noted, that for each method the areas with almost constant or even decreasing VBMD value at the growth of current and voltage are characteristic,
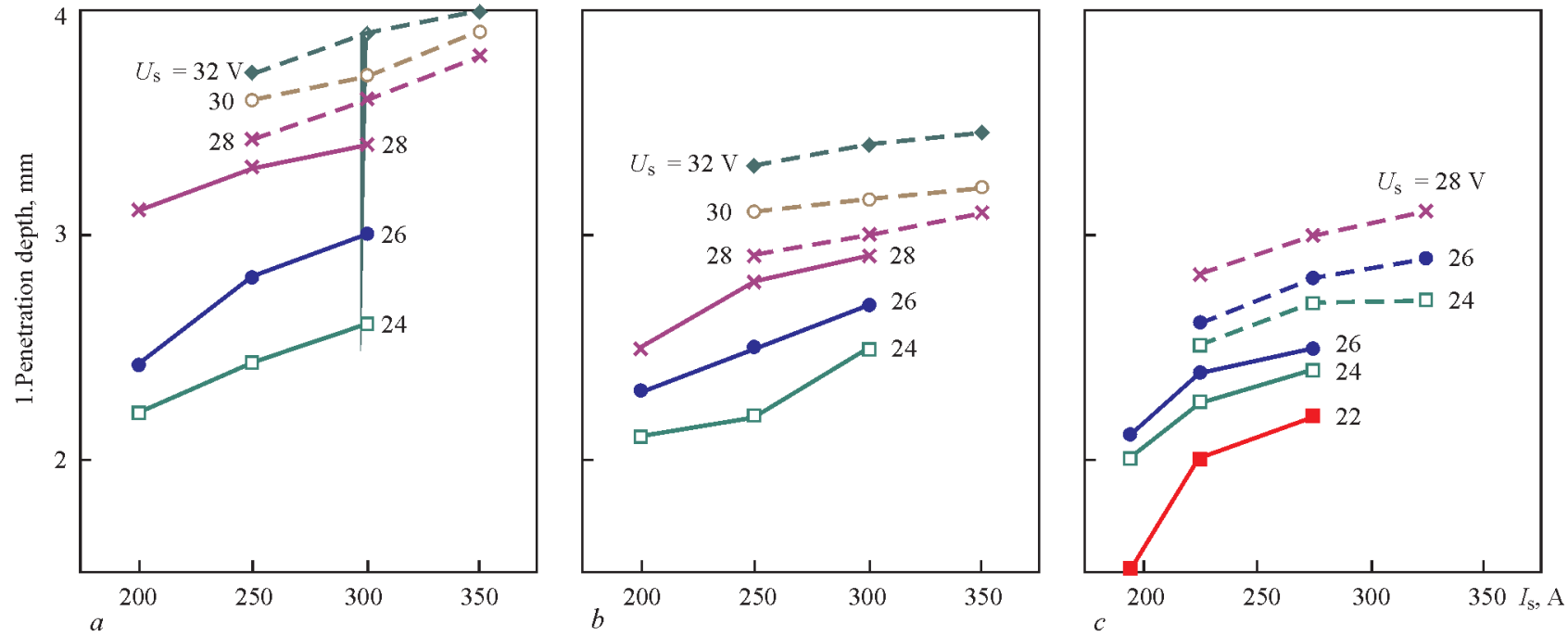

Figure 1. Influence of current on penetration depth in submerged arc surfacing $(a)$, surfacing in shielding gases $(b)$ and using open arc (c) (solid lines — wire of $1.8 \mathrm{~mm}$ diameter; dash lines - $2.8 \mathrm{~mm}$ )
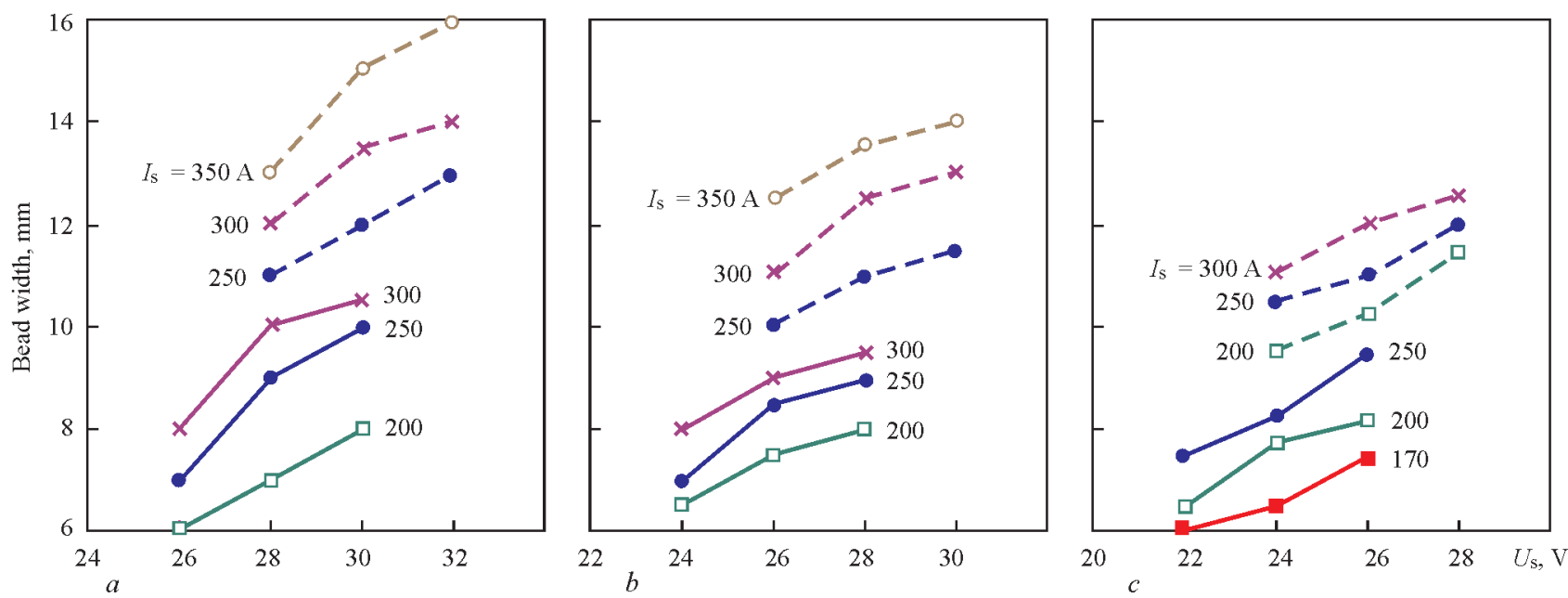

Figure 2. Influence of arc voltage on bead width in submerged arc surfacing $(a)$, surfacing in shielding gases $(b)$ and using open arc $(c)$ (solid lines - wire of $1.8 \mathrm{~mm}$ diameter; dash lines - $2.8 \mathrm{~mm}$ ) 

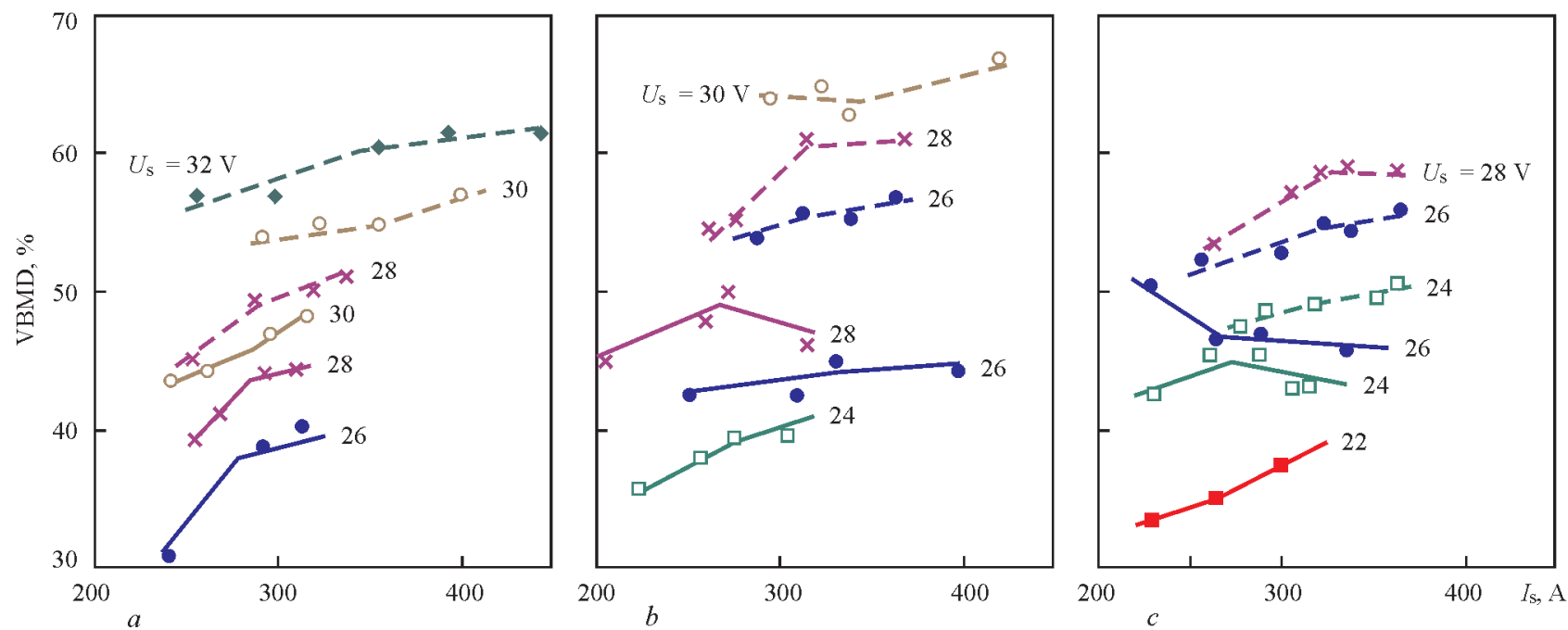

Figure 3. Influence of current and arc voltage on VBMD in submerged arc surfacing $(a)$, surfacing in shielding gases $(b)$ and using open arc (c) (solid lines — wire of $1.8 \mathrm{~mm}$ diameter; dash lines - $2.8 \mathrm{~mm}$ )

which is also explained by the ratio of values of electrical parameters of surfacing modes.

Influence of methods and modes of surfacing on quality of deposited beads formation. Submerged arc surfacing. When using the flux-cored wire of $1.8 \mathrm{~mm}$ diameter a good formation is observed at the conditions: $I_{\mathrm{s}}=220-300 \mathrm{~A}, U_{\mathrm{s}}=28-30 \mathrm{~V}$; for the wire of $2.4 \mathrm{~mm}$ diameter: $I_{\mathrm{s}}=250-350 \mathrm{~A}$, at the same voltage. The reduction of $U_{\mathrm{s}}<28 \mathrm{~V}$, as well as increase in $U_{\mathrm{s}}>30 \mathrm{~V}$ for the wires of the mentioned diameters results, respectively, in too narrow or too wide beads with a non-uniform formation.

For the wire of $2.8 \mathrm{~mm}$ diameter the optimal surfacing mode corresponds to the values $U_{\mathrm{s}}=28-32 \mathrm{~V}$ and $I_{\mathrm{s}}=250-400 \mathrm{~A}$. At the values of voltage $U_{\mathrm{s}}<28 \mathrm{~V}$ and $U_{s}>32 \mathrm{~V}$, the formation of beads is deteriorated, however, even at such «unfavorable» conditions the absence of defects in the deposited metal is observed.

Shielding gas surfacing. In surfacing with fluxcored wire of $1.8 \mathrm{~mm}$ diameter a good formation of deposited beads is observed in the range of modes $U_{\mathrm{s}}$ $=25-27 \mathrm{~V} ; I_{\mathrm{s}}=250-320 \mathrm{~A}$. At the voltage $U_{\mathrm{s}}<25 \mathrm{~V}$

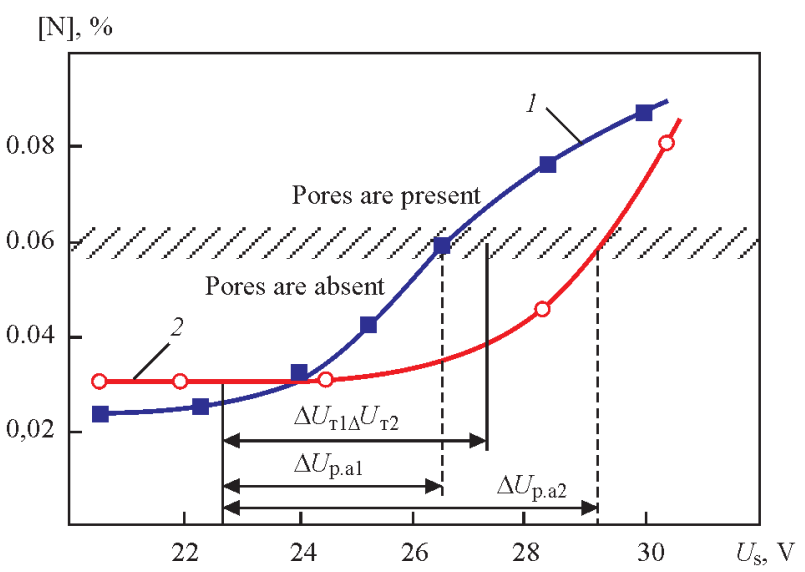

Figure 4. Influence of arc voltage on porosity in deposited metal [4] (see designations in the text) and $U_{s}>27 \mathrm{~V}$ the satisfactory formation and absence of pores are noted, and at increase in voltage by more than $28 \mathrm{~V}$ the pores are appeared in the deposited metal and the formation of beads is poor.

For the wire of $2.4 \mathrm{~mm}$ diameter the range of modes, at which the quality formation of deposited beads is achieved, corresponds to $U_{\mathrm{s}}=26-28 \mathrm{~V} ; I_{\mathrm{s}}=$ $=270-350 \mathrm{~A}$. At the voltage $U_{\mathrm{s}}<25 \mathrm{~V}$ and $U_{\mathrm{s}}>28 \mathrm{~V}$ the formation is satisfactory, the pores are absent.

It is recommended to conduct surfacing using wire of $2.8 \mathrm{~mm}$ diameter at the modes: $U_{\mathrm{s}}=27-29 \mathrm{~V} ; I_{\mathrm{s}}=$ $=270-350 \mathrm{~A}$. In the ranges $U_{\mathrm{s}}=25-26 \mathrm{~V}$ and $U_{\mathrm{s}}=$ $=30-32 \mathrm{~V}$ the formation of deposited beads is satisfactory, the pores are absent. At the voltage $U_{\mathrm{s}}<25 \mathrm{~V}$ and $U_{\mathrm{s}}>32 \mathrm{~V}$ the poor formation of deposited metal and the presence of pores are noted.

Open arc surfacing. For the present method of surfacing in most cases a good formation and the absence of pores are characteristic only for the definite range of surfacing modes. However, in surfacing with open arc, two ranges of modes by arc voltage should be distinguished: $\Delta U_{\mathrm{T}}$ is the range, at which a good formation, minimal spattering, admissible VBMD value and $\Delta U_{\text {p.a }}$ (the range in which the pores are absent) are provided [4].

For different types of deposited metal and compositions, the charges of flux-cored wires $\Delta U_{\mathrm{T}}$ and $\Delta U_{\text {p.a }}$ can differ significantly from each other as to their value. The range of modes, at which $\Delta U_{\mathrm{T}}$ and $\Delta U_{\text {p.a }}$ coincide, is the most preferred for surfacing. As an illustration, Figure 4 shows the influence of arc voltage on the porosity of deposited metal in surfacing using self-shielding wire with the same content of metallic part of the charge, but with a different composition of gas- and slag-forming materials: 1 - rutile, marble, fluorite; 2 - rutile, fluorite, calcium fluorozirconate, mica [4]. 


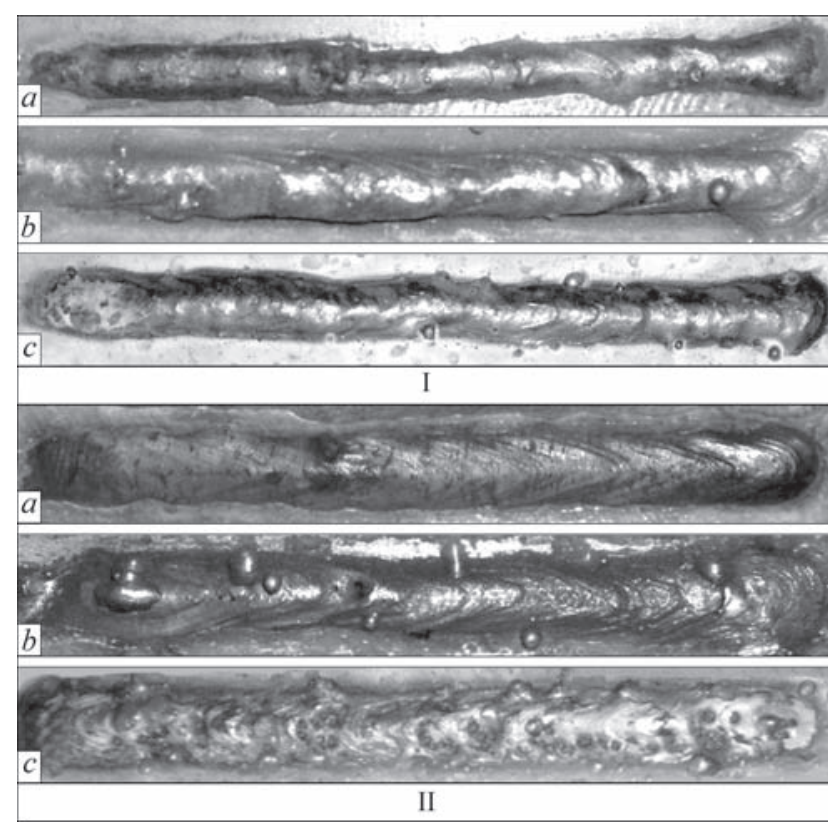

Figure 5. Appearance of beads, deposited using flux-cored wire of $1.8 \mathrm{~mm}$ diameter in submerged arc surfacing $(a)$, surfacing in shielding gases $(b)$, and using open $\operatorname{arc}(c)$ on the modes: $\mathrm{I}-U_{\mathrm{s}}=$ $=24 \mathrm{~V}, I_{\mathrm{s}}=225 \mathrm{~A} ; \mathrm{II}-U_{\mathrm{s}}=28 \mathrm{~V}, I_{\mathrm{s}}=250 \mathrm{~A}$

The carried out investigations showed that for self-shielding wire of $1.8 \mathrm{~mm}$ diameter a good formation of deposited beads and absence of pores are characteristic for the modes $U_{\mathrm{s}}=22-24 \mathrm{~V}$ at the current $I_{\mathrm{s}}=200-250 \mathrm{~A}$. At the voltage $U_{\mathrm{s}}<22 \mathrm{~V}$ the shape of beads is narrow, the formation is satisfactory. At $U_{\mathrm{s}}>24 \mathrm{~V}$ almost in the whole range of currents a significant number of pores and a poor formation of beads are observed. Also at the increase in current and voltage the spattering of metal is increased.

In surfacing with self-shielding flux-cored wires of 2.4 and $2.8 \mathrm{~mm}$ diameter the stable process with a good formation of deposited beads and absence of pores in them is characteristic for surfacing modes $U_{\mathrm{s}}=23-25 \mathrm{~V} ; I_{\mathrm{s}}=220-300 \mathrm{~A}$. For beads, deposited at the modes $U_{\mathrm{s}}<23 \mathrm{~V}$ and $U_{\mathrm{s}}=25-27 \mathrm{~V}$, the absence of pores is also characteristic, but their shape and surface quality can be regarded as not good enough. At the voltage of $U_{\mathrm{s}}>27 \mathrm{~V}$ the process becomes unstable, the beads are characterized by poor formation and the presence of numerous pores.

Thus, for the investigated self-shielding wires the ranges $\Delta U_{\mathrm{T}}$ and $\Delta U_{\text {p.a }}$ almost coincide. The appearance of the most characteristic beads, deposited using flux-cored wires of the diameter of 1.8 and $2.8 \mathrm{~mm}$ at the same modes using three different methods, is shown in Figures 5 and 6.

Based on the obtained data, the conclusion can be made that penetration of base metal is mainly affected by current of surfacing and the quality of deposited metal formation and the stability of surfacing process are affected by arc voltage. Moreover, each diame-

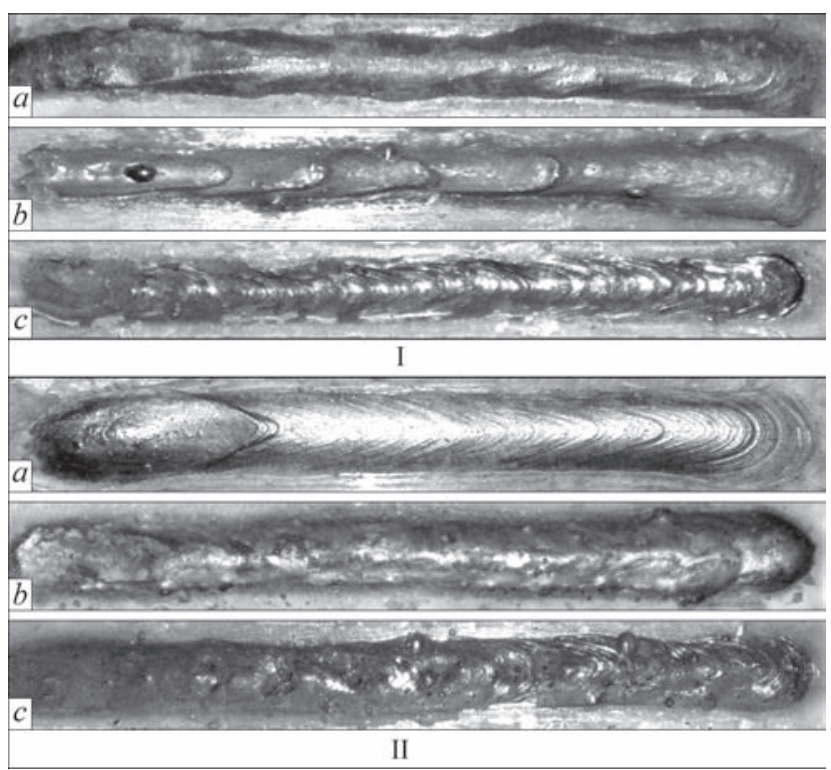

Figure 6. Appearance of beads, deposited using flux-cored wire of $2.8 \mathrm{~mm}$ diameter in submerged arc surfacing $(a)$, surfacing in shielding gases $(b)$, and using open $\operatorname{arc}(c)$ on the modes: $\mathrm{I}-U_{\mathrm{s}}=$ $=24 \mathrm{~V}, I_{\mathrm{s}}=250 \mathrm{~A}$; II $-U_{\mathrm{s}}=28 \mathrm{~V}, I_{\mathrm{s}}=275 \mathrm{~A}$

ter of the wire corresponds to a certain, rather narrow range of $\Delta U_{\mathrm{T}}$ at which a good formation of deposited beads with minimal penetration of base metal is provided. Moreover, as is seen in Figures 5 and 6, this range for different methods of surfacing using wire of the same composition and diameter does not coincide. For example, in surfacing using wire of $1.8 \mathrm{~mm}$ diameter at the mode $U_{s}=24 \mathrm{~V}$ the formation of bead, produced using submerged arc surfacing, is poor, and in surfacing in shielding gases it is satisfactory, whereas in surfacing using self-shielding wire it is good (Figure 5 , mode I). The reverse dependence is seen at the increase in voltage to $28 \mathrm{~V}$ (Figure 5, mode II). The similar regularity is typical in surfacing using wires of 2.4 and $2.8 \mathrm{~mm}$ diameter (Figure 6).

The results obtained in this work, can be used in selection of surfacing modes, which ultimately meet the operation conditions and the requirements to deposited metal for definite parts, and also can be used in the databases when developing computer programs for robotized additive technologies of arc surfacing.

\section{Conclusions}

1. It was established, that the greatest influence on quality of deposited beads formation is exerted by arc voltage. Moreover, the range of $\Delta U_{\mathrm{T}}$ voltage values, at which a good formation of deposited beads is provided, does not coincide in arc surfacing using different methods with the wire of one diameter.

2. The most significant influence of surfacing modes on geometric sizes of beads and penetration of base metal is revealed during submerged arc surfacing. This method provides the widest range of $\Delta U_{\mathrm{T}}$. 
However at the same time it is also characterized by a large penetration depth of base metal. It is possible to provide the minimum possible penetration in quality formation of deposited beads in the case of surfacing using open arc with wire of $1.8 \mathrm{~mm}$ diameter.

3. The optimum ranges of surfacing modes using flux-cored wires were determined, providing producing the high-quality deposited metal of the type 25Kh5FMS with minimum penetration of base metal.

1. Pokhodnya, I.K., Suptel, A.M., Shlepakov, V.N. (1972) Fluxcored wire welding. Kiev: Naukova Dumka.

2. Pokhodnya, I.K., Yavdoshchin, I.R., Paltsevich, A.P. et al. (1994) Metallurgy of arc welding, interaction of metal with gases. Kiev: Naukova Dumka.

3. Pokhodnya, I.K., Shlepakov, V.N., Maksimov, S.Yu. et al. (2010) Research and developments of the E.O. Paton Electric Welding Institute in the field of electric arc welding and surfacing using flux-cored wire (Review). The Paton Welding J., 12, 26-33.

4. Yuzvenko, Yu.A., Kirilyuk, G.A. (1973) Flux-cored wire surfacing. Moscow: Mashinostroenie.

5. Shlepakov, V.N., Gavrilyuk, Yu.A., Kotelchuk, A.S. (2010) State-of-the-art of development and application of flux-cored wires for welding of carbon and low-alloyed steels. The Paton Welding J., 3, 38-42.

6. Shlepakov, V.N. (2014) Physical-metallurgical and welding-technological properties of gas-shielded flux-cored wires in welding of structural steels. Ibid., 6/7, 56-59.

7. Rosert, R. (2014) Application of flux-cored wires for welding under industrial conditions. Ibid., 6/7, 60-64.

8. Kondratiev, I.A., Ryabtsev, I.A. (2014) Flux-cored wires for surfacing of steel rollers for hot rolling. Ibid., 6/7, 99-100.

9. Ryabtsev, I.A. (2004) Surfacing of machine and mechanism parts. Kiev: Ekotekhnologiya.

10. Razikov, M.I. (1962) Automatic $\mathrm{CO}_{2}$ surfacing. Moscow: Mashinostroenie.

11. Demchenko, V.F., Ryabtsev, I.A., Kozlitina, S.S. (1998) Computer system of design of arc surfacing technologies. Avtomatich. Svarka, 11, 61-66.

12. Demchenko, V.F., Ryabtsev, I.A., Kozlitina, S.S. (1999) Computer system of design of technologies for restoration and strengthening of metallurgical equipment parts. Tyazholoe Mashinostroenie, 2, 25-26.

13. Ryabtsev, I.A., Lankin, Yu.N., Soloviov, V.G. et al. (2015) Computer information-and-measuring system for investigation of arc surfacing processes. The Paton Welding J., 9, 32-35.

Received 15.09.2016 


\title{
PECULIARITIES OF BEAD SHAPE REGULATION IN SINGLE-LAYER MICROPLASMA SURFACING ON EDGES OF AIRCRAFT GAS TURBINE ENGINE BLADES*
}

\author{
P.D. ZHEMANYUK ${ }^{1}$, I.A. PETRIK ${ }^{1}$, S.L. CHIGILEJCHIK ${ }^{1}$, A.V. YAROVITSYN ${ }^{2}$ and G.D. KHRUSHCHOV ${ }^{2}$ \\ ${ }^{1}$ JSC «Motor Sich» \\ 15 Motorostroiteley Str., 69068, Zaporozhe, Ukraine. E-mail:motor@motorsich.com \\ ${ }^{2}$ E.O. Paton Electric Welding Institute, NASU \\ 11 Kazimir Malevich Str., 03680, Kiev, Ukraine. E-mail: office@paton.kiev.ua
}

\begin{abstract}
It is a necessary to specify the dependencies of deposited metal shaping due to the need of 5-15 mm height increase of the dimensions of surfacing-repaired damaged areas of blade edges of aircraft GTE of high-temperature nickel alloys in microplasma bead surfacing on narrow substrate of less than $3 \mathrm{~mm}$. A range of change of the process energy indices in «effective heat power of arc-heat input-cross-section area of deposited bead» system was investigated for conditions of corresponding single-layer surfacing, and effectiveness of process regulation of deposited layer cross-section was evaluated. It is determined that heat input change in 100-1600 J/mm range is the most effective regulation of cross-section area of the deposited bead under conditions of base metal limited penetration depth. It is assumed that the determined process relationship between heat input energy, height and cross-section area of the deposited bead will promote for formation of the additional criteria preventing crack formation in the «base-deposited metal» welded joint in repair of the parts of aircraft engines of high-temperature nickel alloys using multi-layer microplasma powder surfacing. 18 Ref., 4 Tables, 8 Figures.
\end{abstract}

Keywords : microplasma powder surfacing, high-temperature nickel alloy and heat-resistant cobalt alloy, narrow substrate, effective heat power of arc, heat input, thermal efficiency, cross-section area of deposited bead

One of the fields of application of arc surfacing on narrow substrate [1] of up to $3 \mathrm{~mm}$ width is the series repair of damaged or worn edges of aircraft gas turbine engine (GTE) blades [2-8]. The working blades of serially repaired aircraft engines D18T, D436, AI222, AI-450 are manufactured of nickel high-temperature alloys with polycrystalline structure (ZhS6U-VI, ZhS6K-VI) or of directionally-solidified alloys (ZhS32-VI and ZhS26-VI) [9]. These high-alloy materials, containing 55 and more vol.\% of $\gamma^{\prime}$-phase, are designed for operation at $1000-1100{ }^{\circ} \mathrm{C}$ temperatures and differ by high tendency to crack formation in fusion welding and/or further heat treatment [9, 10]. Argon-arc welding has been used for repair of such parts for more than 40 years, however, repair of the blade edges was limited by up to $2 \mathrm{~mm}$ depth and filler metal was inferior to base metal on heat resistance [2, 3].

Microplasma powder surfacing [4-8] has been successfully used for more than 10 years at JSC «Motor Sich» and SE «Ivchenko-Progress» for repair of aircraft working blades of given alloys with more than $3-5$ thou. h. running. Several grades of filler powders, in particular, high-temperature nickel alloy ZhS32 [4-8] and high-temperature cobalt and wear-resistant alloy V3K $[5,8]$, are widely used in this process.

Currently, serial repair production requires increase of dimensions of surfacing-repaired areas of blades (edges of platforms, labyrinth ends, Z-shape profiles and blade airfoil) to $5-15 \mathrm{~mm}$ height due to corresponding increase of size of wear zones, burnthrough and thermal fatigue cracks, developing in process of operation of these parts. Their restoration can be characterized as process of multi-layer surfacing, in which «base-deposited metal» welded joint can under certain conditions be susceptible to formation of micro- and macrocracks $[6,10,11]$. In turn, the multi-layer surfacing at some approximation can be presented as collection of single-layer beads. Therefore, it is relevant to expand the knowledges on the boundaries of energy indices range in single-layer surfacing for reasonable selection of such level and methods of balancing of heat input in the part, which provide for process strength of given welded joint, i.e. susceptibility of mentioned above materials to crack formation in fusion welding is not developed.

"Based on materials of paper, presented at the International Conference «Current welding technologies», July 11-13, 2016, Kiev, E.O. Paton Electric Welding Institute of the NAS of Ukraine. 


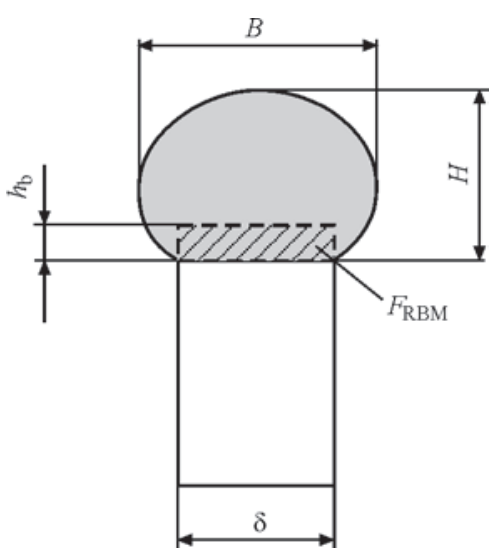

Figure 1. Scheme of measurement of deposited bead size: $\delta$ width of narrow substrate, $B$ - bead width; $H$ - bead height; $h_{\mathrm{b}}, F_{\mathrm{rbm}}$ - depth of penetration and cross-section area of remelted base metal

One of the constituents of this problem is detection of the dependencies and further optimizing the process regulation of shape of bead being deposited on narrow substrate. In addition to reasonable selection of volume of deposited metal in manual and automatic (robotic) surfacing, this allows also optimizing the dimensions of bead side reinforcement $p=0.5(B-\delta)$ in its cross-section (Figure 1).

In turn, side reinforcements of the deposited bead are the allowances being removed by mechanical treatment in formation of set geometry of the element repaired by surfacing. It is a danger of formation of burns and polishing cracks, therefore, abrasive treatment of the parts from high-temperature nickel alloys is carried out using special modes, equipment and abrasive disks $[12,13]$. At that, reduced rates of rotation of abrasive tool (to $25 \mathrm{~m} / \mathrm{s}$ ) and feed (350 $750 \mathrm{~mm} / \mathrm{min}$ ) are used for limiting removal intensity of the treated material [13]. Thus, mechanical treatment of the deposited metal, in spite of technical complexity of shaping of corresponding profile surfaces of the blade, is sufficiently laborious process, additionally requiring highly-qualified specialists, expensive equipment and materials. Therefore, reduction of width of the deposited bead promotes for significant extent decrease of laboriousness and increase of profitability of blade repair.

Aim of the present work lied in evaluation of the range of effective heat power of microplasma arc (previously was determined using flow calorimetry method [1] for corresponding value of welding current) and heat input for conditions of single-layer surfacing on narrow substrate of $\delta=0.3-3.0 \mathrm{~mm}$ width on modes close to optimum ones, and determination of basic dependencies of process regulation of shape of deposited bead cross-section.

Specimens from steel $12 \mathrm{Kh} 18 \mathrm{~N} 10 \mathrm{~T}$ of 90 $100 \times 30-40 \mathrm{~mm}$ size and $0.3-3.0 \mathrm{~mm}$ thickness were used as base metal. Surfacing on modes, described earlier in work [8], was carried out under conditions of free bead formation on the edge of plate being clamped in the jaws. The distance from deposited surface to copper jaws made not less than $20 \mathrm{~mm}$, and that from plasmatron outer exit to specimen was $5 \mathrm{~mm}$. The powders of ZhS32 and V3K alloys of 63-160 $\mu \mathrm{m}$ and 53-150 $\mathrm{m} \mu$ fraction, respectively, with different melting temperature (approximately by $70-90{ }^{\circ} \mathrm{C}$ ) and fluidity of weld pool molten metal were used as fillers. Argon of higher grade on GOST 10157-79 was applied as plasmaforming and transporting gas. The experiments were carried out at two types of equipment, different by type of disperse filler feed, level of constriction of microplasma arc and relative pulse duration of welding current $S$ :

- STARWELD 190H unit, plasmatron HPH80 (diameters of nozzle channels: plasma $d_{\mathrm{pl}}=2 \mathrm{~mm}$, focusing $d_{\mathrm{f}}=3 \mathrm{~mm}$ ), Kennametal Stellite $\mathrm{GmbH}$ company - continuous feed of powder (consumption of transporting gas $Q_{\mathrm{tr}}=31 / \mathrm{min}, S \approx 1.5$;

- UPNS304M2/M3 unit, plasmatron PPS04 $\left(d_{\mathrm{pl}}=2.5 \mathrm{~mm}, d_{\mathrm{f}}=4.5 \mathrm{~mm}\right)$ - dosed feed of powder $\left(Q_{\mathrm{tr}}=21 / \mathrm{min}\right), S \approx 4.5$.

Processing of experimental data was carried out using the regression dependencies of value of efficient heat power of microplasma arc $q_{\mathrm{u}}$ from welding current $I$, received earlier using the flow calorimetry method [1]. Heat input $q_{\mathrm{u}} / v$ was determined by procedure of work [11]:

$$
q_{\mathrm{u}} / v=Q_{\Sigma} / L,
$$

where $Q_{\Sigma}$ is the heat input in the anode taking into account effective efficiency of part heating $[1,11] ; L$ is the given length of elliptic bead cylinder. Cross-section areas of the deposited bead $F_{\mathrm{b}}$ and deposited metal in it $F_{\mathrm{db}}=F_{\mathrm{b}}-F_{\mathrm{rbm}}$ were determined using calculation by procedure of work [14] based on measurement of width, height of bead and base metal penetration depth with up to $0.05 \mathrm{~mm}$ accuracy, according to Figure 1. Thermal efficiency for $\mathrm{ZhS} 32$ deposited metal was determined by calculation [11] proceeding from its cross-section area $F_{\mathrm{db}}$ :

$$
\eta_{\mathrm{th}}=\frac{M_{\mathrm{s}} H_{\mathrm{m}}}{q_{\mathrm{u}}},
$$

where $H_{\mathrm{m}}=861.2$ and $1312.6 \mathrm{~J}$ is the specific enthalpy of $1 \mathrm{~g}$ of deposited metal ZhS32 and base metal 12Kh18N10T, respectively.

Firstly, the dependencies of change of the energy indices of process of microplasma powder surfacing and indices of bead shape for narrow substrate $\delta=$ $=0.3-2.0 \mathrm{~mm}$ (Figure 2 and Table 1) were evaluated. It is determined that the effective heat power of the microplasma arc varies in 30-330 $\mathrm{W}$ range, heat in- 

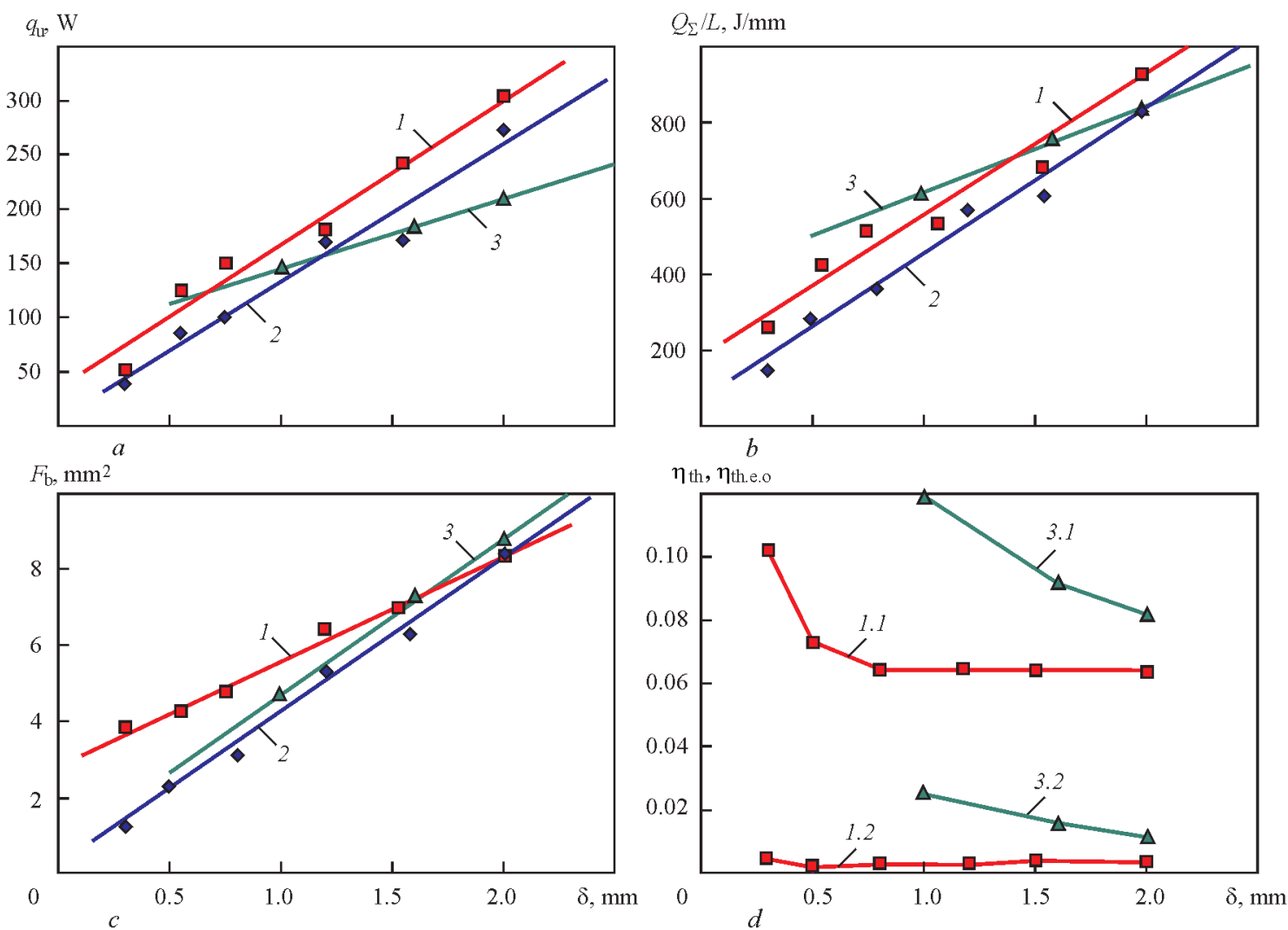

Figure 2. Effect of narrow substrate width $\delta$ on effective heat power of microplasma arc $q_{u}(a)$, heat input $Q_{\Sigma} / L(b)$, cross-section area of deposited bead $F_{\mathrm{b}}(c)$ and thermal efficiency $\eta_{\mathrm{th}}(d): 1$ — surfacing of ZhS32 alloy, Starweld $190 \mathrm{H}$ unit, continuous wire feed, shielding gas Ar; 1.1 - complete thermal efficiency $\eta_{\text {th }}$ of process; 1.2 - component of thermal efficiency used for base metal melting; 2 surfacing of V3K alloy, Starweld 190H unit, continuous powder feed, shielding gas Ar; 3 — surfacing of ZhS32 alloy, UPNS-304M2/ M3 unit, dosed wire feed, shielding gas $95 \% \mathrm{Ar}+5 \% \mathrm{H}_{2} ; 3.1$ - complete thermal efficiency $\eta_{\mathrm{th}}$ of process; 3.2 — component of heat efficiency used for base metal melting

put of the process makes $100-1000 \mathrm{~J} / \mathrm{mm}$, surfacing efficiency is $0.3-1.3 \mathrm{~g} / \mathrm{min}$; bead cross-section area makes $1-9 \mathrm{~mm}^{2} . q_{\mathrm{u}}(\delta), Q_{\Sigma} / L(\delta)$ and $F_{\mathrm{b}}(\delta)$ dependencies are close to linear. Obtained data indicated the specific effect on the process energy indices of filler composition (ZhS32, V3K) and method of disperse wire feed (continuous, dosed), that allows expanding a notion on known methods of process regulation of heat input in the part (welding current, level of plasma arc constriction, reasonable selection of shielding gas composition [1, 4]). Indicated process factors in $q_{\mathrm{u}}<150 \mathrm{~W}$ and $\delta<1.2 \mathrm{~mm}$ range also influences the reduction of deposited bead cross-section. A com- plete thermal efficiency of the process of surfacing on narrow substrate $\delta=0.3-0.2 \mathrm{~mm}$, as a rule, does not exceed $\eta_{\text {th.e }}=6-10 \%$, besides, part of the effective power $q_{\mathrm{u}}$, being spent for melting of base metal, makes $\eta_{\text {th.e. }}=0.16-2.5 \%$. Fraction of the base metal in the deposited one is limited in 5-15\% range, that corresponds with the optimum modes of plasma-powder surfacing [1].

A set range of values of bead shape coefficient $B / H$ in 0.77-1.22 limits (see Table 1 ) allowed specifying technologically possible schemes of shaping of deposited bead [14] varying a series of process factors of microplasma powder surfacing: width of

Table 1. Effect of width of narrow substrate $\delta$ on portion of base metal $\gamma_{\mathrm{b}}$, surfacing efficiency $M_{\mathrm{s}}$ and coefficient of bead shape $B / H$ in microplasma powder surfacing of alloys ZhS32 and V3K

\begin{tabular}{|c|c|c|c|c|c|c|c|c|c|}
\hline \multirow{2}{*}{$\delta, \mathrm{mm}$} & \multicolumn{3}{|c|}{$\gamma_{\mathrm{b}}, \%$} & \multicolumn{3}{c|}{$B / H$} & \multicolumn{3}{c|}{$M_{\mathrm{s}}, \mathrm{g} / \mathrm{min}$} \\
\cline { 2 - 12 } & ZhS32 (c) & ZhS32 (d) & V3K (c) & ZhS32 (c) & ZhS32 (d) & V3K (c) & ZhS32 (c) & ZhS32 (d) & V3K (c) \\
\hline 0.3 & 9.97 & - & 9.26 & 0.787 & - & 1.054 & 0.351 & - & 0.157 \\
\hline 0.55 & 5.11 & - & 5.04 & 0.772 & - & 1.041 & 0.645 & - & 0.333 \\
\hline 0.75 & 8.98 & - & 8.5 & 0.857 & - & 0.930 & 0.639 & - & 0.366 \\
\hline 1.0 & - & 14.16 & & - & 1.201 & - & - & 1.043 & - \\
\hline 1.2 & 11.46 & - & 13.55 & 0.933 & - & 0.936 & 0.826 & - & 0.534 \\
\hline 1.55 & 12.11 & 13.37 & 15.39 & 1.216 & 1.113 & 1.000 & 1.013 & 0.872 & 0.711 \\
\hline 2.0 & 11.19 & 10.64 & 10.31 & 1.032 & 1.206 & 0.969 & 1.276 & 0.958 & 1.261 \\
\hline
\end{tabular}



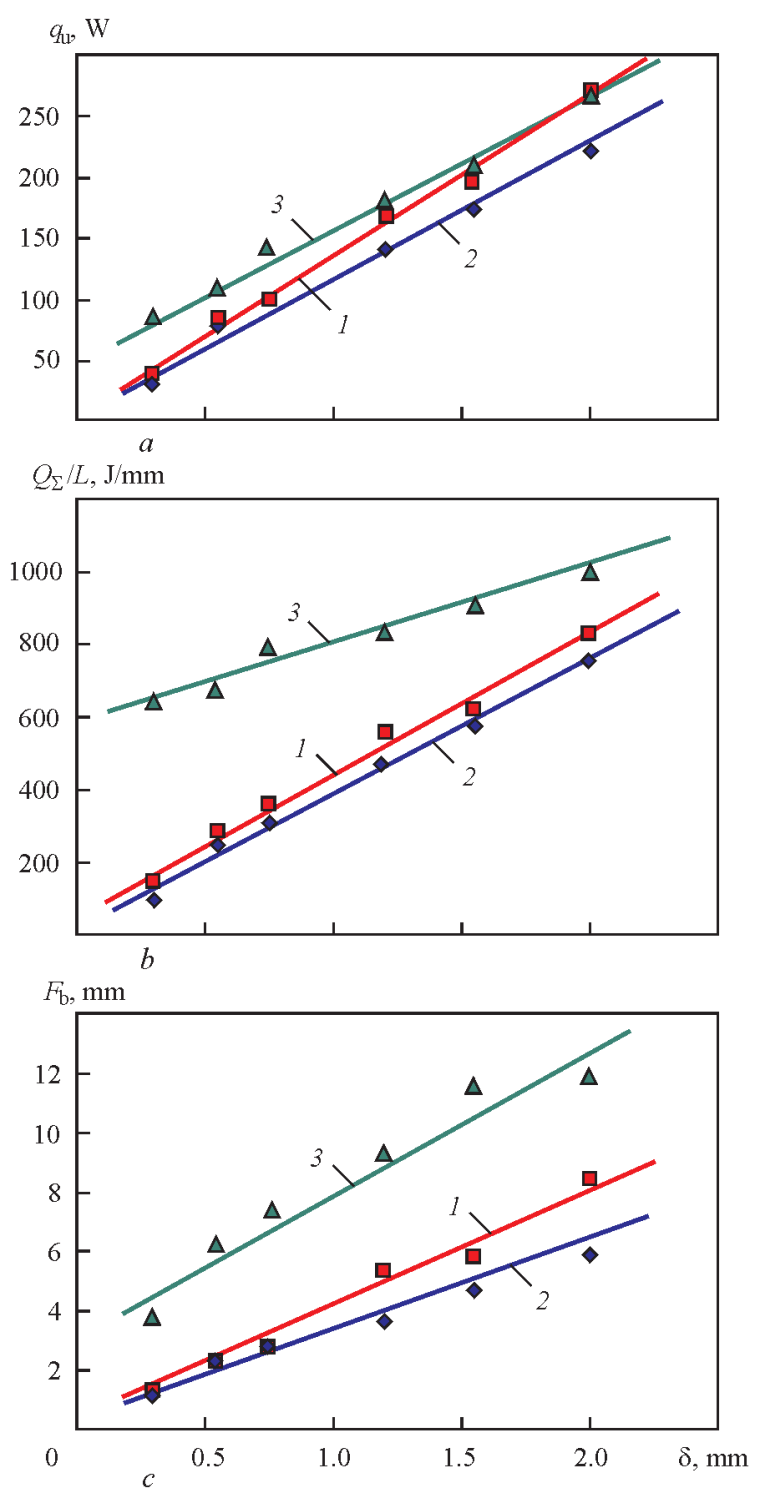

Figure 3. Effect of width of narrow substrate $\delta$ on effective heat power of microplasma arc $q_{\Perp}(a)$, heat input $Q_{\Sigma} / L(b)$, cross-section area of deposited bead $F_{\mathrm{b}}(c)$. Surfacing of V3K alloy, shielding gas Ar, Starweld $190 \mathrm{H}$ unit, continuous powder feed: 1 - direct; 2, 3 - pulse welding current

narrow substrate; effective heat power of arc and efficiency.

$\delta=0.3-2.0 \mathrm{~mm}$ depending on toughness of weld pool molten metal (i.e. deposited metal, since $\left.\gamma_{0} \rightarrow \min \right)$ is characterized by the following changes of shape of deposited beads cross-section:
- at increased toughness (alloy ZhS32) - under the law of increasing ellipse with $H>B$ at $\delta<0.8 \mathrm{~mm}$ and $B>H$ at $\delta>1.5 \mathrm{~mm}$;

- at increased fluidity (alloy $\mathrm{V} 3 \mathrm{~K}$ ) - under the law of increasing circle with $H \approx B$.

Considered above methods of process effect on shape and dimensions of bead being deposited on narrow substrate shall be referred to passive ones, since they can be selected only before surfacing. It is known fact $[1,4]$ that welding current is the process parameter of constricted arc, first of all determining its effective heat power. Respectively, it can have sufficiently easy technological regulation in process of repair surfacing, in particular, at change of width of narrow substrate at local repair of complex geometry blades [4-8]. Therefore, this work also studied the possibility of regulation of bead shape due to application of pulse welding current with different relative pulse duration $S$.

In parallel the investigations were carried out for disperse filler materials V3K (STARWELD 190H unit, $S \approx 1.5$ ) and ZhS32 (UPNS304M2/M3 unit, $S \approx 4.5$ ). Additionally, 2 types of pulse modes were considered, except surfacing with direct welding current (mode 1):

mode 2: $I_{\text {pul }}<I_{\mathrm{b}}, I_{\mathrm{p}}<I_{\mathrm{b}}$;

mode 3: $I_{\text {pul }}^{\text {pul }}>I_{\mathrm{b}}, I_{\mathrm{p}}<I_{\mathrm{b}}$.

where $I_{\mathrm{b}}$ is the basic value of direct welding current; $I_{\text {pul }}, I_{\mathrm{p}}$ are the values of welding current at pulse and pause, respectively.

The dependencies of change of energy parameters of the process of microplasma powder surfacing and bead shape for narrow substrate $\delta=0.3-2.0 \mathrm{~mm}$ are presented in Figure 3, Table 2 and Figure 4, Table 3 for conditions of surfacing of V3K and ZhS32 alloys, respectively. Different position of dependencies $q_{\mathrm{u}}(\delta)$, $Q_{\Sigma} / L(\delta)$ and $F_{\mathrm{b}}(\delta)$ relatively to similar ones in direct current surfacing (see Figures 3, 4) is noted at mode 3 depending on value of relative pulse duration of welding current in surfacing on narrow substrate $\delta \leq 2 \mathrm{~mm}$.

Obtained results indicate the possibility of efficient regulation of the dimensions of cross-section of bead being deposited on narrow substrate, due to reasonable selection of parameters of pulse welding current. Also, pulse current surfacing of V3K alloy promotes for somewhat reduction (per 2-5\%) of base metal

Table 2. Effect of width of narrow substrate $\delta$ on portion of base metal $\gamma_{b}$, surfacing efficiency $M_{\mathrm{s}}$ and coefficient of bead shape $B / H$ in microplasma powder surfacing of alloy V3K using continuous (mode 1) and pulse current (modes 2 and 3 )

\begin{tabular}{|c|c|c|c|c|c|c|c|c|c|}
\hline \multirow{2}{*}{$\delta, \mathrm{mm}$} & \multicolumn{3}{|c|}{$\gamma_{\mathrm{b}}, \%$} & \multicolumn{3}{c|}{$M_{\mathrm{s}}, \mathrm{g} / \mathrm{min}$} & \multicolumn{3}{c|}{$B / H$} \\
\cline { 2 - 11 } & Mode 1 & Mode 2 & Mode 3 & Mode 1 & Mode 2 & Mode 3 & Mode 1 & Mode 2 & Mode 3 \\
\hline 0.3 & 9.26 & 7.47 & 4.73 & 0.157 & 0.116 & 0.251 & 1.05 & 0.71 & 0.72 \\
\hline 0.55 & 5.04 & 7.31 & 1.67 & 0.333 & 0.287 & 0.332 & 1.04 & 0.90 & 0.85 \\
\hline 0.75 & 8.50 & 13.37 & 4.64 & 0.366 & 0.329 & 0.456 & 0.93 & 1.06 & 0.74 \\
\hline 1.2 & 13.55 & 14.12 & 8.20 & 0.534 & 0.485 & 0.785 & 0.94 & 0.92 & 0.83 \\
\hline 1.55 & 15.39 & 8.47 & 6.48 & 0.711 & 0.616 & 1.042 & 1.00 & 0.92 & 0.79 \\
\hline 2.0 & 10.31 & 11.32 & 6.74 & 1.260 & 0.678 & 1.496 & 0.97 & 1.16 & 0.80 \\
\hline
\end{tabular}



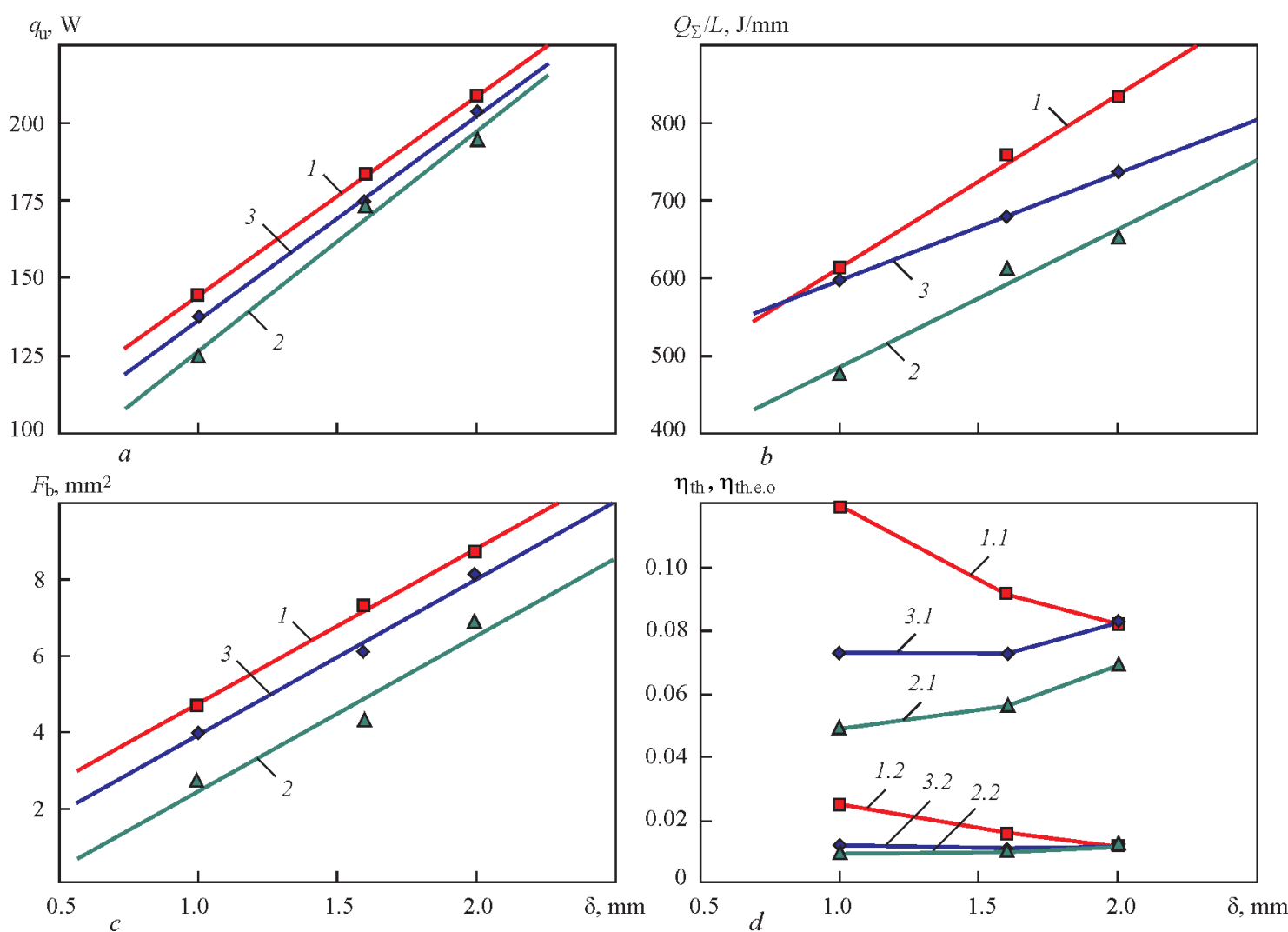

Figure 4. Effect of width of narrow substrate $\delta$ on effective heat power of microplasma arc $q_{\mathrm{u}}(a)$, heat input $Q_{\Sigma} / L$, cross-section area of deposited bead $F_{\mathrm{b}}(c)$ and thermal efficiency $\eta_{\mathrm{th}}(d)$ in variation of narrow substrate width $\delta$. Surfacing of ZhS32 alloy, shielding gas $95 \% \mathrm{Ar}+5 \% \mathrm{H}_{2}$, UPNS-304M2/M3 unit, dosed powder feed: 1 — direct welding current; 2 , 3 — pulse welding current (modes 2 and 3); 1.1, 2.1, 3.1 - complete thermal efficiency $\eta_{\text {th }}$ of process; 1.2, 2.2, 3.2 - component of thermal efficiency $\eta_{\text {th.e.o }}$ used for base metal

fraction in comparison with direct current surfacing (see Table 2). It becomes possible to shape deposited bead under increasing ellipse law with $H>B$ for all range of width of narrow substrate $\delta=0.3-2.0 \mathrm{~mm}$. Possibilities of decrease of base metal fraction and regulation of bead shape coefficient due to application of pulse modes is somewhat limited (see Table 3) in pulse current surfacing of ZhS32 alloy.

The investigations of effect of rate of microplasma powder surfacing of ZhS32 and V3K alloys on energy indices of the process and bead cross-section area were carried out in a mode of automatic direct current surfacing using robotic unit 190HP. It is determined (Figure 5) that increase of rate of surfacing on $\delta=0.3-3.0 \mathrm{~mm}$ width narrow substrate from 1.2 to $3.6 \mathrm{~m} / \mathrm{h}$ promotes for on average 3 times reduction of cross-section area of the deposited bead $F_{b}$, and 4 times decrease of heat inputs in the part $Q_{\Sigma} / L$. The productivity of surfacing on $\delta=3.0 \mathrm{~mm}$ narrow sub- strate in the considered rate range on data of Figure 5 makes approximately $3 \mathrm{~g} / \mathrm{min}$ and reaches the powder feed productivity.

It is additionally shown (see Table 4) that application of disperse filler in microplasma surfacing is more preferable in comparison with filler from microwire, since allows reducing the effective heat power of arc more than 2 times, decreasing 1.8 time heat input, and rising 1.8 time surfacing efficiency. Also, following from work [15], reduction of heat input to laser-powder surfacing level in microplasma powder surfacing is possible with rise of its rate approximately to $22.6 \mathrm{~m} / \mathrm{h}$.

Evaluation of common and separate effect of the process factors of microplasma arc effective heat power and heat input on bead cross-section shape was carried out by means of analysis of goal functions [18] $\varepsilon_{q_{u}}, \varepsilon_{Q_{\Sigma} / L}$, and $\varepsilon_{F}$ in form of relationship of effective heat power of microplasma arc, heat input and

Table 3. Effect of width of narrow substrate $\delta$ on portion of base metal $\gamma_{b}$, surfacing efficiency $M_{\mathrm{s}}$ and coefficient of bead shape $B / H$ in microplasma powder surfacing of alloy ZhS32 using direct (mode 1) and pulse current (modes 2 and 3 )

\begin{tabular}{|c|c|c|c|c|c|c|c|c|c|}
\hline \multirow{2}{*}{$\delta, \mathrm{mm}$} & \multicolumn{3}{|c|}{$\gamma_{\mathrm{b}}, \%$} & \multicolumn{3}{c|}{$M_{\mathrm{s}}, \mathrm{g} / \mathrm{min}$} & \multicolumn{3}{c|}{$B / H$} \\
\cline { 2 - 10 } & Mode 1 & Mode 2 & Mode 3 & Mode 1 & Mode 2 & Mode 3 & Mode 1 & Mode 2 & Mode 3 \\
\hline 1.0 & 17.17 & 15.09 & 11.57 & 0.950 & 0.344 & 0.585 & 1.04 & 0.89 & 0.79 \\
\hline 1.55 & 12.61 & 15.9 & 13.64 & 0.970 & 0.557 & 0.750 & 1.11 & 1.07 & 1.22 \\
\hline 2.0 & 10.63 & 13.7 & 11.08 & 1.020 & 0.773 & 1.004 & 1.21 & 1.11 & 1.07 \\
\hline
\end{tabular}



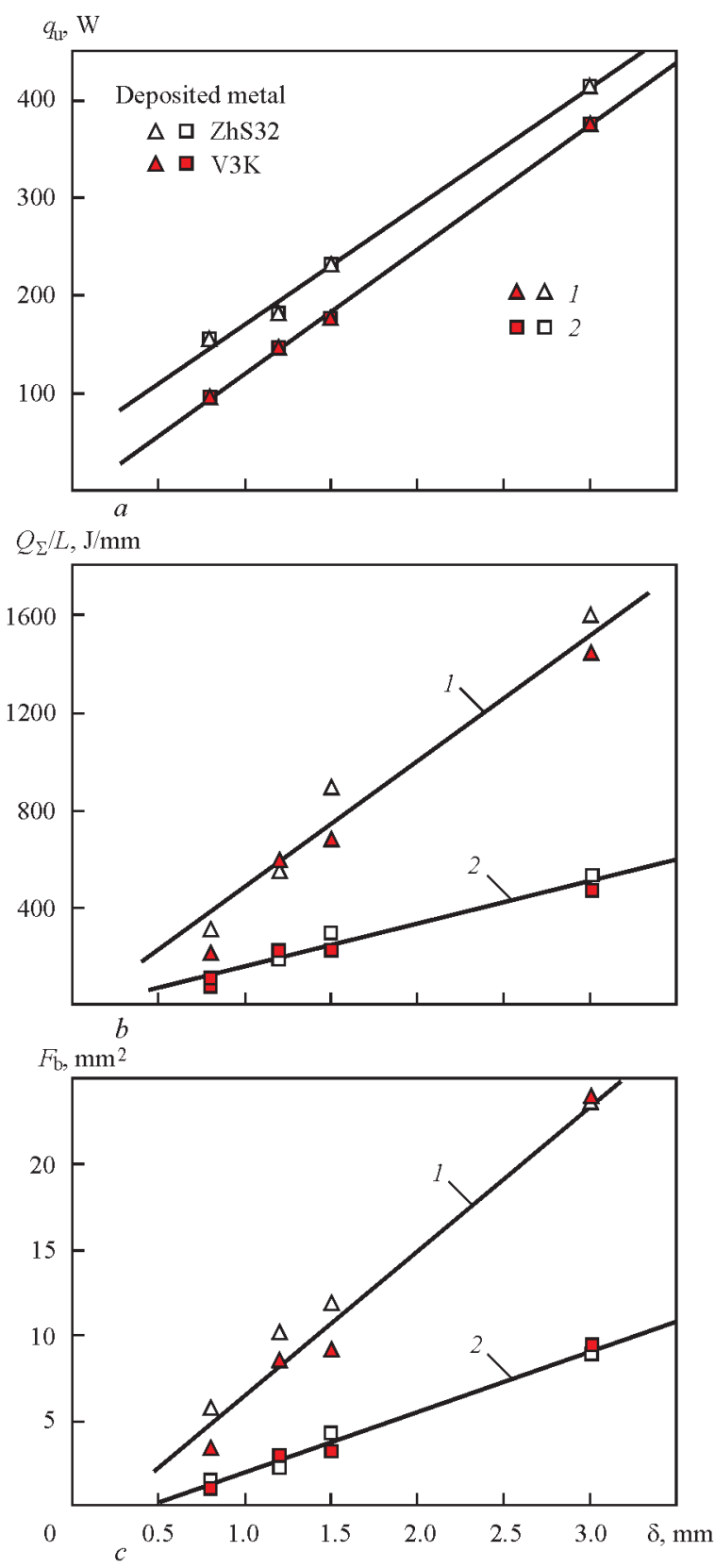

Figure 5. Effect of width of narrow substrate $\delta$ and average surfacing rate on effective heat power of microplasma $\operatorname{arc} q_{u}(a)$, heat input $Q_{\Sigma} / L(b)$, cross-section area of deposited bead $F_{\mathrm{b}}(c): 1$ $1.2 ; 2-3.6 \mathrm{~m} / \mathrm{h}$. Robotic unit Starweld $190 \mathrm{H}$, continuous powder feed, shielding gas $\mathrm{Ar}$

cross-section areas of the deposited bead at current and basic modes of surfacing, respectively. The basic mode was, as a rule, a direct current surfacing mode. The values of goal function $\varepsilon_{F}$ were evaluated at varying process factors in form of different modes of pulse welding current $\left(I_{\text {pul }}<I_{\mathrm{b}}, I_{\mathrm{p}}<I_{\mathrm{b}}\right.$ and $\left.I_{\text {pul }}>I_{\mathrm{b}}, I_{\mathrm{p}}<I_{\mathrm{b}}\right)$ and surfacing rate, which were considered through the indices of effective heat power of microplasma arc and heat input. The regression dependencies of change of goal functions $\varepsilon_{F}=f\left(\varepsilon_{q_{u}}\right)$ and $\varepsilon_{F}=f\left(\varepsilon_{q_{u}}, \varepsilon_{Q_{\Sigma} / L}\right)$, relatively to their basic level $\left(\varepsilon_{q_{u}}=1, \varepsilon_{Q_{\Sigma} / L}=1, \varepsilon_{F}=1\right)$ are presented in form of $2 \mathrm{D}$ and $3 \mathrm{D}$ (contour) plots in Figures 6 and 7.
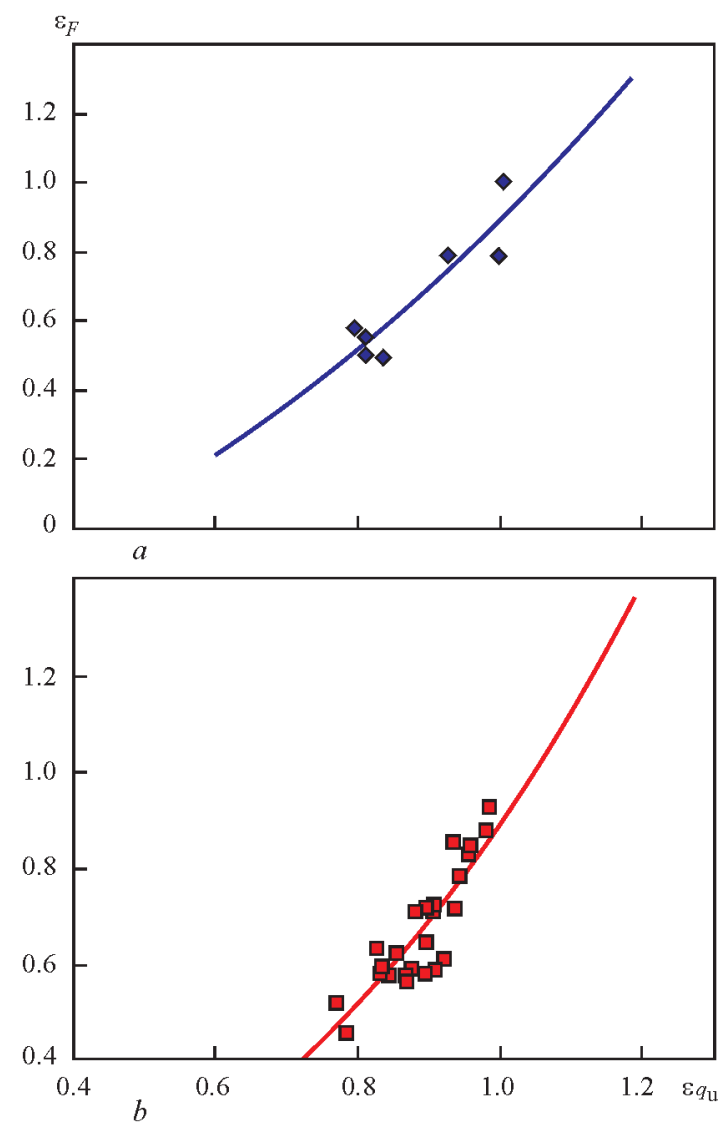

Figure 6. Dependence of relative cross-section area of deposited bead $\varepsilon_{F}$ on relative effective heat power of microplasma arc $\varepsilon_{q_{u}}$ in microplasma powder surfacing on narrow substrate: $a-$ alloy V3K, unit Starweld $190 \mathrm{H}$, continuous powder feed, shielding gas $\mathrm{Ar}, \delta=0.3-3.0 \mathrm{~mm} ; b-$ unit UPNS-304M2/M3, dosed powder feed, shielding gas $95 \% \mathrm{Ar}+5 \% \mathrm{H}_{2}, \delta=1.0-2.0 \mathrm{~mm}$

It is determined that $20 \%$ reduction of effective heat power of microplasma arc promotes for $30-50 \%$ decrease of cross-section area of the deposited bead for V3K and ZhS32 alloys, respectively. At that, the relationship of width B to height of deposited bead $H$ for pulse welding current lies, as a rule, in 0.7-0.92 ranges.

Change of surfacing heat input (mainly due to its rate), in particular in combination with some increase of effective heat power of microplasma arc, has more significant effect on shape of the bead, deposited on narrow substrate (see Figures 6 and 7). 2-3 times increase of heat input in surfacing with continuous feed of powder allows receiving the same rise of bead cross-section area, and up to 3.6 times growth in combination with simultaneous increase of effective heat power of microplasma arc by $70 \%$ (see Figure 7, $a$ ). In surfacing with dosed powder feed, 2.5 times increase of heat input allows rising cross-section area of the deposited bead up to 3.5 times and to 5.5-6 times (see Figure 7, $b$ ) in combination with simultaneous increase of effective heat power of microplasma arc by 10-30 \%.

Simultaneous reduction of effective power of the microplasma arc and heat input per $20-30 \%$ relative- 
Table 4. Comparison of characteristics of bead cross-section $\left(B, H, \gamma_{\mathrm{b}}\right)$, effective power of part heating $q_{\mathrm{u}}$, heat input $Q_{\Sigma} / L$ and surfacing efficiency $M_{\mathrm{s}}$ in microplasma and laser surfacing

\begin{tabular}{|c|c|c|c|c|c|c|c|c|}
\hline $\begin{array}{l}\text { Surfacing } \\
\text { process }\end{array}$ & Deposited metal & $B, \mathrm{~mm}$ & $H, \mathrm{~mm}$ & $q_{\mathrm{u}}, \mathrm{W}$ & $\gamma_{b}, \%$ & $\begin{array}{l}Q_{\Sigma} / L \\
\mathrm{~J} / \mathrm{mm}\end{array}$ & $\begin{array}{l}M_{\mathrm{s}}, \\
\mathrm{g} / \mathrm{min}\end{array}$ & Source \\
\hline $\begin{array}{l}\text { Microplasma, } \\
\approx 22.6 \mathrm{~m} / \mathrm{h}\end{array}$ & Powder H13 tool steel & 2.0 & 0.2 & $\approx 280^{* 1}$ & - & $\approx 45^{*_{1}}$ & 1.0 & Wang H. et al. (2003). [15] $]^{* 3}$ \\
\hline \multirow{2}{*}{$\begin{array}{l}\text { Microplasma, } \\
\approx 3.6 \mathrm{~m} / \mathrm{h}\end{array}$} & Wire AISI P20 Ø 0.3 mm & $1.9 \pm 0.06$ & $0.9 \pm 0.04$ & 400 & $5.12 \pm 0.12$ & 380.95 & 0.47 & Jhavar S. et al. (2014). [16 $]^{* 3}$ \\
\hline & Powder V3K, 53...-160 $\mu \mathrm{m}$ & 2.0 & 1.8 & $\approx 15$ & 211.7 & 0.87 & 1.87 & This work ${ }^{* 2}$ \\
\hline $\begin{array}{l}\text { Yb:YAG Laser } \\
\approx 24 \mathrm{~m} / \mathrm{h}\end{array}$ & Powder Ti-6Al-4V & $1.9-2.1$ & $0.15-0.22$ & 400 & - & 48 & 1.0 & Gharbi et al. (2012). [17] $]^{* 3}$ \\
\hline
\end{tabular}
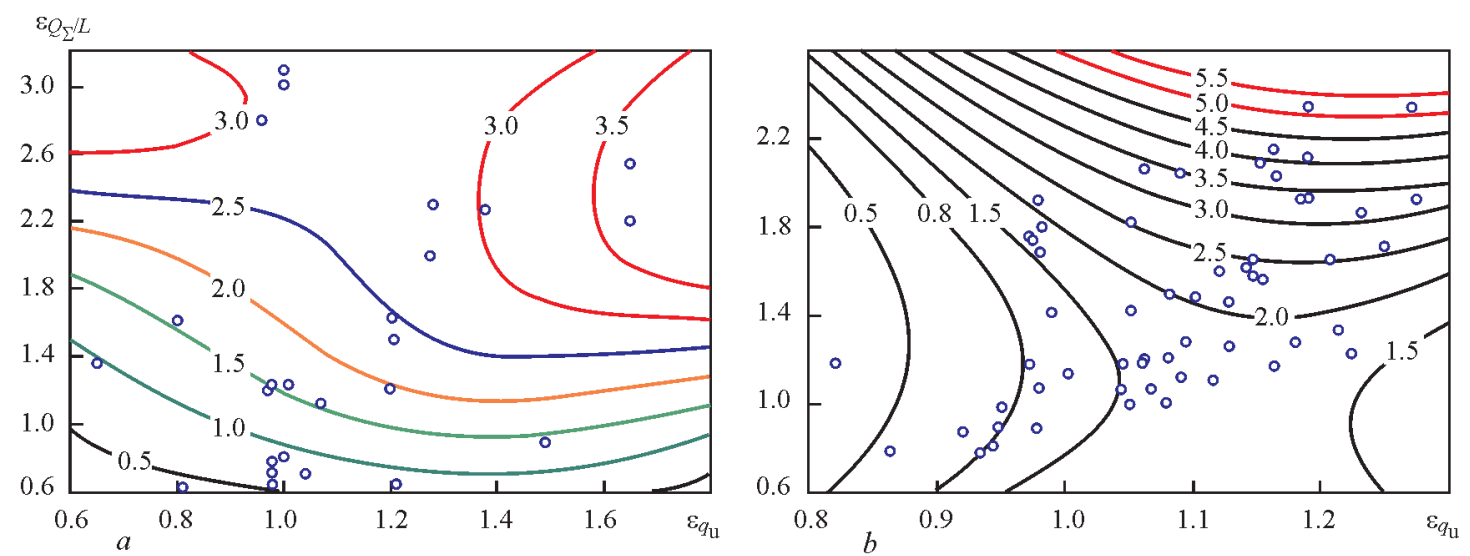

Figure 7. Contour diagram of change of relative area of deposited bead cross-section $\varepsilon_{F}$ on relative effective heat power of microplasma arc $\varepsilon_{q_{u}}$ and relative heat input of microplasma surfacing $\varepsilon_{Q_{\Sigma} / L}: a-$ V3K alloy, unit Starweld 190H, continuous powder feed, shielding gas $\mathrm{Ar}, \delta-0.3-3.0 \mathrm{~mm} ; b-\mathrm{UPNS}-304 \mathrm{M} 2 / \mathrm{M} 3$ unit, dosed powder feed, shielding gas $95 \% \mathrm{Ar}+5 \% \mathrm{H}_{2}, \delta=1.0-2.0 \mathrm{~mm}$

ly to the basic level of $\varepsilon_{q_{u}}, \varepsilon_{Q_{\Sigma} / L}$ values allows 1.5-2.0 times decrease of bead cross-section (see Figure 7).

Analysis of experimental data, given in Figures $2-7$, allowed outlining 3 basic laws of change of cross-section of the bead deposited on narrow substrate of $\delta=0.5-3.0 \mathrm{~mm}$ width. First of them is caused by variation of width of narrow substrate (Figure $8, a$ ) at continuous rate of surfacing: its 6 times extension promotes for 4-8 times increase of effective heat power of the microplasma arc necessary for surfacing, that is accompanied by 8-12 times rise of bead cross-section area. The second is caused by change of effective heat power of microplasma arc per $\pm 20 \%$ at constant width of narrow substrate and surfacing rate (Figure $8, b$ ), that is accompanies by 1.3-2.0 times change of bead cross-section area. The third is promoted by 3-4 times variation of surfacing heat input due to its rate at constant width of narrow substrate and effective heat power of microplasma arc (Figure $8, c$ ), that is accompanied by 3-4 times corresponding changes of bead cross-section area. Present laws of change of bead cross-section, as a rule, simultaneously match on practice to that or another degree.
It was assumed earlier in argon-arc welding [2, 3 , 10] that the process strength in welding of high-temperature nickel alloys with high content of strengthening $\gamma^{\prime}$-phase is determined with a condition of extreme limitation of welding current and base metal penetration depth. Experience of application of the microplasma powder surfacing [4-8] indicates that the pro-
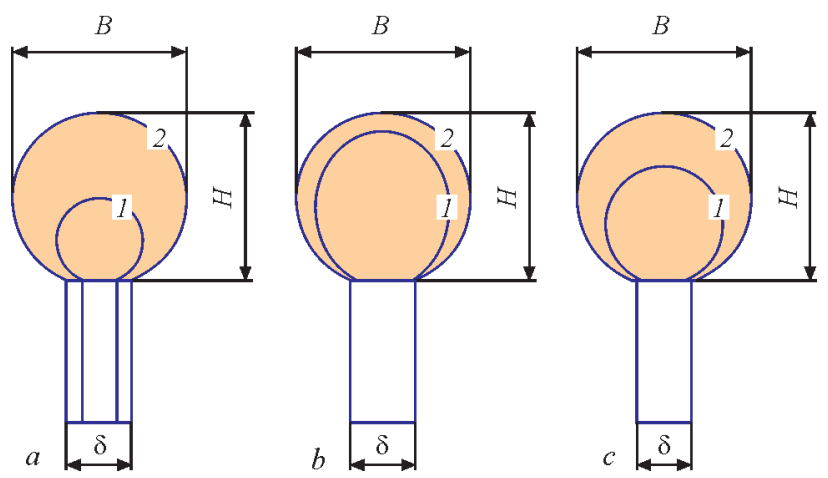

Base metal

Deposited metal

Figure 8. Basic dependencies of change of bead cross-section shape in surfacing on narrow substrate depending on: width of narrow substrate $(a)$, varying effective heat power of microplasma arc (b), changing heat input $(c) ; 1 \rightarrow 2-$ direction of bead cross-section change 
cess strength in single-layer surfacing of blade edges can be provided in sufficiently wide range of mode parameters $\left(I=2-35 \mathrm{~A}, v=0.2-5.0 \mathrm{~m} / \mathrm{h}, F_{\mathrm{b}}<30\right.$ $35 \mathrm{~mm}^{2}$ ), where the base metal penetration depth, as a rule, does not exceed $1 \mathrm{~mm}$.

Analysis of corresponding modes of surfacing on narrow substrate $\delta \leq 3 \mathrm{~mm}$, which are supposed to be close to optimum, showed that 2-4 times change of cross-section area of a bead being deposited promotes for insignificant variation of portion of base metal in the deposited one and it does not exceed $15 \%$. Respectively, portion of heat consumed for base metal melting does not exceed $2.5 \%$ of effective heat power of the microplasma arc. Therefore, it is relevant to formulate additional criteria of the process strength at transfer to multi-layer surfacing of the blade edges.

A surfacing heat input can be such an additional criterion of the process strength based on stated in works $[11,14]$ relationship of tendency to crack formation for considered welded joints and total heat input in the part as well as stated in this work dependencies of regulation of cross-section of the deposited bead. Thus, cross-section area of the deposited layer in multi-layer surfacing shall be selected taking into account heat input for determination of narrow substrate width.

\section{Conclusions}

1. Process range of energy indices was specified for single-layer microplasma powder surfacing on narrow substrate of width less than $3 \mathrm{~mm}$. In keeping with other technological recommendations, it is possible to provide the process strength of welded joint «base-deposited metal», in which at least one of the materials is high-temperature nickel alloy containing more than 55 vol.\% of $\gamma^{\prime}$-phase, using 30-420 W effective heat power of microplasma arc; 100-1600 J/ $\mathrm{mm}$ surfacing heat input; $0.3-3.0 \mathrm{~g} / \mathrm{min}$ surfacing efficiency; $1-25 \mathrm{~mm}^{2}$ deposited bead cross-section area.

2. In this case under conditions of limited base metal penetration depth, the process regulation of shape and size of cross-section of deposited bead can be done by means of change of effective heat power of the microplasma arc, surfacing heat input, reasonable selection of deposited metal composition and powder feed method (dosed, continuous).The most efficient among them at constant width of narrow substrate are 2.5-4 times variation of heat input, 30-50 \% change of effective heat power of the microplasma arc as well as 3.5-6 times variation at their combination. Detected dependencies of the bead shape regulation are used at JSC «Motor Sich» under conditions of serial repair of GTE blades.

3. Additional criteria of the process strength in repair multi-layer microplasma powder surfacing of blade edges of high-temperature nickel alloys can be the value of heat input and related with it height and cross-section area of the deposited metal layer.

1. Gladky, P.V., Pereplyotchikov, E.F., Ryabtsev, I.A. (2007) Plasma surfacing. Kiev: Ekotekhnologiya.

2. Peremilovsky, I.A., Gejchenko, V.S., Frumin, I.I. (1976) Surfacing repair of turbine blades of aircraft engines. Avtomatich. Svarka, 5, 54-56.

3. Petrik, I.A., Peremilovsky, I.A. (2001) Further development of technology for hardening of flange platform faces of turbine blades from high-temperature alloys. Tekhnologicheskie Sistemy, 3, 90-92.

4. Yarovytsyn, O.V. (2009) Microplasma powder surfacing of high-temperature nickel alloys containing 45-65\% of $\gamma^{\prime}$-phase: Syn. of Thesis for Cand. of Techn. Sci. Degree. Kiev: PWI.

5. (2010) Technological Seminar Deloro Stellite in Zaporozhie. The Paton Welding J., 1, 46-49.

6. Yushchenko, K.A., Savchenko, V.S., Yarovitsyn, A.V. et al. (2010) Development of the technology for repair microplasma powder cladding of flange platform faces of aircraft engine high-pressure turbine blades. Ibid., 8, 21-24.

7. Yushchenko, K.A., Yarovitsyn, A.V. (2012) Improvement of technology of repair of upper flange platform faces of aircraft engine blades. In: Complex Program of NASU on Problems of Service Life and Service Safety of Constructions, Structures and Machines. Transact. on Results of 2010-2012. Kiev: PWI.

8. Zhemanyuk, P.D., Petrik, I.A., Chigilejchik, S.L. (2015) Experience of introduction of the technology of reconditioning microplasma powder surfacing at repair of high-pressure turbine blades in batch production. The Paton Welding J., 8, 39-42.

9. Boguslaev, V.A., Muravchenko, V.M., Zhemanyuk, P.D. et al. (2003) Technological support of service characteristics of gas turbine engine parts. Turbine blades. Pt 2. Zaporozhie: JSC Motor Sich.

10. Sorokin, L.I., Lukin, V.I., Bagdasarov, Yu.S. (1997) Weldability of cast high-temperature alloys of ZhS6 type. Svarochn. Proizvodstvo, 6, 12-17.

11. Yarovitsyn, A.V. (2015) Energy approach in analysis of microplasma powder surfacing modes. The Paton Welding J., 5/6, 22-25.

12. Popov, S.A. (1987) Grinding operations. Moscow: Vysshaya Shkola.

13. Kondratyuk, E.V., Leontiev, V.A., Shusha, A.V. et al. (2013) Profile deep grinding of gas turbine engine parts. Promyshlennost $v$ Fokuse, 5, 22-24.

14. Yushchenko, K.A., Yarovitsyn, A.V., Khrushchov, G.D. et al. (2015) Analysis of process of bead shaping in cladding on narrow substrate. The Paton Welding J., 9, 20-27.

15. Wang, H., Jiang, W., Vallant, M. et al. (2003) Microplasma powder deposition as a new solid freeform fabrication process. Proc. Inst. Mech. Engrs., 217(Pt B.J.), 1641-1650.

16. Suyog Jhavar, Jain, N.K., Paul, C.P. (2014) Development of microplasma transferred arc ( $\mu$-PTA) wire deposition process for additive layer manufacturing applications. J. of Materials Processing Technology, 214(5), 1102-1110.

17. Gharbi, M., Peyre P., Gorny, C. et al. (2012) Influence of various process conditions on surface finishes induced by direct metal deposition laser technique on a Ti-6Al-4V alloy. Ibid., 213(5), 791-800.

18. (1988) Mathematical dictionary. Ed. by Yu.V. Prokhorov. Moscow: Sovremennaya Encyclopediya.

Received 06.07.2016 


\title{
EFFECT OF LASER RADIATION ABSORPTION ON EFFICIENCY OF LASER WELDING OF COPPER AND ITS ALLOYS
}

\author{
V.Yu. KHASKIN ${ }^{1,2}$, V.N. KORZHIK ${ }^{1,2}$, T.G. CHIZHSKAYA ${ }^{3}$, V.N. SIDORETS ${ }^{2}$ and LO ZIE ${ }^{1}$ \\ ${ }^{1}$ Guangdong Welding Institute (Chinese-Ukrainian E. O. Paton Institute of Welding) Guangzhou, China \\ ${ }^{2}$ E.O. Paton Electric Welding Institute, NASU \\ 11 Kazimir Malevich Str., 03680, Kiev, Ukraine. E-mail: office@paton.kiev.ua \\ ${ }^{3}$ NTUU «Igor Sikorsky Kyiv Polytechnic Institute» \\ 37 Pobedy Ave., Kiev-56, Ukraine
}

\begin{abstract}
Due to a high reflection power of copper it is usually assumed that the laser welding of products of this material is not rational. However, in the modern industry the problems of joining the parts of copper and its alloys periodically arise, applying narrow welds with a deep vapor-gas channel. Moreover, for technical reasons the use of electron beam welding is not always possible and a sufficiently wide availability of fiber (wavelength of $1.07 \mu \mathrm{m}$ ) and disc (wavelength of $1.03 \mu \mathrm{m}$ ) industrial lasers of the latest generation makes the problem of laser welding of these materials challenging. Therefore, the aim of the work was to study the conditions of absorbing the laser radiation with the wavelength of $1.03-1.07 \mu \mathrm{m}$ by copper and its alloys in laser welding with a deep penetration, as well as to determine the basic parameters of the welding mode and to evaluate the process effectiveness. It was shown in the work that for certain combinations of thickness of copper alloy and density of radiation power with the wavelength of 1.03-1.07 $\mu \mathrm{m}$, the optimal speed of welding process exists, at which its technical and economic efficiency is maximum. This speed should be such that the absorbing capacity (integrated over the spot of laser heating) can be at the level of about 13-15\%. The exceeding of welding speed leads to a sharp decrease in absorbing capacity, and, consequently, to the need in increasing the radiation power and growing the cost of the process. The decrease in welding speed relatively to the optimal one leads to decrease in efficiency, overheating of metal in the weld pool and to such defects of weld shaping, as sagging and metal splashes. 11 Ref., 8 Figures.
\end{abstract}

Ke y w or d s : laser welding, copper, solid-state laser radiation, absorbing factor, radiation power, welding speed

One of the challenging problems of the modern science and engineering in the field of fusion welding of metals is the creation of new power sources, which provide the control of concentration of heat energy introduced to the metal during welding process. This ultimately allows providing the required efficiency of welding, quality of the produced welded joint, process stability and reproduction of its results. In the recent decades in capacity of such controllable heat power source for welding of metallic materials a high-concentrated laser source is ever widely applied, which is realized by thermal effect of the focused laser beam on metal being welded [1].

However, until now the regularities of influence of laser heat source on some metallic materials were studied insufficiently. In particular, such materials include copper and its alloys. Due to a high reflection power of copper it is usually assumed that the laser welding of products of this material is not rational. However, in the modern industry the problems of joining the parts of copper and its alloys periodically arise, applying narrow welds with a deep vapor-gas channel. Moreover, for technical reasons the use of electron beam welding is not always possible and a sufficiently wide availability of fiber (wavelength of $1.07 \mu \mathrm{m}$ ) and disc (wavelength of $1.03 \mu \mathrm{m}$ ) industrial lasers of the latest generation makes the problem of laser welding of these materials challenging [2].

To solve this problem it is necessary to carry out investigation of physics of the process of effect of laser heat power source on welded metal, having the high thermal conductivity and reflection power, which is copper and its alloys, to develop the appropriate mathematical models and to perform computer modeling of the mentioned process. Moreover, it is rational to evaluate the efficiency of the process of laser welding of such materials by determination of basic mode parameters, i.e. the necessary consumption of radiation power for welding at the corresponding speed.

Therefore, the aim of the work is the study of conditions of absorbing the laser radiation with the wavelength of 1.03-1.07 $\mu \mathrm{m}$ by copper and its alloys in laser welding with a deep penetration, as well as the determination of the basic parameters of welding mode and evaluation of the process efficiency.

Laser welding is characterized by the formation of a vapor-gas channel in the metal being welded. In [2] the behavior of the channel during welding is de- 
scribed in detail. In particular, it was noted that at its front wall there is a layer of molten metal, experiencing the constant "perturbations», such as the formation of distortion in the form of a step, which is periodically moved in the channel height. Moreover, the removal of material from the front wall is carried out layer-by-layer during moving the step downwards. It can be explained by the increase in molten metal layer at the front wall, occurring due to transition of radiation energy into heat energy, generated at this wall, in combination with hydrodynamic processes proceeding in the weld pool.

It is known that a part of radiation power is absorbed by the metal being welded, and a part of it is reflected from it. The volume of the absorbed radiation is higher, the higher is the metal temperature. The melt formed on the front wall absorbs radiation well, but due to the movement in the course of welding the front part of the laser beam falls all the time on the poorly heated metal, which leads to decrease in the absorbing factor. Therefore, in laser welding two processes are observed simultaneously:

- improvement of conditions of absorbing the laser radiation due to its hitting on the heated and molten metal of the front wall of the vapor-gas channel, as well as trapping of the certain volume of radiation due to its repeated reflection from channel walls;

- intensive reflection of laser radiation by a poorly heated metal, located directly ahead the vapor-gas channel in the course of welding.

To evaluate the conditions of absorbing the focused laser radiation by copper and its alloys in laser welding, let us assume that the plane specimen is heated by the heat source of high intensity and the spatial distribution of heat flow introduced to the specimen, is symmetrically relative to the axis perpendicular to its surface (relative to the laser beam axis). Let us accept the wavelength of radiation applied for welding

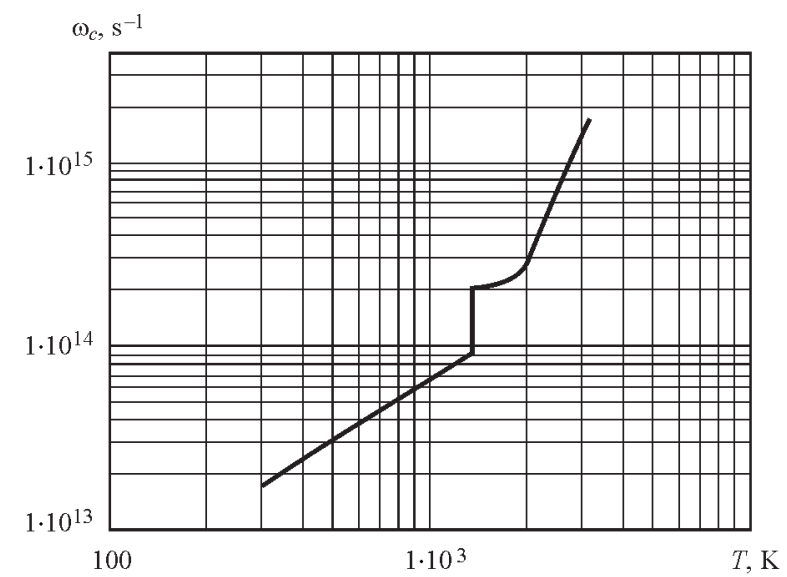

Figure 1. Dependence of relaxation frequency $\omega_{c}$ on temperature $T$ for copper of solid-state laser as equal to $\lambda=1.06 \mu \mathrm{m}$, as included into the investigated range of $1.03-1.07 \mu \mathrm{m}$.

To determine the temperature dependence of the factor of absorbing the laser radiation by metallic materials A(Ts), we will consider the investigated metal (copper) in the frames of model of almost free electrons. In this case, according to Drude-Zener [3], for the real $\varepsilon_{1}$ and imaginary $\varepsilon_{2}$ parts of the integrated permittivity of metal at the frequency of the laser radiation $\omega=2 \pi c / \lambda$, where $c$ is the light speed, $\lambda$ is the radiation wavelength, we will obtain:

$$
\begin{gathered}
\varepsilon_{1}=1-\frac{\omega_{\mathrm{p}}^{2}}{\omega^{2}+\omega_{C}^{2}} ; \\
\varepsilon_{2} \omega=4 \pi \sigma=\frac{\omega_{n} \omega_{\mathrm{p}}^{2}}{\omega^{2}+\omega_{C}^{2}} .
\end{gathered}
$$

Here $\omega_{\mathrm{p}}$ is the frequency of plasma oscillations of free electrons of metal, $\omega_{c}$ is the frequency, numerically equal to the opposite relaxation time of conduction electrons. The value of plasma frequency is determined by the formula:

$$
\omega_{\mathrm{p}}^{2}=\frac{4 \pi n e N_{\mathrm{e}}}{m_{\mathrm{e}}^{*}} ;
$$

where $e$ and $m_{\mathrm{e}}^{*}$ is the charge and effective mass of the electron in the metal [4]. The concentration of the conduction electrons $N_{\mathrm{e}}=V / \Omega$ is determined though the valence $V$ and the atomic volume $\Omega$. The value of the valence for copper was accepted as equal to two. The atomic volume was obtained on the basis of experimental data by density of copper, given in the work [5].

In the limiting case of a constant field, when $\omega=0$, the high-frequency optical conductivity $\sigma$ is converted into static conductivity of the metal:

$$
\sigma(0)=\frac{N_{\mathrm{e}} e}{m_{\mathrm{e}} \omega_{c}} .
$$

The temperature dependence of relaxation frequency $\omega_{c}$ for the considered metals in the solid state was calculated by the following formula [6]:

$$
\omega_{c}=K^{\prime} T^{5} \int_{0}^{\theta / T} \frac{z^{4} d z}{e^{z}-1},
$$

where $\theta$ is the Debye temperature. The values $\omega_{c}$ and, accordingly, $K^{\prime}$ at room temperature for copper were selected in accordance with the data of the work [7]. For copper in the liquid state the experimental values from the works [8, 9] were used. The calculation data obtained in such a way are shown in Figure 1.

The temperature dependence presented in this Figure, has a characteristic gap at the melting temperature of metal $T_{\mathrm{m}}$. According to the formulae (1) and (2) using (3)-(5) the temperature dependences of the real and imaginary parts of the integrated permittivity 


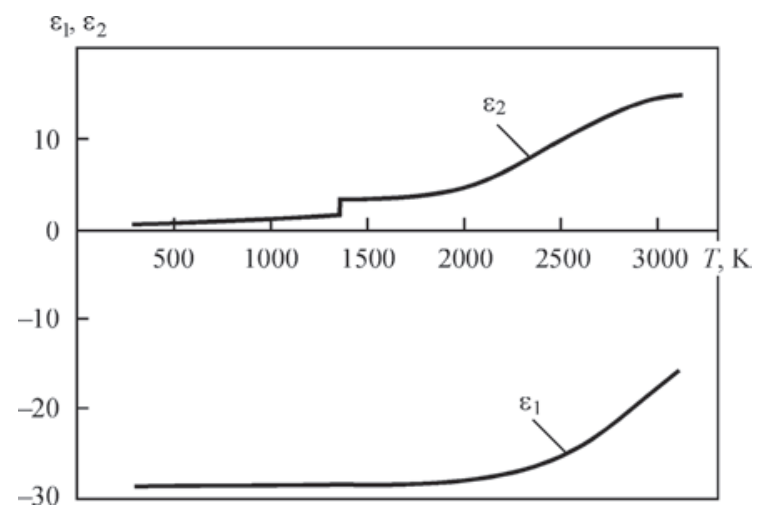

Figure 2. Dependences of real $\varepsilon_{1}$ and imaginary $\varepsilon_{2}$ parts of integrated permittivity of copper on temperature $T$ at frequency of radiation of solid-state laser $(\lambda=1.06 \mu \mathrm{m})$

for copper at the frequency of solid-state laser radiation $(\lambda=1.06 \mu \mathrm{m})$ were plotted, shown in Figure 2 (here and further, the temperature is expressed in Kelvin degrees).

For the further calculations it is convenient to introduce the real $n$ and imaginary $k$ parts of the complex refractive index of metal at the frequency of laser radiation

$$
\sqrt{\varepsilon}=\sqrt{\varepsilon_{1}+i \varepsilon_{2}}=n+i k
$$

using the following formulae for this:

$$
\begin{aligned}
& n=\sqrt{\frac{\sqrt{\varepsilon_{1}^{2}+\varepsilon_{2}^{2}}+\varepsilon_{1}}{2}}, \\
& k=\sqrt{\frac{\sqrt{\varepsilon_{1}^{2}+\varepsilon_{2}^{2}}-\varepsilon_{1}}{2}} .
\end{aligned}
$$

The temperature dependences of the real and imaginary parts of the complex refractive index for copper are shown in Figure 3.

Using the obtained values $n$ and $k$, let us determine the laser absorbing factor, normally falling on the plane metal surface (absorbing capacity), according to the known formula

$$
A=\frac{4 n}{(1+n)^{2}+k^{2}} .
$$

In some cases the more important parameter is the reflection factor (reflectance), which can be determined according to the formula

$$
R=1-A=\frac{(1-n)^{2}+k^{2}}{(1+n)^{2}+k^{2}} .
$$

Figure 4 shows the results of calculations of temperature dependences of the absorbing factor of radiation of solid-state laser for copper in the range from room to boiling temperatures of metal $T_{\mathrm{b}}$ and higher.

The calculation dependence of absorbing capacity, obtained for the selected type of radiation, was compared with the available experimental data [6-9] and the matching was quite satisfactory. According to the dependence, shown in Figure 5, to achieve the maximum values of absorbing factor of the surface

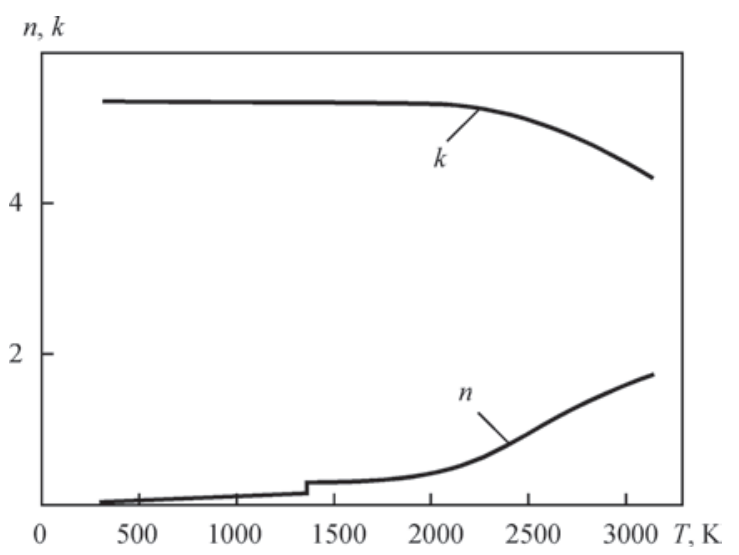

Figure 3. Dependences of real $n$ and imaginary $k$ part of the integrated refractive index of copper on temperature $T$ at frequency of radiation of solid-state laser $(\lambda=1.06 \mu \mathrm{m})$

of the welded copper alloy in the zone of acting laser radiation with the wavelength of $1.06 \mu \mathrm{m}$, it should be heated to boiling temperature $T_{b}$. However, even heating to melting temperature $T_{\mathrm{m}}$ is sufficient for an abrupt jumpy increase in absorbing capacity from $2.0-2.5$ to $4.5-5.0 \%$.

To determine the temperature distributions in the depth and on the surface of the copper specimen welded using focused laser radiation, the calculation using the method of finite differences was conducted involving an implicit difference scheme. For this purpose the software product of the own development was applied, based on the computational and experimental methods, described in the work [10]. During calculations the thermophysical characteristics of copper were used given in the work [11]. The data obtained in the process of computer modeling were compared with the experimental results. While conducting the latter, the disc laser of the model TruDisk 10002 (company TRUMPF, Germany) was applied with the capacity of up to $10.0 \mathrm{KW}$. To move the welding head, the robot of the model KR $60 \mathrm{HA}$ (the company KUKA, Germany) was used. Welding of specimens of copper of the type M1 of size $100 \times 50 \times 3 \mathrm{~mm}$ was performed in argon shielding with deposition and

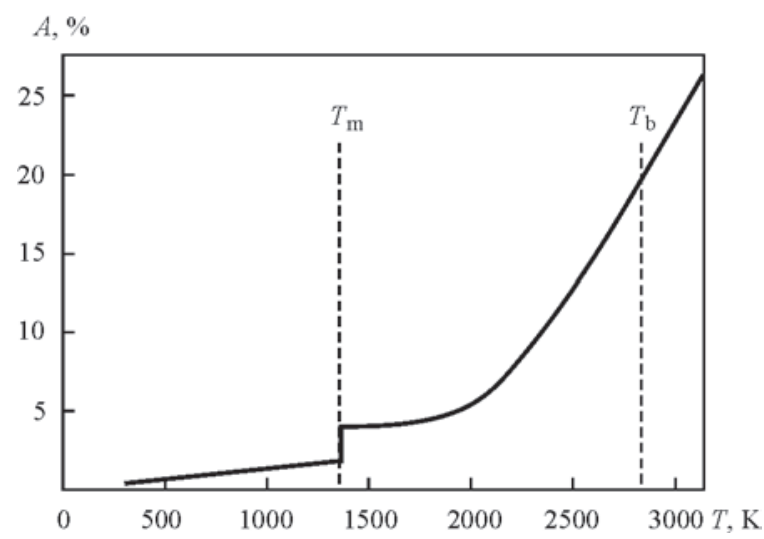

Figure 4. Dependences of absorbing capacity $A$ of copper on temperature $T$ for radiation with wavelength of $1.06 \mu \mathrm{m}$ 

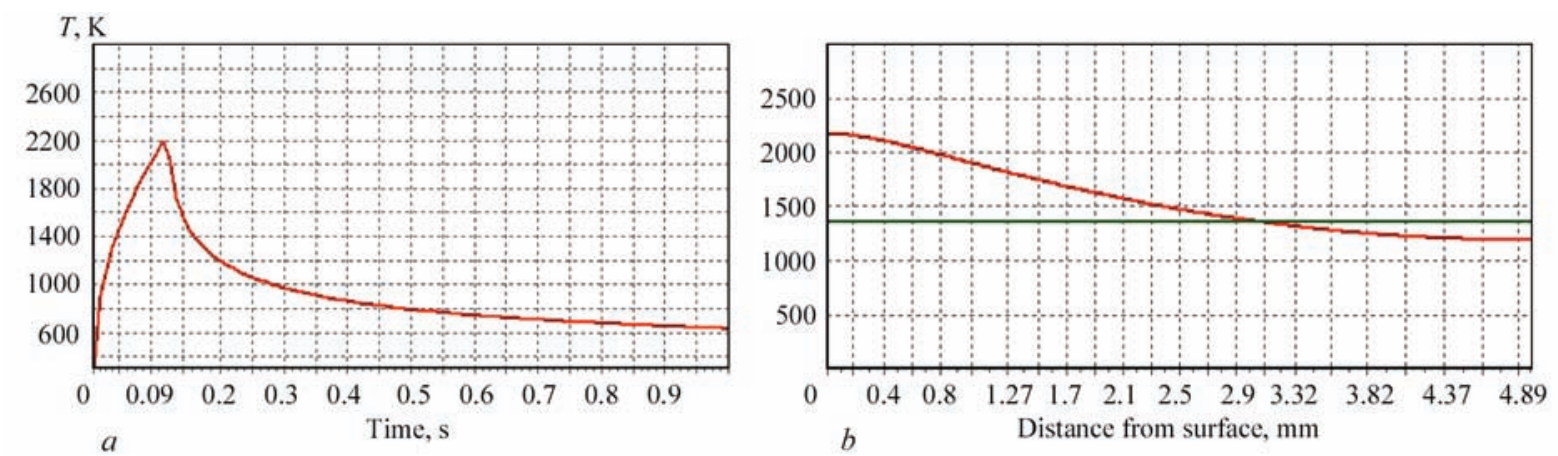

Figure 5. Distribution of temperatures $T$ on the surface $(a)$ and in the depth $(b)$ of copper plate of 5 mm thickness in laser welding using radiation of solid-state laser $(A=13 \%)$ with density of power $4.5 \cdot 10^{7} \cdot \mathrm{W} / \mathrm{cm}^{2}$ and speed $v_{\mathrm{w}}=90 \mathrm{~m} / \mathrm{h}(25 \mathrm{~mm} / \mathrm{s})$
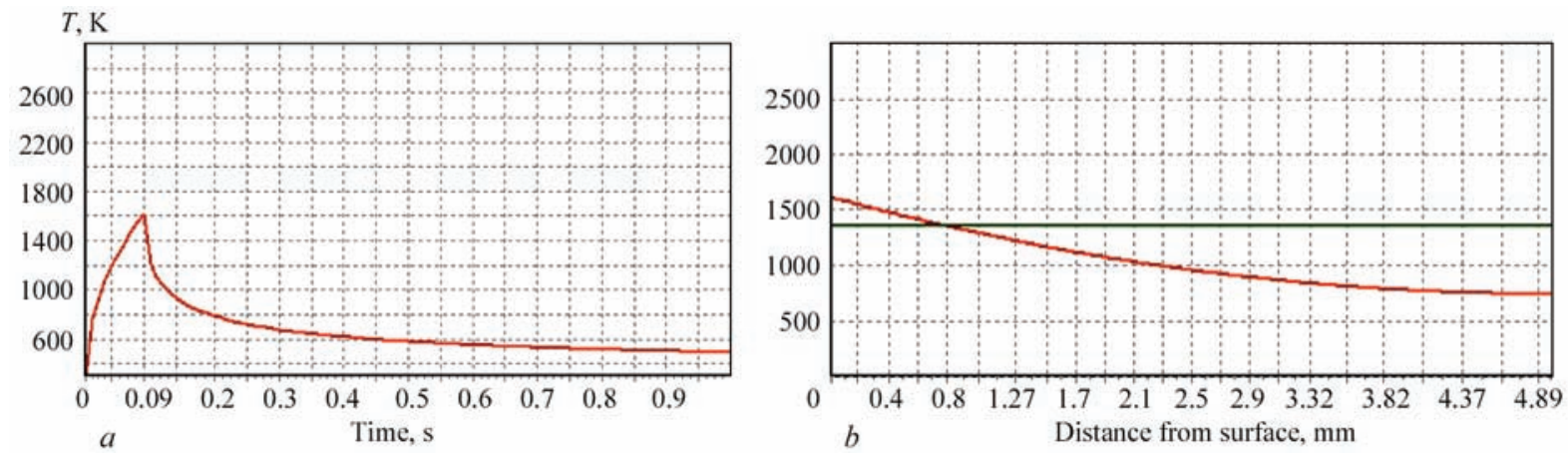

Figure 6. Distribution of temperatures $T$ on the surface $(a)$ and in the depth $(b)$ of copper plate of $5 \mathrm{~mm}$ thickness in laser welding using radiation of solid-state laser $(A=10 \%)$ with density of power $4.5 \cdot 10^{7} \mathrm{~W} / \mathrm{cm}^{2}$ and speed $v_{\mathrm{w}}=120 \mathrm{~m} / \mathrm{h}(33.3 \mathrm{~mm} / \mathrm{s})$

butt welds at the density of laser radiation power of $4.5 \cdot 10^{7} \mathrm{~W} / \mathrm{cm}^{2}$.

The investigations show that for the fixed thickness of penetrated specimen (in this case $\delta=3 \mathrm{~mm}$ ) it is possible to select such welding speed $v_{\text {opt }}$ at which not more than one third of the length of heat source (i.e. diameter of laser radiation) acts constantly on the solid surface of copper, located directly ahead the vapor-gas channel during welding. In this region the absorbing capacity of the surface A changes from 2.0 to $5.0 \%$. Approximately two thirds of the length of the heat source (i.e. diameter of laser radiation) will fall in this case to the vapor-gas channel, the temperature in which reaches not lower than $2900 \mathrm{~K}$, and the absorbing capacity is 19-20\%. Such welding speed amounts to about $v_{\text {opt }} \leq 25 \mathrm{~mm} / \mathrm{s}(90 \mathrm{~m} / \mathrm{h})$. It provides the absorbing capacity in the range of 13-15\% integrated on the spot of laser heating. In this case, the penetration depth will amount to not less than $3 \mathrm{~mm}$ (see Figure 5).

With increase in welding speed $v_{\mathrm{w}} \geq v_{\mathrm{opt}}$ the volume of laser power, falling to the region of a low absorbing capacity, will increase and a part of this energy, falling to the region with a high absorbing capacity, on the contrary, will decrease. This will result in decrease of integrated absorbing capacity of less than $13 \%$ and, consequently, in need of increasing the laser radiation power. The last moment will result in increase in the cost of running meter of weld and the corresponding decrease in technical and economic efficiency of the
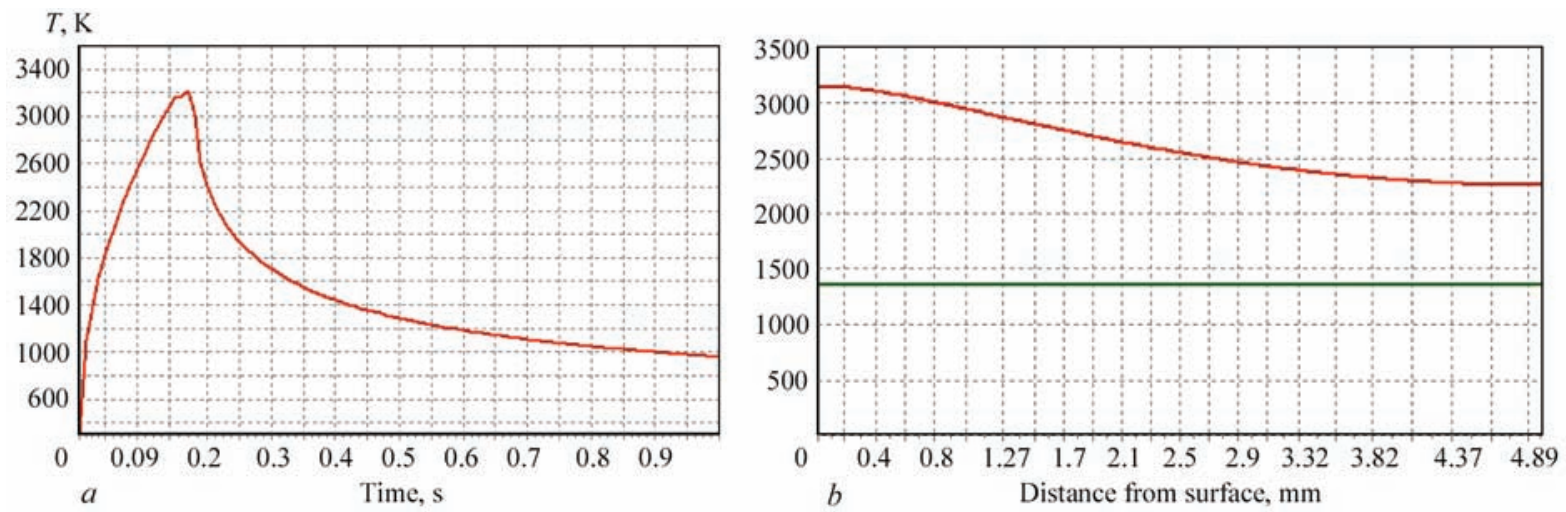

Figure 7. Distribution of temperatures $T$ on the surface $(a)$ and in the depth $(b)$ of copper plate of 5 mm thickness in laser welding using radiation of solid-state laser $(A=17 \%)$ with density of power $4.5 \cdot 10^{7} \mathrm{~W} / \mathrm{cm}^{2}$ and speed $v_{\mathrm{w}}=60 \mathrm{~m} / \mathrm{h}(16.7 \mathrm{~mm} / \mathrm{s})$ 
process. In this case, the penetration depth is much smaller than the required $3 \mathrm{~mm}$, which will lead to the lack of penetration (Figure 6).

With decrease in welding speed relatively to the selected one $\left(v_{\mathrm{w}} \leq v_{\mathrm{opt}}\right)$ the greater part of radiation will fall to the vapor-gas channel, and absorbing capacity will increase by more than $15 \%$. However, in this case the process efficiency will decrease $\left(v_{\mathrm{w}} \leq 16.7 \mathrm{~mm} / \mathrm{s}\right.$ or $\left.v_{\mathrm{w}} \leq 60 \mathrm{~m} / \mathrm{h}\right)$, and it will become less effective. In this case, the penetration depth will significantly exceed the required $3 \mathrm{~mm}$, which will result in such shaping defects as sagging and splashes of the weld metal (Figure 7).

To perform the experimental verification of the predicted results of laser welding on plane specimens the surfacing welds were produced, then the penetration depth was measured on macrosections and compared with the calculation data. In addition, at the calculation modes the butt joints were welded (Figure 8). Such verification allowed establishing that the calculation accuracy amounts to about 5-8 \%, which in the case of technological calculations is a satisfactory indicator.

Thus, the study of conditions of absorbing the laser radiation with the wavelength of 1.03-1.07 $\mu \mathrm{m}$ in welding with deep penetration of copper and its alloys allows stating that for a certain combination of welding material thickness and density of radiation power, such an optimal process speed exists, at which its technical and economic efficiency is maximum. This speed corresponds to the integrated one over the spot of laser heating of absorbing capacity of about $13-15 \%$. The exceeding of welding speed leads to a sharp decrease in absorbing capacity, and, consequently, to the need in increasing the radiation power and growing of the process cost. The decrease in welding speed relatively to the optimal one leads to the decrease in efficiency, overheating of metal in the weld pool and to such defects of weld shaping, as sagging and metal splashes.

The work was carried out at the support of the Foreign Experts Program of China No. WQ20124400119,
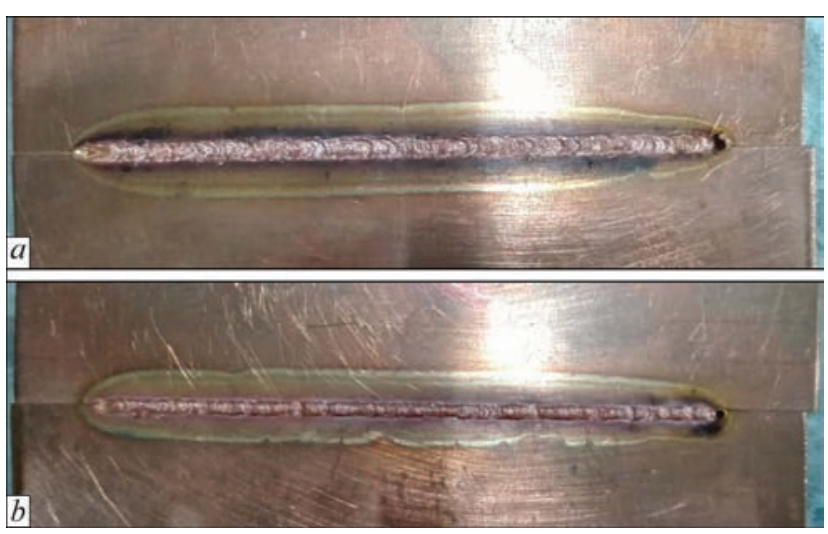

Figure 8. Butt joint of sheet copper M1 $(\delta=3 \mathrm{~mm})$ produced by laser welding in argon using radiation of power density $4.5 \cdot 10^{7} \mathrm{~W} /$ $\mathrm{cm}^{2}$ and speed $v_{\mathrm{w}}=90 \mathrm{~m} / \mathrm{h}(25 \mathrm{~mm} / \mathrm{s}): a$ - top; $b$ - bottom

Program of the Innovation Group of the Province Guangdong, China No. 201101C0104901263, Guangdong research Project No. 2015A050502039, Guangdong research Project No. 2016 B050501002.

1. Grigoryants, A.G., Shiganov, I.N. (1988) Laser equipment and technology. Book 5: Laser welding of metals. Manual for inst. of higher education. Ed. by A.G. Grigoryants. Moscow: Vysshaya Shkola.

2. Bernadsky, V.N., Shelyagin, V.D., Makovetskaya, O.K. (2007) Present market of laser equipment for welding and processing of materials. The Paton Welding J., 10, 44-49.

3. Noskov, M.M. (1983) Optical and magnetooptical properties of metals. Sverdlovsk: UNTs AN SSSR.

4. Kiselev, A.I., Akashev, L.A., Kononenko, V.I. (2004) Effective mass of electrons in melts of aluminium, cesium and Al-3 at.\% Ce binary system. Zh. Tekhnicheskoj Fiziki, 74(Issue 3), 20-23.

5. Zinoviev, V.E. (1989) Thermophysical properties of metals at high temperatures: Refer. Book. Moscow: Metallurgiya.

6. Ujihara, K. (1972) Reflectivity of metals at high temperatures. J. of Applied Physics, 43(5), 2376-2383.

7. Ordal, M.A., Long, L.L., Bell, R.J. et al. (1983) Optical properties of the metals $\mathrm{Al}, \mathrm{Co}, \mathrm{Cu}, \mathrm{Au}, \mathrm{Fe}, \mathrm{Pb}, \mathrm{Ni}, \mathrm{Pd}, \mathrm{Pt}, \mathrm{Ag}, \mathrm{Ti}$ and $\mathrm{W}$ in the infrared and far infrared. Applied Optics, 22(7), 1099-1119.

8. Miller, J. (1969) Optical properties of liquid metals at high temperatures. Phil. Mag., Vol. 20, 12(Issue 168), 1115-1132.

9. Comins, N.R. (1972) The optical properties of liquid metals. Ibid., 25(Issue 4), 817-831.

10. Khaskin, V.Yu. (2012) Experiment-calculated method for determination of conditions of laser surfacing processes. Nauka ta Innovatsii, 8(6), 5-16. 


\title{
INFORMATION-MEASURING SYSTEM FOR ARC WELDING AND SURFACING
}

\author{
Yu.N. LANKIN and V.G. SOLOVIOV \\ E.O. Paton Electric Welding Institute, NASU \\ 11 Kazimir Malevich Str., 03680, Kiev, Ukraine. E-mail: office@paton.kiev.ua
}

\begin{abstract}
Information-measuring system for arc welding and surfacing was developed. The system allows automatic determination of process state zones, i.e. zone of arc striking, arc running, short-circuiting, open-circuit and arc extinction, thus eliminating any subjectivity in zone identification; and provides an extended set of calculated statistical parameters for each of the states. For this purpose, digitizing of welding current and voltage signals, computer processing by algorithms of automatic recognition and clustering of periodic status zones, using empirical rules, analysis of histograms of distribution of current and voltage signals separately, as well as of histograms of their joint distribution, are used. Built information-measuring system for arc welding and surfacing based on ADC E14-440 and notebook allows calculation of 29 statistical parameters, characterizing the process. Information-measuring system performs automatic identification of the state of welding/surfacing process, thus eliminating the human factor influence on the derived estimates of statistical parameters of the process. 11 Ref., 4 Tables, 8 Figures.
\end{abstract}

Ke yw ord s: information-measuring system, welding process, welding, surfacing, clustering, welding process state, arc short-circuiting, arc extinction

Of all the process parameters, the main scope of information about the welding process is provided by the electric parameters, namely welding current $I_{\mathrm{w}}$ and arc voltage $U_{\text {a }}$. They are also the easiest to measure. Therefore, $I_{\mathrm{w}}$ and $U_{\mathrm{a}}$ are used for studying the processes of welding/surfacing in most cases, and numerous information-measuring systems (IMS) have been created for their measurement, recording, processing and visualization. Measurement and analysis of electric parameters of arc welding/surfacing process is used for quality control, determination of properties, mode selection and regulation of the process.

Composition of all IMS is basically the same: monitored parameter sensors, normalizing signal transducers, analog-digital converter (ADC), data processing and visualization device, and software. In research practice, IMS are mostly assembled from purchased above-mentioned modules. Commercially available IMS are also known, for instance, ADAM III, Arc Guard, Weldcheck [1], Hannover XV (AH XV) [2], DAREG [3], ARCDATA LQ-1N [4], ARCDATA LQ-2 [5], Arcwatch ${ }^{\mathrm{TM}}$, APN-1, APN-2 [7].

Analysis of welding current and arc voltage records is usually performed by standard statistical methods, the number of analyzed characteristics being extremely limited.

Several process states during welding can be singled out (Figure 1): open-circuit mode of welding source (OC); arc striking (AS); steady-state arc process with periods of short-circuiting (SC); periods of arc running

(c) Yu.N. LANKIN and V.G. SOLOVIOV, 2016
(AR) and arc extinction (AE). Each of these states is characterized by its statistical indices and threshold binarization levels to determine their beginning and end. Usually, only the steady-state arc process is studied, for which purpose respective fragments of the records have to be manually chosen practically in all IMS. This essentially influences the results of subsequent statistical processing of the data, making them dependent on the specific researcher, conditions of electric signal recording, and record fragment selected for processing. A pleasant exception are works $[8,9]$, where the problem of automatic identification of the states of consumable-electrode welding process is, apparently, solved, for welding source certification IMS, by clustering current and voltage data.

Described below is arc welding IMS, differing from the known systems by automatic determination of welding process state zones and expanded set of calculated statistical parameters for each process state [10].

Data acquisition. Measurement and recording of arc welding current and voltage is performed using versatile module ADC E14-440 (USB2 bus), which is particularly convenient to create portable measuring systems based on a notebook. Table 1 gives the modes of arc surfacing with $1.6 \mathrm{~mm}$ wire in $\mathrm{CO}_{2}$, and Table 2 - in a mixture of shielding gases $(82 \% \mathrm{Ar}+$ $\left.18 \% \mathrm{CO}_{2}\right)$.

For ADC the requirements to quantization level and sampling interval of signals of voltage source $U_{w}$ and current source $I_{\mathrm{w}}$ are determined by the requirements to accuracy of determination of root mean 
square (RMS) deviation of SC voltage $\sigma^{U}{ }^{\text {sc }}$ and RMS deviation of SC duration $\sigma^{T}$ sc . Preliminary estimates of $\sigma^{U_{s c}}$ and $\sigma_{\text {sc }}^{T_{\text {sc }}}$ showed that $\sigma_{\text {sc }}$ is equal to approximately $2 \mathrm{~V}$, and $\sigma^{T}{ }_{\text {sc }}$ is $5 \mathrm{~ms}$. As the accuracy of the order of $1 \%$ is usually sufficient for process parameters, limit measurement error was taken to be $\sigma_{\mathrm{sc}}^{U_{\mathrm{sc}}}=0.02 \mathrm{~V}$, and $\sigma_{\mathrm{sc}}^{T_{\mathrm{sc}}}=$ $=0.05 \mathrm{~ms}$.

Maximum frequency of ADC E14-440 at digitizing of the two parameters is $200 \mathrm{kHz}$, and digit capacity is 14 bits, i.e. sampling interval is $0.005 \mathrm{~ms}$, and quantization level is $0.05 \%$. This more than satisfies the above requirements. To limit the size of obtained records, minimum admissible sampling frequency of $20 \mathrm{kHz}$ was selected.

Data processing. Algorithms of automatic recognition of OC, AS, SC, AR and arc extinction AE periods have been developed for computer processing of $I_{\mathrm{w}}$ and $U_{\mathrm{w}}$ signals, recorded using E14-440 module and PowerGraph software. The algorithms use empirical rules, analysis of distribution histograms of $I_{\mathrm{w}}$ and $U_{\mathrm{w}}$ signals separately, and analysis of histograms of joint distribution of $I_{w}$ and $U_{w}$.

Obvious features of $I_{w}$ and $U_{w}$ signals, which can be used at data clustering to single out welding process periods, are as follows:

- increased rate of variation of $I_{w}$ and $U_{w}$ signal at the moment of SC appearance;

- «zero» or close to zero $I_{\mathrm{w}}$ value and higher $U_{w}$ value in OC or AE periods;

- increased $I_{\mathrm{w}}$ value and lower $U_{\mathrm{w}}$ value in SC period;

- relatively mean values of $I_{w}$ and $U_{w}$ in AR period;

- OC period is characteristic only for beginning and/or end of signal records;

- AE period appears only after AR or SC periods;

- AE period, which exceeds a certain time limit, is a $\mathrm{OC}$;

Table 1. Modes of $\mathrm{CO}_{2}$ arc surfacing with $1.6 \mathrm{~mm}$ wire

\begin{tabular}{|c|c|c|c|}
\hline $\begin{array}{c}\text { Number } \\
\text { of arc } \\
\text { surfacing } \\
\text { mode }\end{array}$ & $\begin{array}{c}\text { Wire feed } \\
\text { rate, } \mathrm{m} / \mathrm{h}\end{array}$ & $\begin{array}{c}\text { Source voltage, } \\
U_{\mathrm{w}}, \mathrm{V}\end{array}$ & $\begin{array}{c}\text { Source current, } \\
I_{\mathrm{w}}, \mathrm{A}\end{array}$ \\
\hline 1 & 160 & 26 & 120 \\
\hline 2 & 330 & $28-29$ & 220 \\
\hline 3 & 220 & $27-28$ & 150 \\
\hline 4 & 420 & 30 & 260 \\
\hline 5 & 460 & 60 & $270-280$ \\
\hline
\end{tabular}
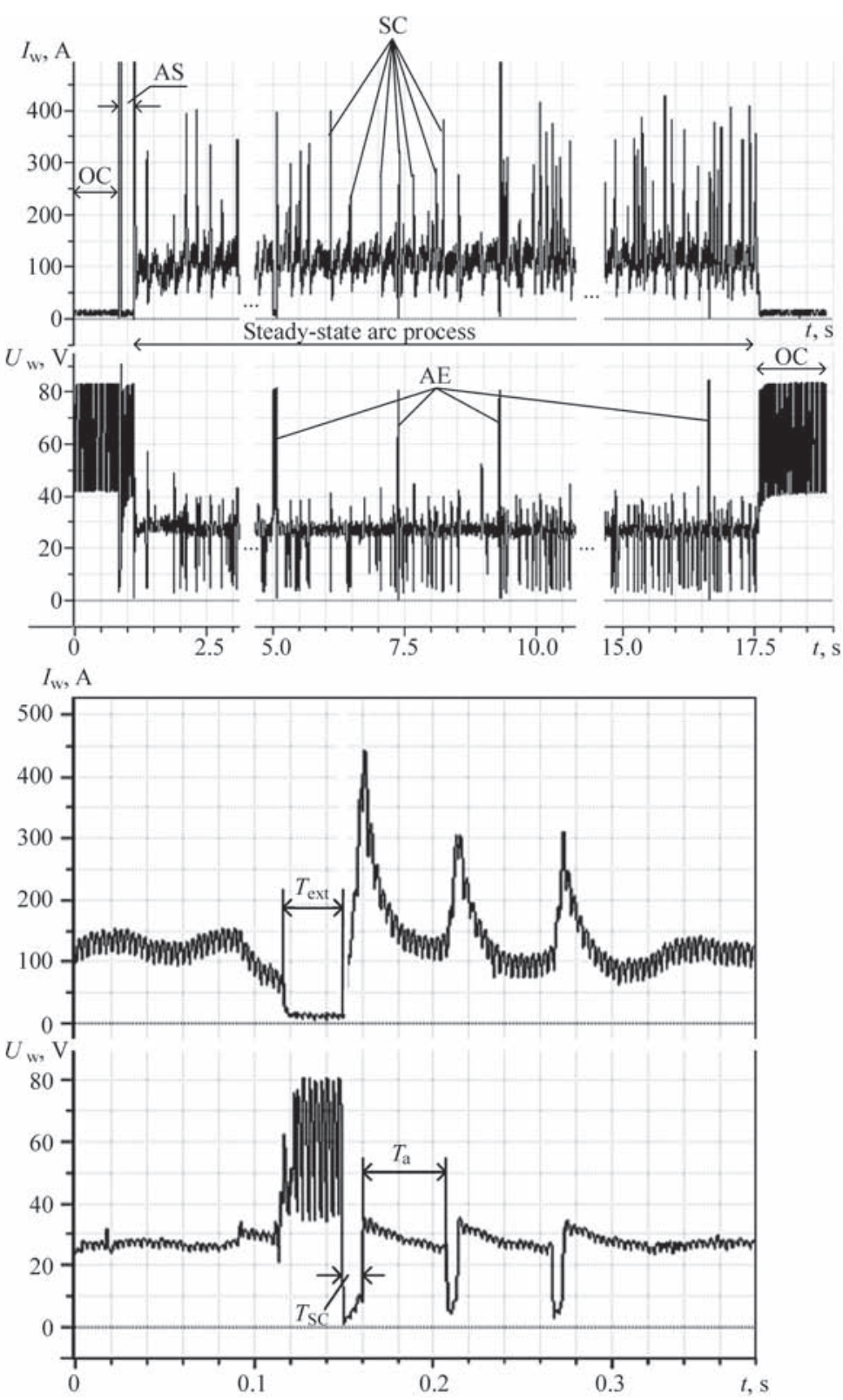

Figure 1. Record of $\mathrm{CO}_{2}$ welding process

- AS period starts at first SC, and ends at first appearance of the period of AR steady-state process;

- steady-state welding process is observed from the beginning of first AR period and up to the moment of the beginning of OC period at the end of recording;

Table 2. Modes of arc surfacing in a mixture of gases of $82 \%$ $\mathrm{Ar}+13 \% \mathrm{CO}_{2}$

\begin{tabular}{|c|c|c|c|}
\hline $\begin{array}{c}\text { Number } \\
\text { of arc } \\
\text { surfacing } \\
\text { mode }\end{array}$ & $\begin{array}{c}\text { Wire feed rate, } \\
\mathrm{m} / \mathrm{h}\end{array}$ & $\begin{array}{c}\text { Source voltage, } \\
U_{\mathrm{w}}, \mathrm{V}\end{array}$ & $\begin{array}{c}\text { Source current, } \\
I_{\mathrm{w}}, \mathrm{A}\end{array}$ \\
\hline 1 & 220 & 28 & $170-180$ \\
\hline 2 & 25 & $18-20$ & $40-50$ \\
\hline 3 & 155 & 28 & 120 \\
\hline 4 & 225 & 30 & 150 \\
\hline 5 & 325 & 30 & 200 \\
\hline 6 & 520 & 30 & 250 \\
\hline 7 & 450 & 40 & 250 \\
\hline
\end{tabular}



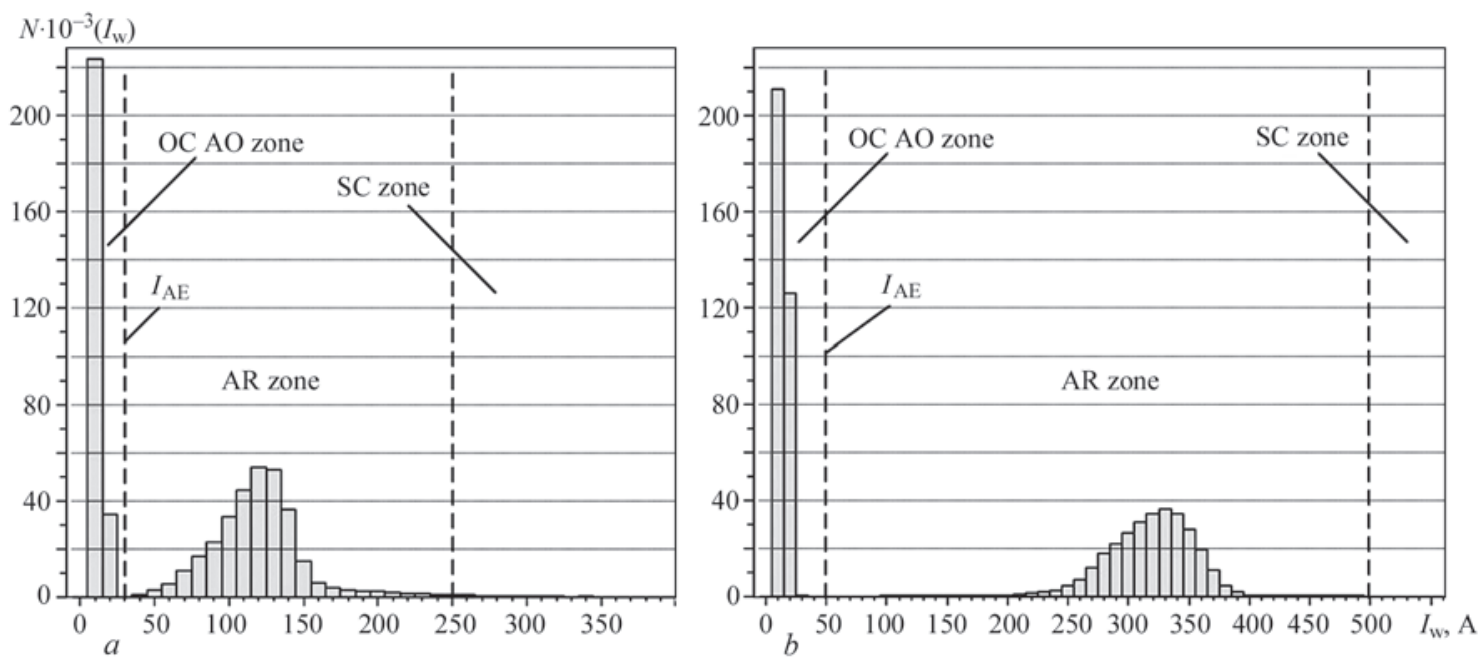

Figure 2. Histogram of distribution density $N$ of $I_{\mathrm{w}}$ values for processes of $\mathrm{CO}_{2}$ welding $1(a)$ and 5 (b) (see Table 1)

- «zero» $I_{w}$ and $U_{w}$ values are indicative of a switched off source.

Considering that $U_{\mathrm{w}}$ in OC period can vary within a wide range and with sufficiently high rate in some cases (300 Hz frequency of change), beginning of AS period $t_{n}$ is determined not by the first «abrupt» exceeding a certain limit change of $I_{w}$ and/or $U_{w}$ signals, but by the change of $I_{w}$ level in keeping with the following algorithm:

$$
t_{n}=\left\{\begin{array}{l}
\frac{\bar{I}_{i}}{\bar{I}_{i-1}}>\left(\text { at } t \geq t_{k}\right) \\
\bar{I}_{i} \\
\frac{\bar{I}_{i-1}}{{ }^{\prime}} \leq\left(\text { at } t<t_{k}\right)
\end{array},\right.
$$

where $\bar{I}_{i}=\bar{I}_{i-1}+\frac{I_{i}}{N}-\frac{I_{i-N}}{N} ; I_{i}$ is the $i$-th value of $I_{\mathrm{w}} ; I_{i}$ is the $i$-th value of averaged $I_{w}$ value; $\infty$ is the constant value, determined experimentally ( $\infty=2$ is assumed); $N$ is the number of samples, determining the interval of moving averaging ( $N=100$ is assumed).

A similar algorithm was used to determine the moment of the end of steady-state welding process $t_{k}$, and the moment of OC beginning at the end of observation with the only difference that the moving averaging should be implemented in the opposite direction: from the end to the beginning.

Preliminary identification of SC, AR and AE states of the process is based on analysis of histograms of distribution of probability density of $I_{\mathrm{w}}$ and $U_{\mathrm{w}}$ signals.

To be specific, let us consider two processes in $\mathrm{CO}_{2}: 1$ and 5 . Process 1 (Figure 1 ) is characterized by a large number of arc extinctions and quite fast striking, while 5 differs by rather long AS period and long record of OC period at the end of the process.

As one can see from Figure 2, $a, b$ the histograms differ strongly by the ranges of current variations and modes, but have the same nature of distribution density. In both the cases, three characteristic regions are present, which kind of divide the entire range of current variation into three zones. For process 1 these are ranges of $0-30,30-250$ and $250-860 \mathrm{~A}$. For process 5 these are ranges of $0-50,50-500$ and $500-1060 \mathrm{~A}$.

The same can be said also about voltage histograms for process 1 (Figure 3 ) and 5 (Figure 4). For 1 these are ranges of $0-17,17-40$, and $40-90 \mathrm{~V}$, and for 5 these are $0-43$, 43-65 and 65-107 V.

It is obvious that these zones represent three different states of the welding process: SC; AR, OC or AE. We will define the boundaries of the zones as follows:

- $U_{\mathrm{SA}}$ is the boundary of SC and AR zones;

- $U_{\mathrm{AE}}$ is the boundary of zones AR and OC or AE; - $I_{\mathrm{AO}}$ is the boundary of zone AR and OC or AE.

To determine the boundaries of $U_{\mathrm{SA}}$ and $U_{\mathrm{AE}}$ zones, it is logical to move to the left and to the right from AR zone mode up to the first minimums of voltage density distribution. As the arcing process is the most probable state of the arc in arc welding, the mode of the entire range of distribution density can be taken as the approximation of AR zone mode. However, in research practice OC duration can sometimes be greater than AR duration, which results in the entire implementation mode being in OC and AE zones (Figure 5). Therefore, before computer processing the observation record should be «cleaned» from excessive OC periods. It is sufficient for OC periods at the beginning and end of the record not to exceed $1 \mathrm{~s}$ at more than $10 \mathrm{~s}$ total duration of the record.

To «clean» the record from excessive OC periods, all the entries made $1 \mathrm{~s}$ before $t_{n}$, and $1 \mathrm{~s}$ after $t_{k}$ are automatically removed. Figure 5 shows the histogram of distribution density of voltage after «cleaning».

Figure 6 gives the histogram of distribution density of current after «cleaning» for process 5 . As we can see, compared to the histogram, shown in Figure 3, $b$, the frequency of current values appearing in OC and $\mathrm{AE}$ zones was greatly reduced, but not to the point when the entire record mode can be considered an AR zone mode. This is related to the fact that current in $\mathrm{OC}$ and $\mathrm{AE}$ periods has small scatter of values that increases distribution density of current in this zone. 


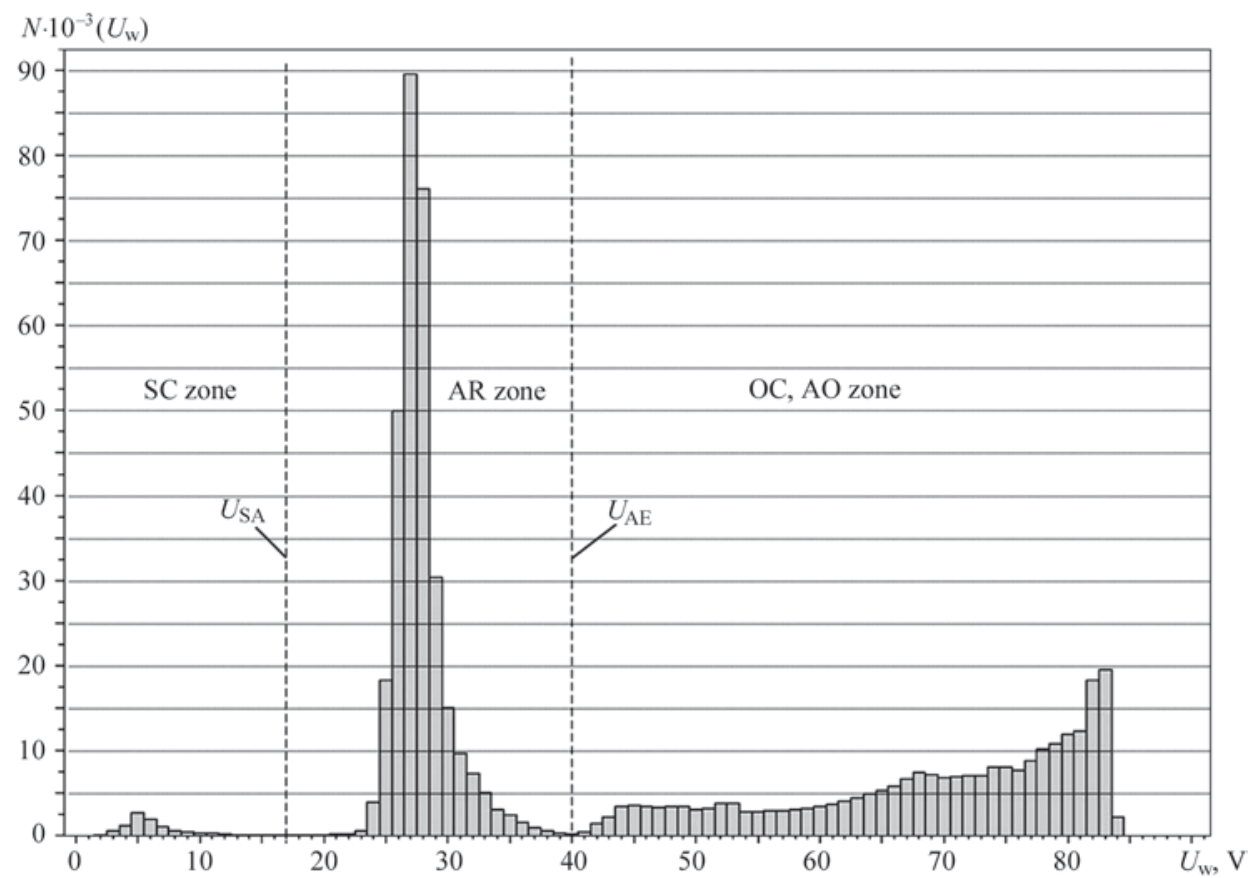

Figure 3. Histogram of distribution density $N$ of $U_{w}$ values for $\mathrm{CO}_{2}$ welding process 1

The above-mentioned circumstance does not allow applying a similar algorithm of searching for zone boundaries for currents, as the one for voltages. In this case, it is proposed to use the feature of current histogram by which it differs from voltage histogram, namely $\mathrm{OC}$ and $\mathrm{AE}$ zones in the current histogram are much narrower than SC and AR zones. Assuming that $\mathrm{OC}$ and $\mathrm{AE}$ zone is in the range from 0 up to $40 \mathrm{~A}$, and narrowing the search for $I_{\mathrm{AE}}$ boundary to these limits, it will be reduced to searching for a mode and gradient descent to the right of the mode to reach a minimum. Searching for boundary of AR and SC zones in the current histogram becomes senseless, because of «blurred» boundaries.

Boundaries of the three zones determined by current and voltage histograms are very inaccurate, as the zones overlap with each other and a signal with the value level, approximately corresponding to the zone boundary, can belong to either of them. The accuracy of determination of zone boundary can be enhanced by analysis of joint density of $I_{\mathrm{w}}$ and $U_{\mathrm{w}}$ distribution (Figure 7).

The graph clearly shows the zones of arc running and SC. Open circuit zone is less clearly visible, as there are no arc extinctions in process 3 (see Table 3), and open circuit periods here have been «cleaned». The surface between the zones is practically even that is indicative of the rarity of appearance of $I_{\mathrm{w}}$ and $U_{\mathrm{w}}$ combination in these locations.

$L_{\mathrm{AR}-\mathrm{SC}}$ boundary between SC and AR zones is defined as a projection on a plane $\left(I_{w}, U_{w}\right)$ of the trajectory of movement of a certain point in a 3D space, mov-

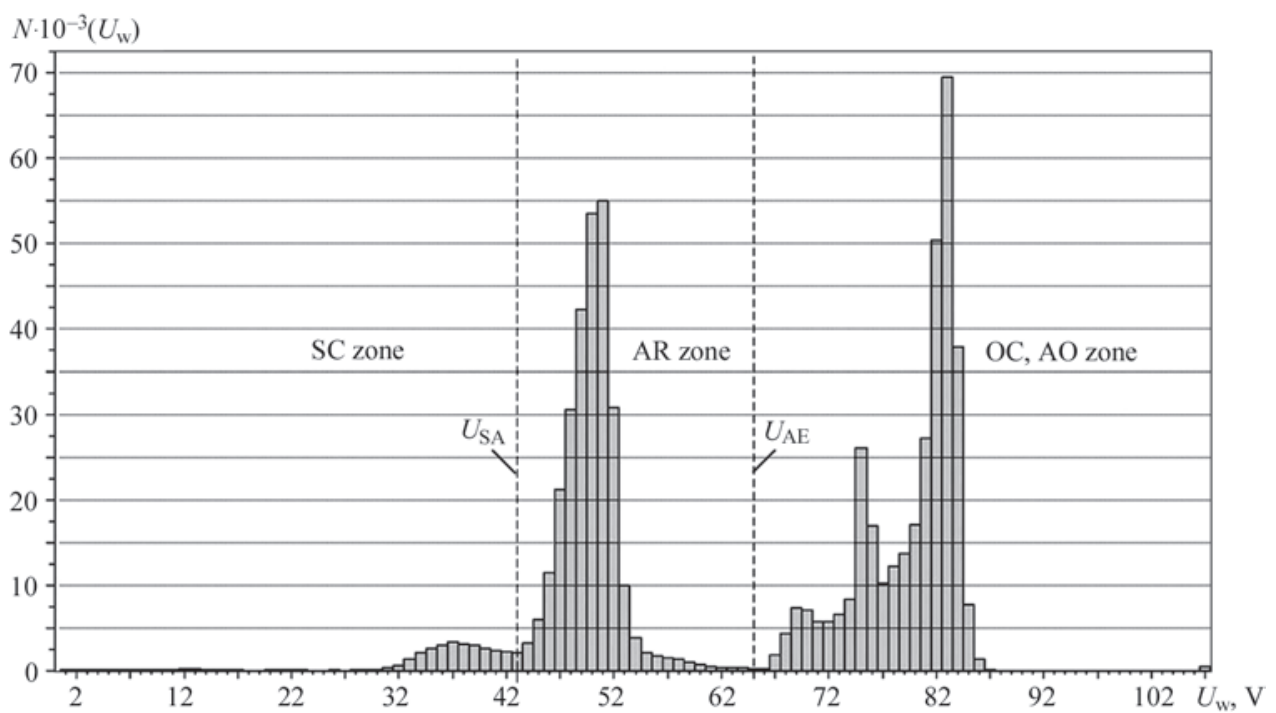

Figure 4. Histogram of distribution density $N$ of $U_{w}$ values for $\mathrm{CO}_{2}$ welding process 5 


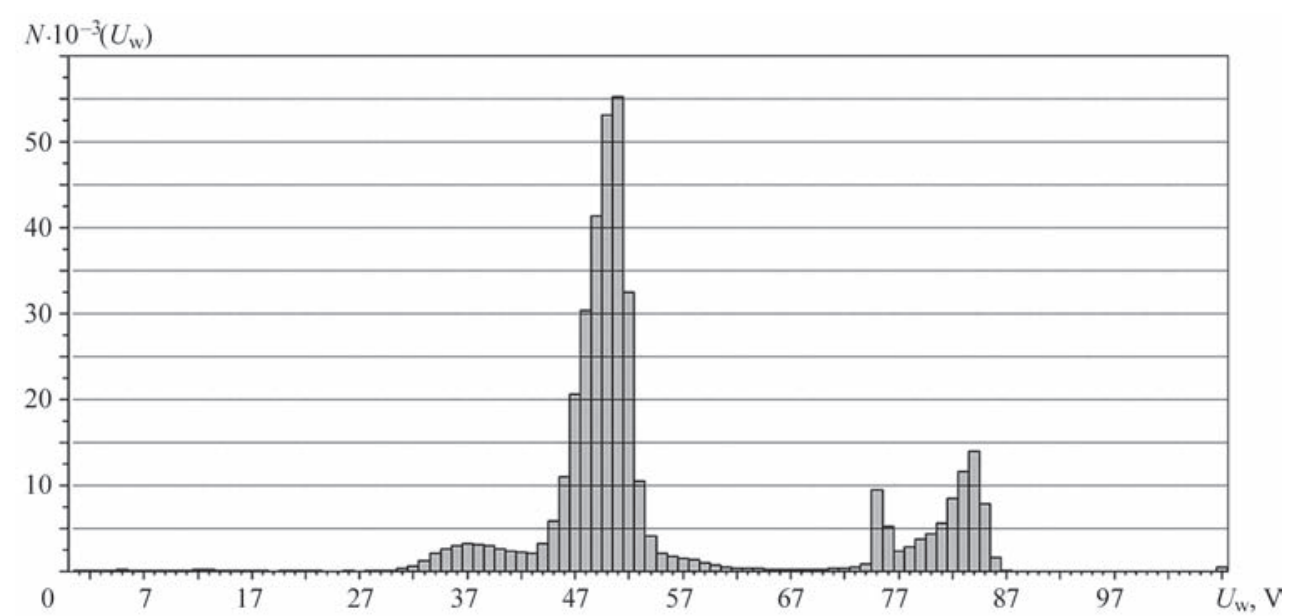

Figure 5. Histogram of distribution density $N$ of $U_{w}$ values for $\mathrm{CO}_{2}$ welding process 5 after «cleaning»

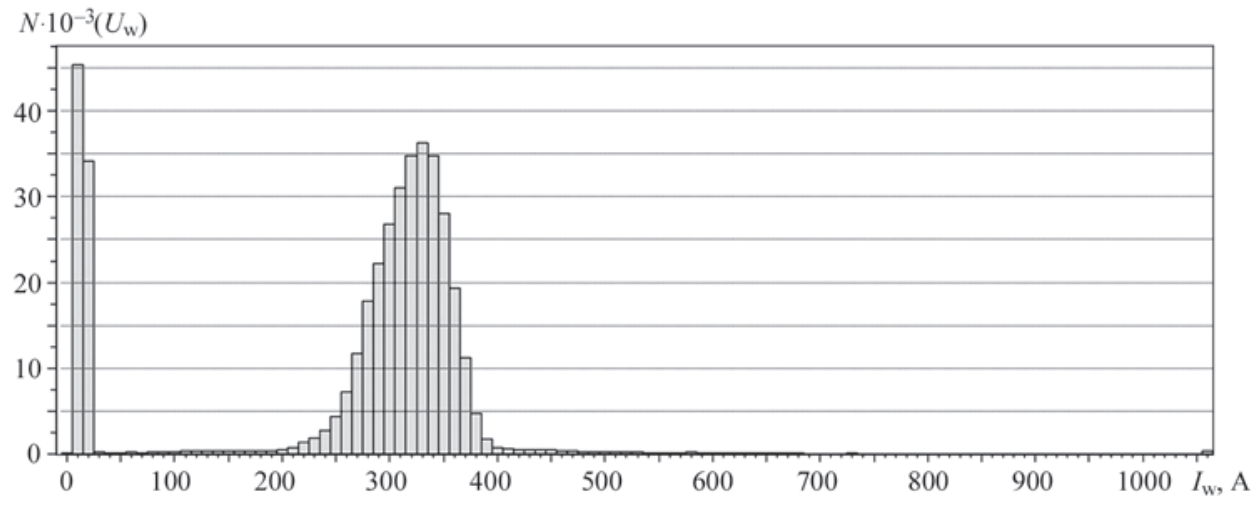

Figure 6. Histogram of distribution density $N$ of $I_{w}$ values for $\mathrm{CO}_{2}$ welding process 5 after «cleaning»

ing in a certain direction from the assigned location by the algorithm of «search for least resistance path». Surface in space $\left(I_{w}, U_{w} N\left(I_{w}, U_{w}\right)\right)$, where $N\left(I_{w}, U_{w}\right)$ is the value of density of joint distribution of $I_{w}, U_{w}$, is assigned in the tabulated form. Taken as the initial point for searching for the boundary, are the coordinates of point $A$ (see Figure 7) with the above derived $U_{\mathrm{SA}}$ value and «zero» current, i.e. $A\left(0, U_{\mathrm{SA}}, N\left(0, U_{\mathrm{SA}}\right)\right)$. $L_{\mathrm{AR}-\mathrm{SC}}$ path is drawn so that at movement from point $A$ towards increase of current value in each step $i$ value $N\left(I_{\mathrm{w}}(i), U_{\mathrm{w}}(j)\right)$ was the smallest of the neighbouring values $N\left(I_{\mathrm{w}}(i), U_{\mathrm{w}}(j-1)\right)$ and $N\left(I_{\mathrm{w}}(i), U_{\mathrm{w}}(j+1)\right)$.

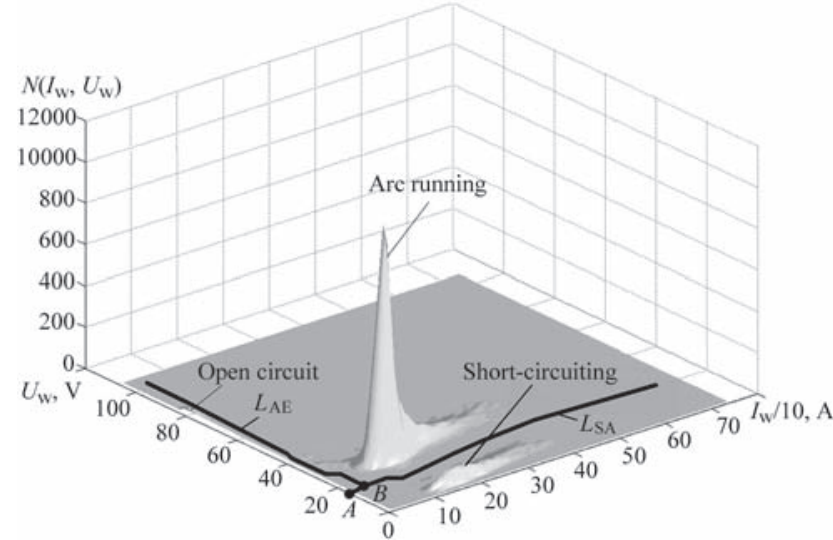

Figure 7. Graph of the function of joint density distribution of $I_{\mathrm{w}}$ and $U_{\mathrm{w}}$ for $\mathrm{CO}_{2}$ welding process 3
Boundary of AE and AR zones is found in a similar way. Point $B\left(I_{\mathrm{AE}}, U_{\mathrm{SA}}, N\left(I_{\mathrm{AE}}, U_{\mathrm{SA}}\right)\right)$ is taken as the initial point for searching for the boundary. $L_{\mathrm{AR}-\mathrm{OC}}$ trajectory from point $B$ towards increase of voltage value is drawn so that in each step $j$, value $N\left(I_{w}(i), U_{w}(j)\right)$ was the smallest of the neighbouring values $N\left(I_{\mathrm{w}}(i-\right.$ $\left.1), U_{w}(j)\right)$ and $N\left(I_{w}(i+1), U_{w}(j)\right)$ (see Figure 7).

IMS of welding process parameters. A program of processing a binary file of 2-channel recording of welding current and voltage, created with PowerGraph software, was developed. The main format of the program is given in Figure 8.

The procedure for calculating the welding process parameters is as follows:

1. Signal filtering is performed:

- eliminating transient spikes (up to $0.1 \mathrm{~ms}$ ) for $I_{\mathrm{w}}$;

- filtering both the signals, using a non-linear filter with variable structure [11], which completely repeats the signal without delay, if the speed of its change does not exceed a certain assigned value $\varepsilon$, determined experimentally (in our case for current $\varepsilon=15 \mathrm{~A}$, and for voltage $\varepsilon=5 \mathrm{~V}$ );

$$
\overline{I_{\mathrm{w}}(i)}=I_{\mathrm{w}}(i-1)+\frac{\Delta I_{\mathrm{w}}(i)}{\left|\Delta I_{\mathrm{w}}(i)\right|} \varepsilon
$$

provided $\left|\Delta I_{\mathrm{w}}(i)\right|>\varepsilon$, otherwise $\overline{I_{\mathrm{w}}(i)}=I_{\mathrm{w}}(i)$. Similarly, for expression: 
Table 3. Parameters of $\mathrm{CO}_{2}$ welding process

\begin{tabular}{|c|c|c|c|c|c|}
\hline \multirow{2}{*}{$\mathrm{CO}_{2}$ welding process parameters } & \multicolumn{5}{|c|}{ Process number } \\
\hline & 1 & 2 & 3 & 4 & 5 \\
\hline Welding process duration, $\mathrm{s}$ & 16.8 & 19.9 & 14.0 & 16.6 & 17.7 \\
\hline AS duration, $\mathrm{s}$ & 0.31 & 0.31 & 0.34 & 0.23 & 2.68 \\
\hline Number of SC during AS period & 2 & 2 & 3 & 2 & 15 \\
\hline Average current of arc process, A & 121 & 231 & 167 & 283 & 317 \\
\hline Average voltage of arc process, $\mathrm{V}$ & 27.5 & 28.9 & 26.8 & 30.8 & 48.7 \\
\hline RMS value of arc process current, $\mathrm{A}$ & 40.7 & 62 & 55.6 & 84.9 & 42.9 \\
\hline RMS value of arc process voltage, $\mathrm{V}$ & 5.7 & 7.1 & 7.3 & 7.8 & 5.6 \\
\hline Average arc current, A & 120 & 226 & 162 & 274 & 318 \\
\hline RMS value of arc current, $A$ & 35.2 & 53.8 & 48.8 & 69 & 37.6 \\
\hline Average arc voltage, $\mathrm{V}$ & 27.8 & 30.7 & 28.8 & 32.9 & 48.7 \\
\hline RMS value of arc voltage, $\mathrm{V}$ & 2.4 & 2.9 & 2.7 & 3.8 & 4.8 \\
\hline Average SC current, A & 196 & 287 & 218 & 362 & 308 \\
\hline Average SC voltage, V & 6.2 & 10.1 & 7.1 & 12.9 & 12.4 \\
\hline RMS value of SC voltage, $\mathrm{V}$ & 2.6 & 3.2 & 2.6 & 4.1 & 4.3 \\
\hline Average SC duration, ms & 4.29 & 4.01 & 4.61 & 3.69 & 3.11 \\
\hline RMS value of SC duration, ms & 2.1 & 1.4 & 1.3 & 2.3 & 1.3 \\
\hline Average arcing time, $\mathrm{s}$ & 0.14 & 0.0 & 0.05 & 0.03 & 0.87 \\
\hline RMS value of arcing, $s$ & 0.119 & 0.033 & 0.026 & 0.0217 & 2.545 \\
\hline Average SC frequency, $\mathrm{Hz}$ & 6.75 & 21.7 & 19.3 & 27.5 & 1.1 \\
\hline Average number of AE per min & 15 & 0 & 0 & 0 & 12 \\
\hline
\end{tabular}

$$
\overline{U_{\mathrm{w}}(i)}=U_{\mathrm{w}}(i-1)+\frac{\Delta U_{\mathrm{w}}(i)}{\left|\Delta U_{\mathrm{w}}(i)\right|} \varepsilon
$$

provided $\left|\Delta U_{\mathrm{w}}(i)\right|>\varepsilon$, otherwise $\overline{U_{\mathrm{w}}(i)}=U_{\mathrm{w}}(i)$.

2. Record cleaning from excessive OC periods is performed. As a result of «cleaning», sections of OC periods of not more than $1 \mathrm{~s}$ duration remain at the beginning and end of the records.

3. Calculation of distribution density of voltage is performed with $5 \mathrm{~V}$ increment, $U_{\mathrm{SA}}$ and $U_{\mathrm{AE}}$ are calculated.

4. Current distribution density is calculated with 5 A increments in the section from 0 up to $31 \mathrm{~A}$. The mode in this region is determined, then the location of density minimum ( $I_{\mathrm{AO}}$ position) to the right of the mode in 0-31 A region is determined.

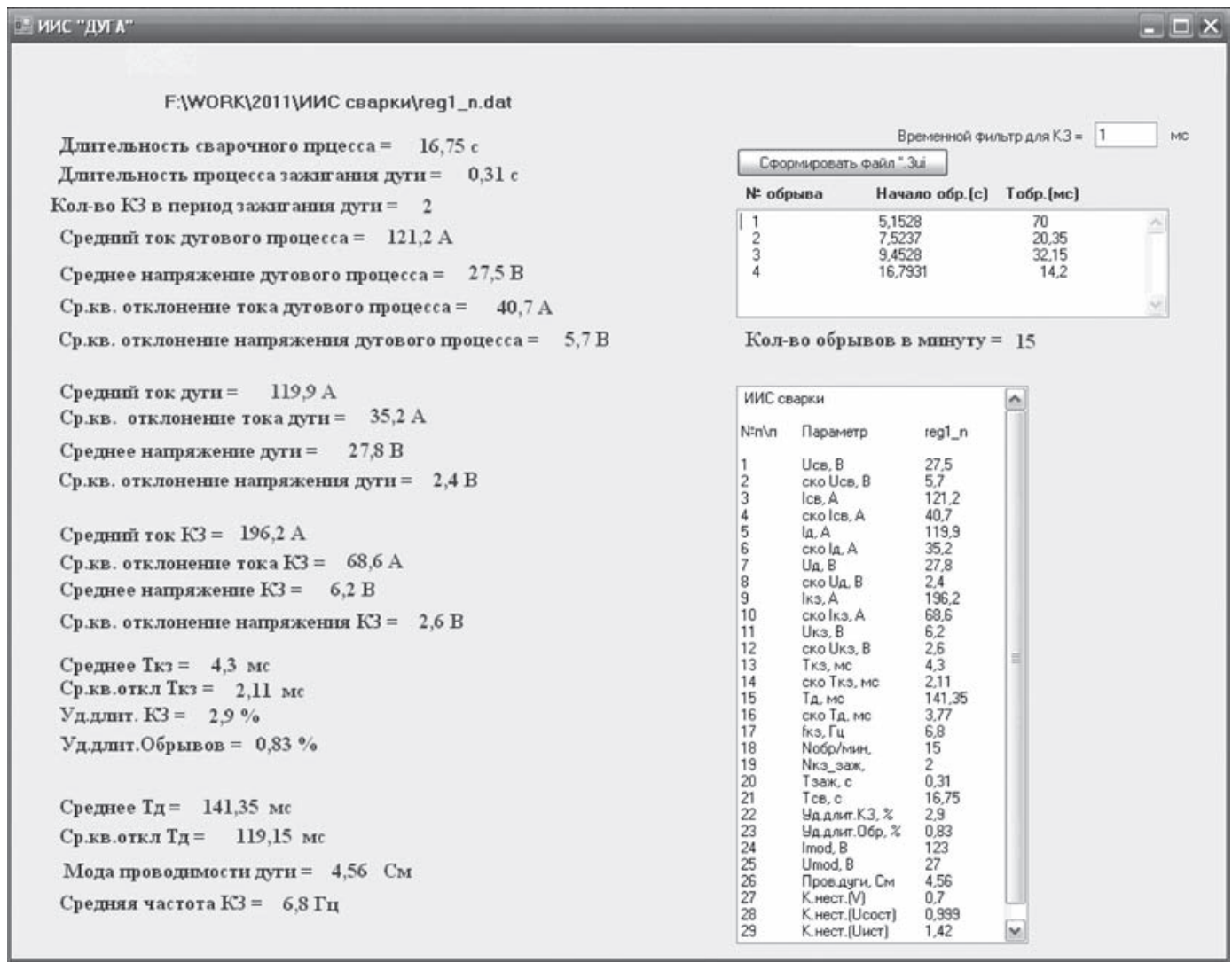

Figure 8. Format of presentation of data on parameters of $\mathrm{CO}_{2}$ welding process 1 
Table 4. Parameters of the process of welding in a mixture of $\mathrm{CO}_{2}$ with argon

\begin{tabular}{|c|c|c|c|c|c|c|c|}
\hline \multirow{2}{*}{$\mathrm{CO}_{2}$ welding process parameters } & \multicolumn{7}{|c|}{ Process number } \\
\hline & 1 & 2 & 3 & 4 & 5 & 6 & 7 \\
\hline Welding process duration, $\mathrm{s}$ & 16.9 & 19.8 & 16.5 & 14.9 & 12.0 & 13.3 & 21.9 \\
\hline AS duration, $\mathrm{s}$ & 0.45 & 2.02 & 0.39 & 0.0 & 0.0 & 0.22 & 3.09 \\
\hline Number of SC during AS period & 2 & 7 & 2 & 1 & 1 & 2 & 10 \\
\hline Average current of arc process, $\mathrm{A}$ & 166 & 55 & 141 & 171 & 219 & 251 & 267 \\
\hline Average voltage of arc process, $\mathrm{V}$ & 30.1 & 17.1 & 29.3 & 30.7 & 31.6 & 31.5 & 41.9 \\
\hline RMS value of arc process current, $\mathrm{A}$ & 20.4 & 40.4 & 26.6 & 27.5 & 23.3 & 27.1 & 28.2 \\
\hline RMS value of arc process voltage, $\mathrm{V}$ & 1.8 & 4.7 & 2 & 1.6 & 1.7 & 2.5 & 2.6 \\
\hline Average arc current, $\mathrm{A}$ & 166 & 49 & 141 & 170 & 219 & 251 & 267 \\
\hline RMS value of arc current, $\mathrm{A}$ & 19.6 & 30.5 & 25.9 & 21.8 & 23.3 & 27 & 28.2 \\
\hline Average arc voltage, $\mathrm{V}$ & 30.1 & 18.1 & 29.4 & 30.7 & 31.6 & 31.5 & 41.9 \\
\hline RMS value of arc voltage, $\mathrm{V}$ & 1.3 & 1.8 & 1.6 & 1.4 & 1.7 & 2.4 & 2.6 \\
\hline Average SC current, A & 246 & 127 & 226 & 423 & No SC & 278 & No SC \\
\hline Average SC voltage, $\mathrm{V}$ & 9.4 & 4 & 6.9 & 14.3 & Same & 14.4 & Same \\
\hline RMS value of SC voltage, $\mathrm{V}$ & 2.7 & 1.6 & 2.2 & 8.4 & 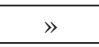 & 5.9 & 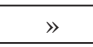 \\
\hline Average SC duration, ms & 3.89 & 9.07 & 4.79 & 5.01 & $»$ & 1.58 & $»$ \\
\hline RMS value of SC duration, ms & 1.2 & 4.2 & 1.4 & 3.2 & $»$ & 0.2 & $»$ \\
\hline Average arcing time, s & 1.096 & 0.111 & 1.46 & 1.855 & 11.975 & 1.302 & 18 \\
\hline RMS value of arcing, $s$ & 1.852 & 0.202 & 1.748 & 3.266 & 0 & 2.138 & 0 \\
\hline Average SC frequency, $\mathrm{Hz}$ & 0.85 & 8.26 & 0.62 & 0.47 & No SC & 0.69 & No SC \\
\hline Average number of AE per min & 0 & 3 & 0 & 4 & 0 & 0 & 0 \\
\hline
\end{tabular}

5. The function of joint density distribution of $I_{w}$ and $U_{w}$ is calculated for current with $10 \mathrm{~A}$ increment, and for voltage with $1 \mathrm{~V}$ increment.

6. Boundaries of AR and SC zones $-L_{\mathrm{AR}-\mathrm{SC}}$ and boundary of AR and OC (AO) zones $-L_{\mathrm{AR}-\mathrm{OC}}$ are calculated, as well as $L_{\mathrm{AR}-\mathrm{SC}}$ and $L_{\mathrm{AR}-\mathrm{OC}}$ projections on plane $\left[U_{\mathrm{w},} I_{\mathrm{w}}\right]$, i.e. $U_{\mathrm{w}}=\operatorname{Tr}\left(I_{\mathrm{w}}\right)$ and $I_{\mathrm{w}}=\operatorname{Tr} u\left(U_{\mathrm{w}}\right)$, respectively.

7. Welding process clustering is performed.

Process state array $K d d(i)$ is formed for its subsequent analysis. Each process state in $K d d(i)$ array is encoded by a certain value of signal level:

- $K d d(i)_{\mathrm{OC}, \mathrm{AO}}$ when the following condition is satisfied:

$$
\begin{gathered}
U_{\mathrm{w}}(i)>\left[\operatorname { T r i } \left(I _ { \mathrm { w } } ( i ) \operatorname { O r } \left(U_{\mathrm{w}}(i) \leq U_{\mathrm{SA}}\right.\right.\right. \\
\text { And } \left.\left.I_{\mathrm{w}}(i) \leq U_{\mathrm{AO}}\right)\right] \text { And } I_{\mathrm{w}}(i) \leq \operatorname{Tru}\left(U_{\mathrm{w}}(i)\right) ;
\end{gathered}
$$
fied:

- $K d d(i)_{\mathrm{SC}}$ when the following condition is satis-

$$
\begin{gathered}
U_{\mathrm{w}}(i) \leq\left[\operatorname { T r i } \left(I _ { \mathrm { w } } ( i ) \operatorname { O r } \left(U_{\mathrm{w}}(i) \leq U_{\mathrm{SA}}\right.\right.\right. \\
\text { And } \left.\left.I_{\mathrm{w}}(i) \leq I_{\mathrm{AO}}\right)\right] ;
\end{gathered}
$$
fied:

- $K d d(i)_{\mathrm{AR}}$ when the following condition is satis-

$$
\begin{aligned}
U_{\mathrm{w}}(i) & >\left[\operatorname { T r i } \left(I _ { \mathrm { w } } ( i ) \operatorname { O r } \left(U_{\mathrm{w}}(i)>U_{\mathrm{SA}}\right.\right.\right. \\
\text { And } I_{\mathrm{w}}(i) & \left.\left.>U_{\mathrm{AO}}\right)\right] \text { And } I_{\mathrm{w}}(i)>\operatorname{Tru}\left(U_{\mathrm{w}}(i)\right) .
\end{aligned}
$$

Tables 3 and 4 give the results of IMS operation for welding modes, given in Tables 1 and 2.

\section{Conclusions}

1. Presented IMS enables obtaining a wide range of statistical indices of the process electrical parameters for analysis of all the stages, namely source switching on, arc striking, steady-state arc process and completion of welding.
2. IMS performs automatic identification of the welding process state, thus eliminating the human factor influence on the derived assessments of statistical parameters of the process.

1. Blakeley, P.J. (1992) Developments in monitoring systems for resistance and arc welding. In: Proc. of Int. Conf. on Automated Welding Systems in Manufacturing (Gateshead, England, November 1992). Woodhead Publishing, Ltd., 1992, 40.

2. Wu, C.S., Polte, T., Rehffeldt, D. (2001) A fuzzy logic system for process monitoring and quality evaluation in GMAW. Welding J., 2, 33-38.

3. ELMA-Technik. Daten-Registrier-Anlage fuer die Schweisstechnik (DAREG): Firmenschrift ELMA-Technik GmbH \& Co-KG, Aachen.

4. ARCDATA LQ-5N System. Geraete zur Ueberwachung, Dokumentation und Regelung der Schweissdaten beim Lichtbogenschweissen: Messer Griesheim Firmenschift 30.0102 d/e.

5. ARCDATA LQ-2 System. Schweissdaten-Ueberwachungsgeraete zur Qualitaetskontrolle beim Lichtbogenschweissen: Messer Griesheim Firmenschift 30.0104 d/e.

6. Ogunbiyi, B., Norrish, J. (1996) GMAW metal transfer and arc stability assessment using monitoring indices. In: Proc. of $6^{\text {th }}$ Int. Conf. on Computer Technology in Welding (Lanaken, Belgium, 9-12 June 1996).

7. Pokhodnya, I.K., Gorpenyuk, V.N., Milichenko, S.S. et al. (1990) Metallurgy of arc welding: Processes in arc and melting of electrodes. Ed. by I.K. Pokhodnya. Kiev: PWI.

8. Beketov, V.G., (2006) Information-measuring system for certification of arc welding power sources (in machine-building): Syn. of Thesis for Cand. of Techn. Sci. Degree. Volgodonsk.

9. Ulyanova, O.V. (2006) Information-measuring system for certification of arc welding power sources (in machine-building) based on parameters of Markovian model of melting process: Syn. of Thesis for Cand. of Techn. Sci. Degree. Volgodonsk.

10. Lankin, Yu.N. (2011) Indicators of stability of the GMAW process. The Paton Welding J., 1, 6-13.

11. Soloviov, V.G., Kapelisty, A.I., Fedas, V.N., Udovenko, T.N. Non-linear filter. Author's cert. 1190361. Publ. 30.05.1984. 


\title{
DEVICE FOR EXCITATION AND STABILIZATION OF WELDING ARC
}

\author{
V.V. BURLAKA and S.V. GULAKOV \\ State Higher Educational Establishment «Pre-Azov State Technical University» (PSTU) \\ 7 Universitetskaya Str., 87500, Mariupol, Ukraine. E-mail: office@pstu.edu
}

\begin{abstract}
The circuit design of the device for formation of increased voltage was proposed, providing facilitation of ignition and stabilization of welding arc burning at direct/alternating current. The device operates according to the algorithm LiftArc and provides ignition of the arc at a minimum required power due to limitation of rate of voltage growth at the arc gap. For safe operation the time limit for action of higher voltage was also introduced. Due to application of the advanced elementary base it was possible to simplify the electric circuit of the device for arc stabilization at maintaining the high consumer properties. 10 Ref., 5 Figures.
\end{abstract}

Keywords : electric arc, welding, arc ignition, stabilization of arc burning, welding inverter, open-circuit voltage

In manual arc welding with a covered electrode, as well as in welding in inert gas (MIG), including that with a non-consumable electrode (TIG) the need is occurred, firstly, to facilitate the initiation of arc discharge, secondly, to stabilize the process of arc burning. At the power supply from the alternating current mains, the repeated excitation of arc should occur after each transition of power source voltage through zero. Moreover, in TIG welding it is desirable to limit the power, which is released at the arc gap breakdown, as at the increased discharge power the erosion of non-consumable electrode occurs, which reduces its service life. Therefore, the urgent problem is the design of device for arc stabilization, which will realize the exciting of arc at the minimum required discharge energy and provide a stable burning of the arc during welding process.

In manual arc welding using electrodes at direct current with the power supply from inverter source the problems with ignition and maintaining of the arc (arc burns unstable, electrode often «sticks») are occurred. The cause is the low open-circuit voltage $U_{o-c}$ of inverter power sources for arc welding. Thus, for the sources, designed according to the bridge circuit, $U_{\text {o-c }}$ amounts to 60-65 V; for the sources based on forward converter $U_{\text {o-c }}$ amounts to 50-60 V (pulses of the amplitude of about $100 \mathrm{~V}$ and pulse duty factor of 0.5 ).

The conventional devices for arc stabilization include step-up transformer, spark generator with a discharger and high-frequency (broadband) transformer, the secondary winding of which is connected in series or in parallel with the arc gap [1-4]. Such a circuit allows forming high-voltage pulses at the arc gap and providing ignition of the arc. Among its disadvantages the large dimensions and weight of the transformers, complicated control of pulses power, wide range of generated electromagnetic interferences, short service life of discharger and the need in its periodical replacement should be mentioned.

In the works [5-8] the devices for arc stabilization are described, in which contact-free switching elements like transistors and thyristors are applied. This provides a significant improvement in the reliability of welding equipment, fitted with such devices, and the possibility to control characteristics of igniting pulses within the wide ranges.

In the work [9] the device for arc stabilization was proposed, providing the control of power for excitation of the arc due to changes in the supply voltage of resonance circuits. In the circuit of the device the additional controllable source of the higher voltage of direct current, two resonant circuits with appropriate control circuits were introduced. This leads to complication of circuit, increase in power losses and deteriorates the consumer qualities of the device.

In the work [10] the method for increasing intensity of plasma formation was proposed due to the use of several resonance circuits, operating at a phase shift and loaded to the common high-frequency transformer. However, the use of non-firing thyristors in the devices as the key elements, does not allow increasing the operating frequency, simplifying the circuit and improving the weight and size characteristics of the arc stabilizer $[9,10]$. 


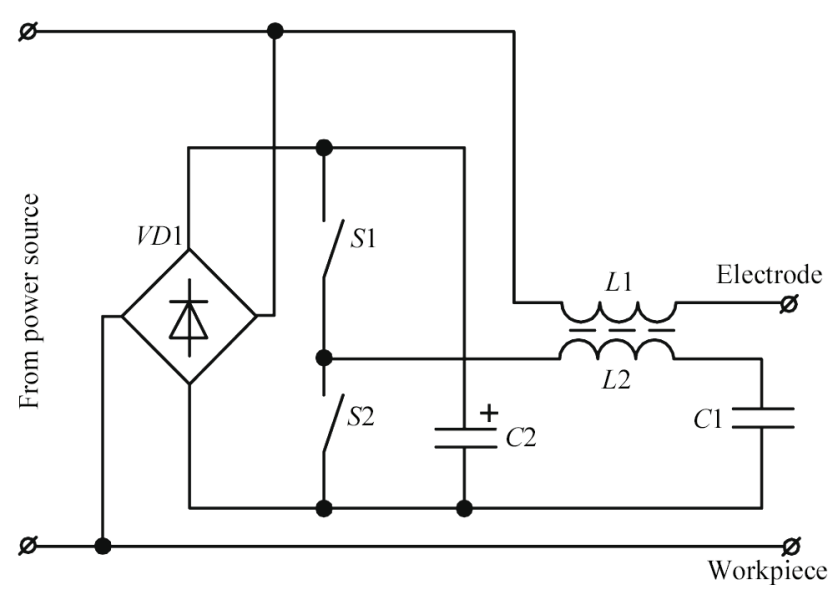

Figure 1. Block-diagram of device for arc stabilization

The authors designed the device for arc stabilization which is switched in series with the electrode and allows the formation of higher voltage at the latter. The device does not require a separate power source (it is supplied from the welding power source), allows increasing the resistance of non-consumable electrode in TIG welding due to limitation of the rate of voltage growth at it and excitation of arc with the minimum required power, increasing the duration of period of maintaining the higher voltage at the electrode in manual arc welding and facilitating the process of arc initiation.

It is based on the principle of producing the higher voltage by «pumping» the serial resonant circuit from the controllable source of alternating voltage with a variable frequency. As the latter the switching unit on the field-effect transistors was used, controlled from the single-crystal microcontroller.

Figure 1 shows the block diagram and Figure 2 shows the principal electric circuit of the designed device for arc stabilization.

During switching on of the power source, the capacitor $C 2$ (see Figure 1) is charged through the diode bridge VD1 up to open-circuit voltage of the source.
In the case of manual arc welding the arc excitation is carried out after short-circuiting (SC) of the electrode at the workpiece (function Lift-Arc). The control program monitors the voltage at the output of the source. During SC the voltage becomes close to zero. At this time, the supply of the circuit is provided by the charged capacitor $C 2$.

During removal of electrode from the workpiece the SC disappears, at the output of power source the voltage appears. At this time the switching unit, formed by the keys $S 1, S 2$, starts operation. It operates at the pulse duty factor of $50 \%$ and at a variable frequency. The operation starts from the maximum frequency, which significantly exceeds the resonance frequency of the circuit $L 2 C 1$. By decreasing the output frequency of the switching unit the current of the circuit $L 2 C 1$ and the voltage at the throttle $L 1$ grow. Further, two scenarios are possible:

- at some voltage the arc initiation occurs at $L 1$. The voltage at the output of the power source is reduced to the value of voltage at the arc gap, the control system blocks the operation of the keys $S 1, S 2$. In such a way a «soft» ignition of the arc is provided;

- reaching the required (maximum) current of "pumping» the circuit $L 2 C 1$, the reduction in frequency is stopped, the system switches to the steady state. To provide the safe use of the device, the high voltage at the output is only supported during the preset holding time, after which the operation of the keys $S 1, S 2$ is blocked.

The operation at the frequencies higher than the frequency of serial resonance of the circuit $L 2 C 1$ provides «soft» switching on of the power keys due to inductive nature of input impedance of the circuit, which in capacity of keys allows applying the field-effect transistors, characterized by a relatively longer time of reverse recovery of the inverse diode.

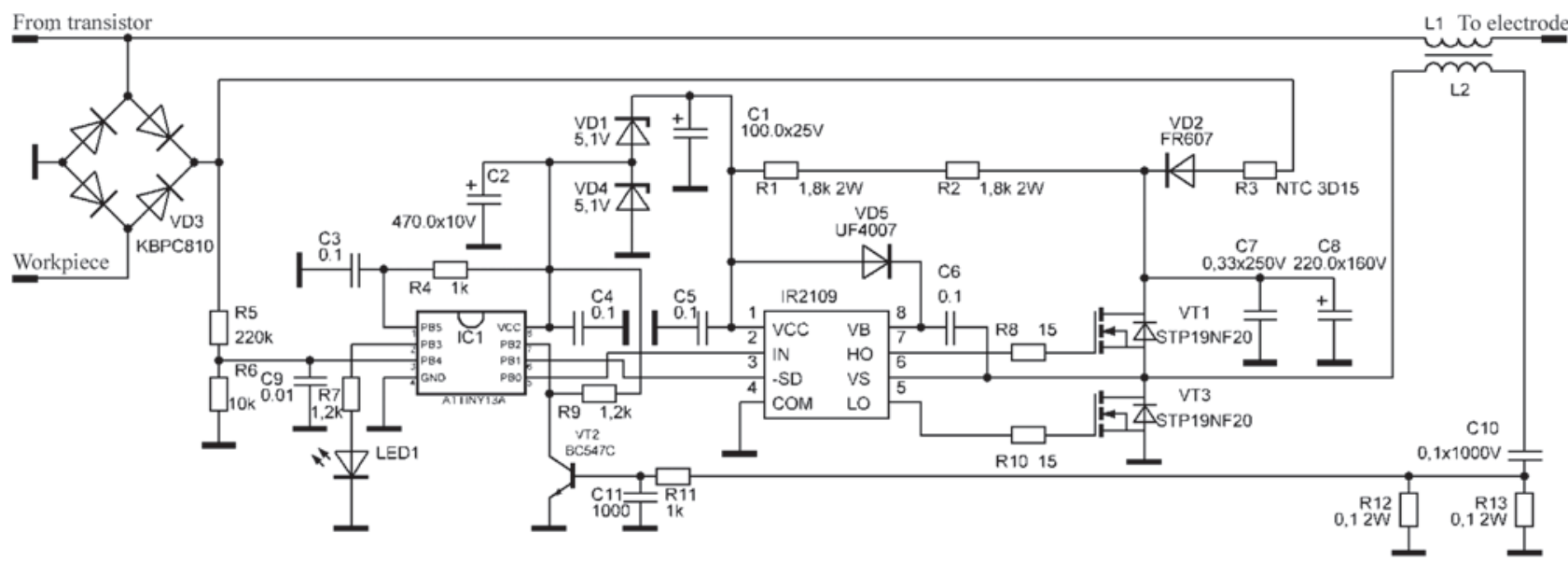

Figure 2. Principal electric diagram of device for arc stabilization 


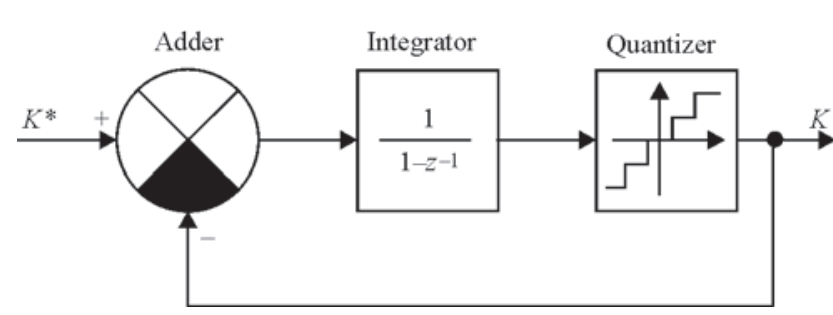

Figure 3. Structural scheme of algorithm for realization of fractional division factor

In case of TIG welding the operation of the system is similar, only the parameters of the circuit $L 2 C 1$ are different (it is necessary to provide a higher voltage as compared to the manual arc welding). The arc initiation occurs after each transition of the power source voltage through zero.

The elements VD1, C2 also protect the output of power source from entry of high-voltage from the throttle $L 1$.

In the practical realization of the device for arc stabilization for manual arc welding (see Figure 2) the keys $S 1$ and $S 2$ are produced on MOSFET transistors STP19NF20, the diode bridge VD1 of the type KBPC810, capacitors $C 1$ of $0.1 \mu \mathrm{F} \times 1000 \mathrm{~V}, C 2$ of $220 \mu \mathrm{F} \times 160 \mathrm{~V}$. The throttle is wound on the core ETD59/ 31/22 with a non-magnetic gap of $0.4 \mathrm{~mm}$ for linearization of weber-ampere characteristics. $L 1$ has 14 turns, $L 2$ has 12 turns.

The maximum current of circuit pumping is determined by the resistance of resistors $R 12, R 13$ and firing voltage of the transistor VT2, which approximately amounts to $0.6 \mathrm{~V}$. For the rated values, shown in the circuit, the amplitude of the current in the circuit can reach $12 \mathrm{~A}$.

The formation of the controlling pulses for transistors of the keys $S 1, S 2$ is carried out using the specialized driver IR2109 from the single-crystal microcontroller ATTINY13A. The switching frequency can vary from 18.8 to $72.0 \mathrm{kHz}$. The resonance frequency of the circuit $L 2 C 1$ amounts to more than $42 \mathrm{kHz}$.

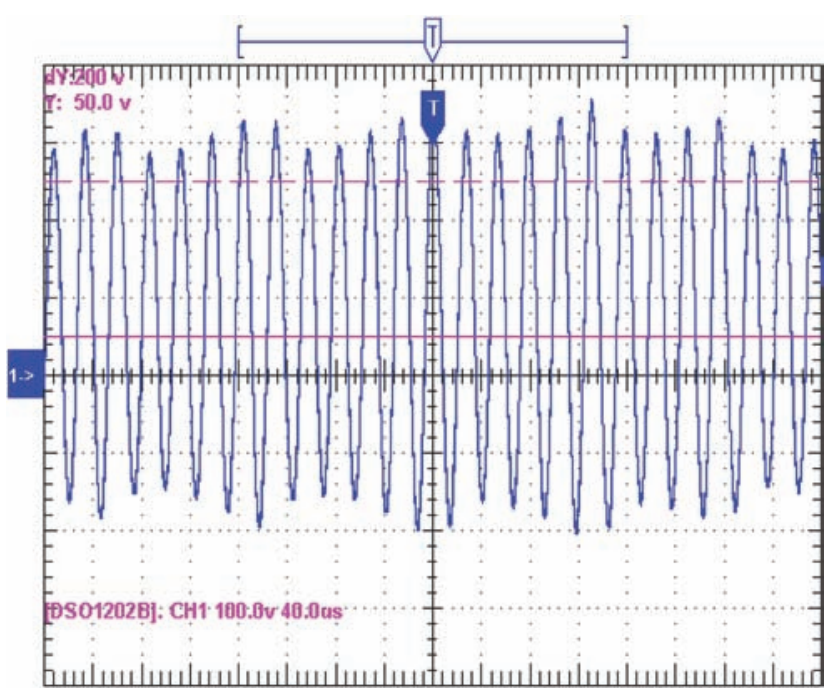

Figure 4. Oscillogram of output voltage (100 V/div; $40 \mu \mathrm{s} / \mathrm{div})$

To reduce the discreteness of change of the output frequency in the control program the division of clock frequency $(4.8 \mathrm{MHz})$ of the controller was realized by the fractional coefficient. For this purpose the software sigma-delta modulator was used, the circuit of which is shown in Figure 3, where $K^{*}$ is the required division factor (can be fractional); $K$ is the actual division factor (integral).

The work of the algorithm results in the fact that the value of the coefficient $K$ changes within some period so, that the average value of $K$ strives to the preset $K^{*}$.

Figure 4 shows the oscillogram of the output voltage of the device in the absence of the arc. The periodic oscillations of the amplitude are explained by the work of algorithm of formation of fractional division factor.

The amplitude of the voltage at the electrode during operation of the device exceeds $300 \mathrm{~V}$, which provides an easy ignition of the arc in manual arc welding. The time holding for the initiation of arc is established as about $1 \mathrm{~s}$, in accordance with the requirements of DSTU 2456-94.

The appearance of the device is shown in Figure 5.

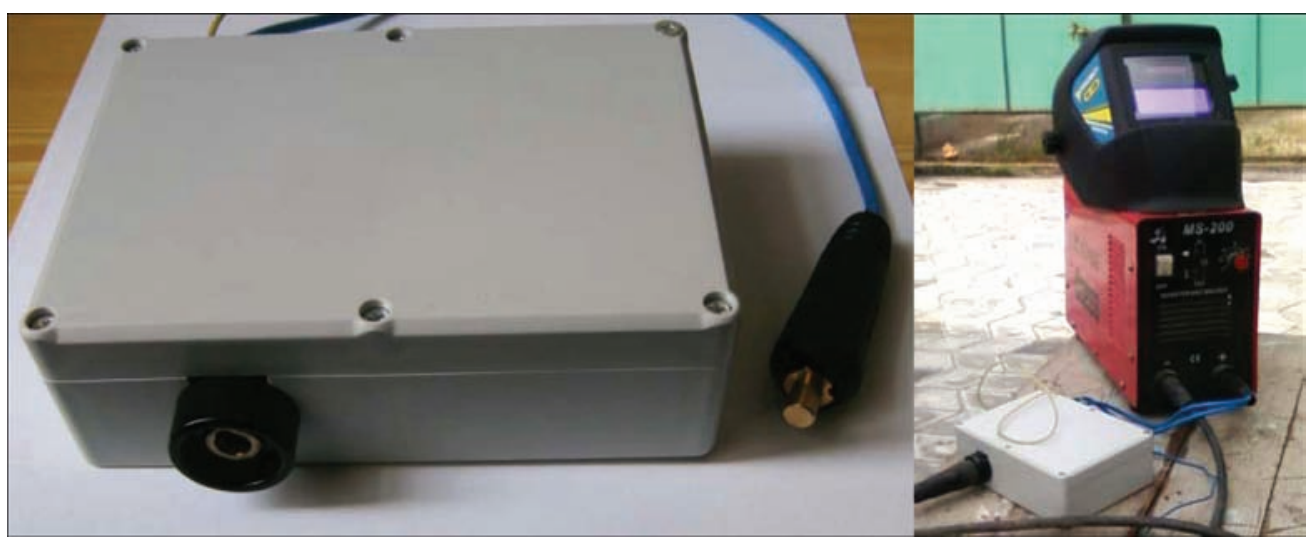

Figure 5. Appearance of device for arc stabilization 
The application of the proposed device for arc stabilization allows improving the stability of quality of welded joints, the resistance of non-consumable electrode (in TIG welding) and facilitating the process of arc initiation in manual arc welding, especially while using welding electrodes of direct current.

1. Solodsky, S.A., Brunov, O.G., Ilyashchenko, D.P. (2012) Power sources for arc welding. Tomsk: TPU.

2. Belinsky, S.M., Garbul, A.F., Gusakovsky, V.G. et al. (1986) Equipment for arc welding: Refer. Book. Ed. by V.V. Smirnov. Leningrad: Energoatomizdat.

3. Andrianov, A.A., Sidorets, V.N. (2009) Optimization of conditions for stabilizing of alternating current welding arc. Elektrotekhnika i Elektromekhanika, 2, 5-8.

4. Makhlin, N.M., Korotynsky, A.E. (2014) Analysis and procedure of calculation of series connection electronic devices for contactless arc excitation. The Paton Welding J., 1, 30-40.
5. Paton, B.E., Zaruba, I.I., Dymenko, V.V. et al. (2007) Welding power sources with pulsed stabilizing of burning arc. Kiev: Ekotekhnologiya.

6. Makhlin, N.M., Korotynsky. A.E. (2015) Asynchronous exciters and stabilizers of welding arc. Analysis and design procedure. Pt 1. The Paton Welding J., 3/4, 24-35.

7. Makhlin, N.M., Korotynsky, A.E. (2015) Asynchronous exciters and stabilizers of welding arc. Analysis and calculation procedure. Pt 2. Ibid., 7, 26-37.

8. Makhlin, N.M. (2015) Peculiarities of contactless ignitions of alternating current arc. Ibid., 10, 29-35.

9. Makhlin, N.M., Korotynsky, O.E., Skopyuk, M.I. Device for excitation and stabilizing of process of alternating current arc burning. Pat. 109334 Ukraine. Int. Cl. K B23K 9/067(2006.01); B23K 9/073 (2006.01). Fil. 14.01.2014; Publ. 10.08.2015.

10. Korotynsky, O.E., Skopyuk, M.I. Pulsed plasma source. Pat. 86432 Ukraine. Int. Cl. K B23K 9/00 (2009). Fil. 28.02.2007; Publ. 27.04.2009. 